ANTONIO JosÉ TEBChERANI

\title{
Painel imunoistoquímico para distinção entre tricoepitelioma e carcinoma basocelular desenvolvido utilizando a técnica do TMA
}

Tese apresentada à Faculdade de Medicina da Universidade de São Paulo para obtenção do título de Doutor em Ciências

Programa de Dermatologia

Orientadora: Profa. Dra. Mirian Nacagami Sotto

São Paulo 
Dados Internacionais de Catalogação na Publicação (CIP)

Preparada pela Biblioteca da

Faculdade de Medicina da Universidade de São Paulo

Creprodução autorizada pelo autor

Tebcherani, Antonio José

Painel imunoistoquímico para distinção entre tricoepitelioma e carcinoma basocelular desenvolvido utilizando a técnica do TMA / Antonio José Tebcherani.

-- São Paulo, 2012.

Tese(doutorado)--Faculdade de Medicina da Universidade de São Paulo.

Programa de Dermatologia.

Orientadora: Mirian Nacagami Sotto.

Descritores: 1.Carcinoma basocelular 2.Neoplasias cutâneas

3.Imunoistoquímica 4.Análise em microssérie 5.Modelos lineares 6.Modelos logísticos

USP/FM/DBD-026/12 


\section{DEDICATÓRIA}


A meu querido pai Elie Tanios Tebcherani (in memorian) que em meio a tantas dificuldades conseguiu me entregar o mundo, para que eu realizasse tudo o que eu julgava impossível.

A minha querida esposa Lígia Sales Tebcherani, sem dúvida a mais "preciosa" de todas as minhas conquistas.

A minha irmã Mariselma Tebcherani e a minha mãe Alexandra Helou Tebcherani por estarem sempre comigo apesar da distância. 
AGRADECIMENTOS 
À Dra. Mirian Nacagami Sotto pela proposição do desafio de levar adiante este projeto e pela orientação sempre presente durante todo o trabalho.

Ao Dr. Heitor Franco de Andrade Junior pela condução na realização e na interpretação dos estudos estatísticos.

À bióloga do Laboratório de Dermatologia Tropical do HC-FMUSP, Fernanda Guedes, pela padronização das reações da Citoqueratina 15 e D240.

Ao Dr. Fernando Soares e ao Dr. Rafael Malagoli, do Serviço de Anatomia Patológica do Hospital A.C.Camargo, pela digitalização das lâminas.

Ao Sr. Maurício Domingues pelo auxílio na elaboração das páginas com as figuras.

À CAPES-PROAP que financiou este trabalho.

À família Sales pelo imenso carinho com o qual eu fui recebido em São Paulo.

Aos diretores do Serviço de Dermatologia do Complexo Hospitalar Padre Bento de Guarulhos: Dr. Vitor Manoel Silva dos Reis, Dr. Mario César Pires e Dra. Maria do Rosário Vidigal, e a toda equipe de dermatologistas, cirurgiões, residentes de Dermatologia, corpo de enfermagem e funcionários, pela confiança e amizade.

À Dra. Neusa Yuriko Sakai Valente pelo apoio e incentivo constantes no estudo da dermatopatologia.

À chefia do Serviço de Anatomia Patológica do Hospital do Servidor Público Estadual de São Paulo, Dr. Luiz Celso Mattosinho França e Dra. Maria Isete Fares Franco, pela autorização para inclusão das suas amostras neste trabalho. 
Aos funcionários dos três laboratórios que foram de imensa ajuda no acesso aos casos analisados:

Laboratório de Patologia do Serviço de Anatomia Patológica do Hospital do Servidor Público Estadual (São Paulo - SP): Fernanda Queiróz (agente administrativo), Inês Berenice de Oliveira (agente administrativo), Ivani Graciete de Souza (técnica de autópsia) e Luiza Silva Arruda (técnica de autópsia).

Laboratório de Dermatopatologia da Divisão de Clínica Dermatológica do Hospital das Clínicas da Faculdade de Medicina da Universidade de São Paulo (HC-FMUSP): Jaqueline Maria da Cruz Meneghin (técnica em histopatologia), Leandro Riente (agente administrativo), Luciana Fontana Cassemiro (técnica em histopatologia) e Maria Cristina Galhardo (técnica em histopatologia).

Laboratório de Dermatopatologia do Serviço de Dermatologia do Complexo Hospitalar Padre Bento de Guarulhos (Guarulhos - SP): Isabel Cristina Berra (agente administrativo), Marisa Aparecida da Silva (técnica em histopatologia) e Patrícia Duque (técnica em histopatologia). 


\section{NORMALIZAÇÃO ADOTADA}

Esta tese está de acordo com as seguintes normas, em vigor no momento desta publicação:

Referências: adaptado do International Committe of Medical Journals Editors (Vancouver).

Universidade de São Paulo. Faculdade de Medicina. Serviço de Biblioteca e Documentação. Guia de Apresentação de Dissertações, Teses e Monografias. Elaborado por Anneliese Carneiro da Cunha, Maria Julia de A. L. Freddi, Maria F. Crestana, Marinalva de Souza Aragão, Suely Campos Cardoso, Valéria Vilhena. $3^{\mathrm{a}}$ ed. São Paulo: Serviço de Biblioteca e Documentação; 2011.

Abreviaturas dos títulos dos periódicos de acordo com List of Journals Indexed in Index Medicus. 
SUMÁRIO 
Lista de abreviaturas

Lista de tabelas

Lista de figuras

Resumo

Summary

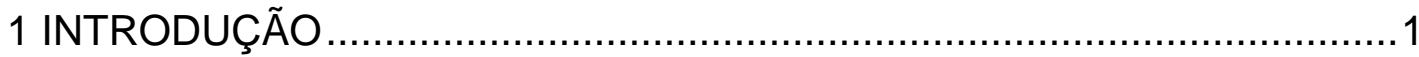

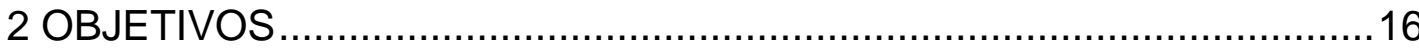

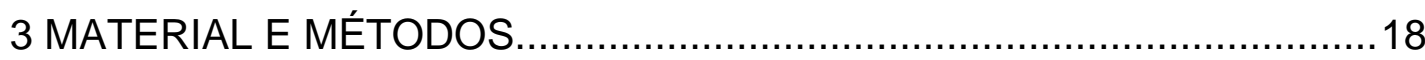

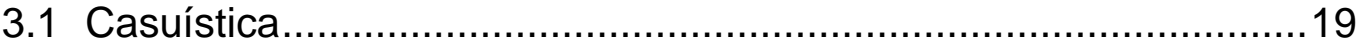

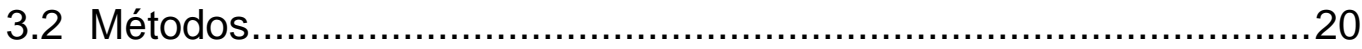

3.2.1 Técnica de arranjo em matriz de amostras teciduais "tissue microarray" ....................................................20

3.2.2 Técnica de imunoistoquímica .....................................23

3.2.3 Análise do material ................................................26

3.2.4 Análise estatística dos resultados obtidos do primeiro bloco de TMA analisado ................................................27

3.2.5 Análise estatística dos resultados de toda a casuística considerando-se os imunomarcadores selecionados ..........27

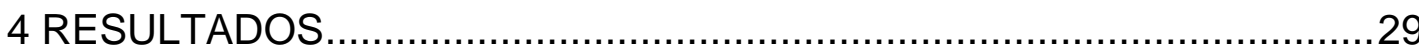

4.1 Exame imunoistoquímico do primeiro bloco de TMA com representação de 85 tricoepiteliomas e 62 carcinomas basocelulares

4.2 Análise estatística dos resultados obtidos do primeiro bloco de TMA analisado

4.3 Exame imunoistoquímico de toda a amostra............................45

4.4 Análise estatística dos resultados de toda a casuística considerando-se os imunomarcadores selecionados...................48

4.5 Análise dos resultados por regressão linear multifatorial ...............52

4.6 Análise dos resultados por regressão logística multifatorial ............53

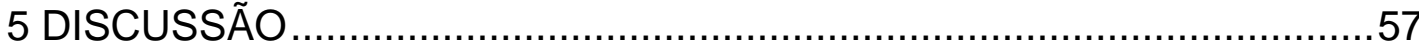

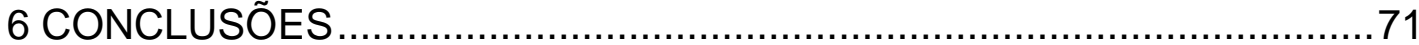

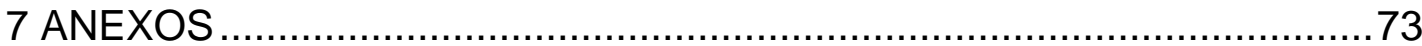

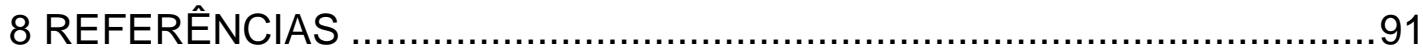


LISTAS 


\section{LISTA DE ABREVIATURAS}

\begin{tabular}{|c|c|}
\hline BSA & - solução de albumina bovina \\
\hline $\mathrm{CBC}$ & - carcinoma basocelular \\
\hline CD & - "cluster of differentiation" \\
\hline CEA & - antígeno carcinoembriônico \\
\hline $\mathrm{CK}$ & - citoqueratina \\
\hline $\mathrm{DAB}$ & - diaminobenzidina \\
\hline EMA & $\begin{array}{l}\text { - "Epithelial Membrane Antigen" (antígeno de membrana } \\
\text { epitelial) }\end{array}$ \\
\hline FISH & $\begin{array}{l}\text { - "Fluorescence in situ hibridization" (hibridação } \\
\text { fluorescente in situ) }\end{array}$ \\
\hline GCDFP-15 & - "Gross cystic disease fluid protein-15" \\
\hline $\mathrm{hH}$ & - "Human hair keratin" (queratina do pelo humano). \\
\hline HC-FMUSP & $\begin{array}{l}\text { - Hospital das Clínicas da Faculdade de Medicina da } \\
\text { Universidade de São Paulo }\end{array}$ \\
\hline LIG & $\begin{array}{l}\text { - "Labelling imunnostaining group" (grupo de expressões } \\
\text { imunoistoquímicas). }\end{array}$ \\
\hline LIM & - Laboratório de Investigação Médica \\
\hline PBS & - solução salina tamponada com fosfatos \\
\hline PCNA & $\begin{array}{l}\text { - "Proliferating nuclear cell antigen" (antígeno nuclear de } \\
\text { proliferação celular) }\end{array}$ \\
\hline RNA-ISH & - "RNA in situ hibridization" (hibridação in situ de RNA) \\
\hline TE & - tricoepitelioma \\
\hline TGF-beta & - "Transforming Growth Factor Beta" \\
\hline TMA & $\begin{array}{l}\text { - "tissue microarrray" (arranjo em matriz de amostras } \\
\text { teciduais) }\end{array}$ \\
\hline UEA & - aglutinina do Ullex europeus \\
\hline
\end{tabular}




\section{LISTA DE TABELAS}

Tabela 1 - Autores, casuística e anticorpos isolados e painéis imunoistoquímicos para o estudo comparativo do tricoepitelioma, tumores derivados do folículo piloso e do carcinoma basocelular.

Tabela 2 - Anticorpos utilizados, código/clone, diluição de uso e procedimento de recuperação antigênica

Tabela 3 - Padrões de expressão dos antígenos CD34, CD10, BCL2, antígeno de membrana epitelial (EMA), citoqueratina 20 , citoqueratina $15, \quad D 2-40$ e $34 \beta$ E12 em tricoepiteliomas e carcinomas basocelulares agrupados no primeiro bloco analisado de "tissue microarray"

Tabela 4 - Comparação dos padrões de expressão dos casos de tricoepitelioma e de carcinoma basocelular, para os antígenos CD34, CD10, antígeno de membrana epitelial (EMA), citoqueratina 20, citoqueratina 15 e D2-40 em toda a amostra obtida em "tissue microarray"

Tabela 5 - Tricoepitelioma e carcinoma basocelular: imunomarcação com painel de anticorpos. Exemplo da distribuição dos resultados obtidos e transformados para valores de "zero" e "um"

Tabela 6 - Regressão linear multifatorial para a variante dependente "tricoepitelioma - tricoq", dispostos em ordem decrescente de eficiência (ver coluna com valores de Beta). $R=0,73429491 R^{2}=0,53918901 . \underline{R^{2}=0,53093920}$. $F(7,391)=65,358 p$

Tabela 7 - Regressão linear multifatorial para a variante dependente "tricoepitelioma - tricoq", após a exclusão do padrão EMAsq, dispostos em ordem decrescente de eficiência de acordo com os valores de Beta. $R=0,73759864$. $R^{2}=$ $0,54405175 . R^{2}=0,53835240 . F(5,400)=95,459 p$

Tabela 8 - Comparação entre os achados obtidos com a exploração dos resultados pelas técnicas de regressão linear múltipla e regressão logística múltipla para o diagnóstico do tricoepitelioma, de acordo com os perfis imunoistoquímicos de expressão antigênica, dispostos em ordem decrescente de eficácia. 
Tabela 9 - Discriminação entre tricoepitelioma e carcinoma basocelular pela imunoistoquímica. Associação de marcadores de acordo com a sua significância em estudo com regressão logística múltipla............................56 


\section{LISTA DE FIGURAS}

Figura 1 - Técnica de construção do "tissue microarray" (TMA) .............22

Figura 2 - Tricoepitelioma e carcinoma basocelular: características histopatológicas e expressão do antígeno CD34 ................. 36

Figura 3 - Tricoepitelioma e carcinoma basocelular: expressão dos antígenos CD34, BCL-2 e CD10 .................................... 38

Figura 4 - Tricoepitelioma e carcinoma basocelular: expressão de CD10, antígeno de membrana epitelial (EMA) e citoqueratinas 20 e 15

Figura 5 - Tricoepitelioma e carcinoma basocelular: expressão de citoqueratina 15, D2-40 e 34 $\beta$ E12 
RESUMO

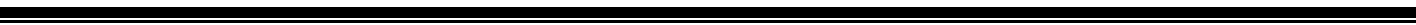


Tebcherani AJ. Painel imunoistoquímico para distinção entre tricoepitelioma e carcinoma basocelular desenvolvido utilizando a técnica do TMA [Tese]. São Paulo: Faculdade de Medicina da Universidade de São Paulo; 2012. 100 p.

O diagnóstico das neoplasias cutâneas do folículo piloso, particularmente do tricoepitelioma (TE), frequentemente representa dificuldade diagnóstica com o carcinoma basocelular (CBC). As semelhanças clínicas e histopatológicas somadas aos artefatos de amostragem (amostras exíguas por biopsias incisionais ou parcialmente danificadas por esmagamento ou fulguração) podem provocar situações de dificuldade na diagnose diferencial entre as duas neoplasias. $O$ diagnóstico de certeza é importante, pois o CBC tem caráter agressivo local e, quando não totalmente excisado, infiltra os tecidos adjacentes. $O$ TE é uma lesão benigna, sem capacidade de invasão local, não havendo recomendação de excisão com margem cirúrgica. Vários marcadores imunoistoquímicos têm sido propostos na literatura médica para auxiliar no diagnóstico diferencial entre o TE e o CBC. Esses estudos, entretanto, têm resultados conflitantes que podem estar relacionados à pequena casuística avaliada, que geralmente não excede 50 casos de TE. A técnica do arranjo em matriz de amostras teciduais, "tissue microarray" (TMA), permite a avaliação de um número grande de amostras teciduais, que podem ser submetidas de modo simultâneo aos procedimentos das reações imunoistoquímicas. O objetivo do presente estudo foi o de submeter uma ampla amostra de TE e CBC, obtida através da técnica de TMA, aos marcadores imunoistoquímicos descritos, com a finalidade de identificar um marcador, ou painel de marcadores, capaz de auxiliar a diferenciação do TE do CBC. Cortes histológicos de quatro blocos de TMA representando espécimes de 162 TE e 328 CBC foram submetidos às reações imunoistoquímicas com os anticorpos CD34, BCL-2, CD 10, antígeno de membrana epitelial (EMA), citoqueratinas (CK) 20 e 15, D2-40 e $34 \beta$ E12. A fim de facilitar a avaliação dos resultados e padrões de expressão antigênica, os espécimes foram digitalizados para obtenção de lâminas histológicas virtuais. Estas foram analisadas por meio de um programa de computador. Fez-se inicialmente a análise dos resultados de 85 TE e 62 CBC representados no primeiro bloco de TMA. Esta verificação identificou a expressão dos marcadores CD34, CD10, EMA, CK15, CK20 e D2-40 com diferença significativa entre os TE e os CBC. Procedeu-se a seguir a avaliação da imunomarcação de toda a casuística. As análises estatísticas de regressão linear multifatorial e regressão logística multifatorial indicaram os marcadores e padrões de expressão em ordem decrescente de importância: D2 40 positivo em células tumorais periféricas, CK 15 positivo em células tumorais periféricas, CD10 positivo no estroma tumoral, CK 20 positivo em células tumorais periféricas e positividade estromal de CD 34. A regressão logística evidenciou ainda que, na amostra examinada, a presença de três ou quatro desses marcadores, com exceção do CD 34, pode identificar 35,9\% dos TE. Nossos resultados, obtidos pelo estudo de casuística expressiva, são 
concordantes com os achados de outros trabalhos que sugerem que o TE e o CBC são neoplasias que estão em diferentes pontos da mesma linhagem de diferenciação dos tumores basalóides foliculares e que, por este motivo, podem expressar os mesmos marcadores/perfil antigênico epitelial e estromal. Embora o painel de quatro anticorpos acima relatado possa ser de grande ajuda, e até mesmo identificar $35,9 \%$ dos TE, os critérios histopatológicos clássicos e clínicos ainda devem ser os principais guias para o diagnóstico diferencial entre o TE e o CBC.

Descritores: carcinoma basocelular, neoplasias cutâneas, imunoistoquímica, análise em microssérie, modelos lineares, modelos logísticos. 
Tebcherani AJ. Diagnostic utility of immunohistochemical panel in distinguishing trichoepithelioma and basal cell carcinoma: Evaluation using tissue microarray samples [Thesis]. São Paulo: "Faculdade de Medicina da Universidade de São Paulo"; 2012. 100 p.

Trichoepithelioma is a benign neoplasm that shares both clinical and histological features with basal cell carcinoma. It is important to distinguish these neoplasms because they have different clinical behavior and require proper therapeutic planning. Many studies have addressed the use of immunohistochemistry to improve the differential diagnosis of these tumors. These studies present conflicting results when addressing the same markers, probably due to the small number of basaloid tumors that comprised their studies, which generally did not exceed 50 cases. We built a tissue microarray with 162 trichoepithelioma and 328 basal cell carcinoma biopsies and tested a panel of immune markers composed of CD34, CD10, epithelial membrane antigen, BCL-2, cytokeratins 15 and 20 and D2-40. The results were analyzed using multiple linear and logistic regression models. This analysis revealed a model that could differentiate trichoepithelioma from basal cell carcinoma in $35,9 \%$ of the cases. The panel of immunohistochemical markers required to differentiate between these tumors was composed of CD10, cytokeratin 15, cytokeratin 20 and D2-40. The results obtained in this work were generated from a large number of biopsies and resulted in the confirmation of overlapping epithelial and stromal immunohistochemical profiles from these basaloid tumors. The results also corroborate the point of view that trichoepithelioma and basal cell carcinoma tumors represent two different points in the same line of differentiation. Despite the use of panels of immune markers, histopathological criteria associated with clinical data certainly remain the best guideline for the differential diagnosis of trichoepithelioma and basal cell carcinoma.

Descriptors: basal cell carcinoma, cutaneous neoplasms, immunohistochemistry, microarray analysis, linear models, logistic models. 
1 INTRODUÇÃO 
A identificação das neoplasias cutâneas é um dos exercícios mais frequentes na prática rotineira do patologista cirúrgico. Os critérios morfológicos para a diferenciação entre as neoplasias cutâneas mais comuns, que são o carcinoma basocelular, o melanoma e o carcinoma espinocelular, são bastante consistentes.

Porém, quando comparamos o carcinoma basocelular (CBC), a neoplasia cutânea mais frequente ${ }^{1}$, com as neoplasias cutâneas primárias do folículo piloso (benignas e malignas), particularmente o tricoepitelioma (TE), algumas semelhanças histopatológicas somadas a artefatos de amostragem (amostras exíguas em biopsias incisionais ou amostras parcialmente danificadas por artefatos de esmagamento ou fulguração) podem provocar situações de dificuldade diagnóstica ${ }^{1}$.

Com relação aos aspectos clínicos, os CBC são mais frequentes em áreas expostas à radiação solar, especialmente cabeça e pescoço, em pacientes a partir da quarta década de vida. A lesão pode apresentar tamanhos variados ${ }^{2}$

Os TE apresentam-se clinicamente de duas maneiras. Nos casos de herança familiar são múltiplos e têm dimensões que variam de $2 \mathrm{~mm}$ a 8 mm. As lesões iniciam-se na adolescência e localizam-se na face, principalmente no sulco nasogeniano, mento e região supralabial. O tricoepitelioma solitário localiza-se preferencialmente na face e pescoço e acomete pacientes em uma faixa etária maior ${ }^{3}$. 
Os critérios para o diagnóstico histopatológico do TE compreendem ${ }^{4}$ :

1. Nodulação dérmica de contornos regulares e definidos, composta por células de aspecto "basalóide" (citoplasma escasso e fracamente basofílico, contendo núcleo hipercromático).

2. Paliçada celular periférica nos grupamentos celulares.

3. Estroma colagenizado e denso, envolvendo os grupamentos celulares epiteliais.

4. Cistos córneos intratumorais, repletos de ceratina, que podem se calcificar, ocasionalmente.

5. Infiltrado inflamatório estromal mínimo ou ausente.

6. Mucina estromal ausente.

7. Fendas localizadas entre o estroma peritumoral e a derme adjacente.

Os critérios histopatológicos para o diagnóstico do CBC são os seguintes ${ }^{1}$ :

1. Grupamentos de células com aspecto basalóide, com leve a moderado pleomorfismo nuclear (citoplasma escasso e fracamente basofílico, contendo núcleo hipercromático, com aumento da relação núcleocitoplasma).

2. Células se dispondo em "paliçada" na periferia dos grupamentos celulares.

3. Número de mitoses variável.

4. Presença de mucina entre estes grupamentos celulares.

5. Fendas "artefactuais", localizadas entre a neoplasia e a derme adjacente, decorrentes da deposição de mucina. 
6. Presença variável de células inflamatórias (linfócitos, macrófagos e plasmócitos) no estroma adjacente.

O CBC tem caráter agressivo local e, caso não totalmente excisado, infiltra os tecidos adjacentes ${ }^{2}$. A exérese da lesão deve ser feita com margens que podem ser de $2 \mathrm{~mm}, 4 \mathrm{~mm}$ e até $5 \mathrm{~mm}$, dependendo do tipo histológico, da localização e do tamanho da lesão.,

O TE, por outro lado, é uma lesão benigna, sem capacidade de invasão local, não havendo recomendação de margem cirúrgica para sua excisão $0^{6,7}$.

A imunoistoquímica se tornou uma importante ferramenta de trabalho do patologista, tendo aplicação nos procedimentos de diagnóstico e prognóstico em todas as áreas da patologia cirúrgica ${ }^{8}$. A sua utilização tem sido impulsionada pelo aparecimento de vários marcadores ${ }^{9}$.

A disponibilidade de diversos anticorpos permitiu a elaboração de painéis que auxiliam na identificação de neoplasias pouco diferenciadas ${ }^{10,11}$.

Vários autores têm publicado artigos com o propósito de identificar marcadores imunoistoquímicos, que possam diferenciar o $\mathrm{CBC}$ dos tumores anexiais cutâneos benignos com diferenciação folicular.

Kirschmann et al. ${ }^{12}$, em 1994, verificam a expressão do antígeno CD34 em 16 TE e 19 CBC. O antígeno CD34 é expresso pelas célulastronco da linhagem mielomonocítica, células endoteliais e pelos dendrócitos dérmicos que ocupam a derme reticular e adventicial nas adjacências dos anexos cutâneos. Estes autores descrevem a positividade do antígeno 
CD34 nos elementos fusocelulares que circundam os blocos celulares basalóides dos espécimes de TE. Esse padrão de expressão de CD34, entretanto, não foi observado nos casos de CBC.

A expressão do antígeno $\mathrm{BCL}-2$, relacionado à proteção do mecanismo de apoptose, foi analisada por Smoller et al. ${ }^{3}$ em 1994, como possível diferenciador de TE e CBC. Os pesquisadores estudam 10 TE e 10 CBC e observam uma clara diferença na expressão do BCL-2 nestas duas neoplasias. Todos os TE expressam este antígeno na camada mais externa das células epiteliais neoplásicas, enquanto todos os CBC exibem positividade difusa nas células basaliomatosas.

A expressão de CD34 por células epiteliais do triquilemoma desmoplásico, outra neoplasia de origem folicular, é descrita em estudo de sete casos. Este aspecto não é observado nos sete casos de CBC do mesmo estudo ${ }^{14}$.

Outros trabalhos enfocam a expressão de citoqueratinas (CK) com o objetivo de diferenciar o CBC de neoplasias epiteliais basalóides.

A expressão de CK 20, marcador de células de Merkel $^{15}$, é considerada útil na diferenciação do tricoblastoma do CBC. Schulz e Hartschuh $^{16}$, em 1997, ao estudarem 205 CBC e 36 tricoblastomas, verificam maior densidade de células de Merkel, no componente basalóide da neoplasia e na epiderme suprajacente, em 15 dos 36 dos tricoblastomas avaliados. 
Outros autores propõem painéis imunoistoquímicos para a diferenciação do CBC e neoplasias basalóides foliculares benignas.

Um painel composto por três marcadores BCL-2, CD34 e o "Transforming Growth Factor Beta" (TGF- $\beta$ ) é proposto por Verhaegh et al. ${ }^{17}$, em 1997, para o estudo de 17 tumores, sendo nove TE e oito CBC. Todos TE $(100,0 \%)$ e um CBC $(6,0 \%)$ são positivos para o TGF- $\beta$. O BCL-2 é observado difusamente nas células epiteliais tumorais de sete CBC $(41,2 \%)$ e um TE $(6,0 \%)$. A imunoexpressão do CD 34 é verificada no estroma peritumoral de dois CBC $(12,0 \%)$ e sete TE $(41,2 \%)^{17}$.

Swanson et al. ${ }^{18}$, em 1998, utilizam painel imunoistoquímico composto pelos marcadores Ber-EP4, CD34 e BCL-2, para estudar 103 biopsias incisionais de neoplasias cutâneas: 45 CBC, 22 carcinomas espinocelulares e 36 TE. Observam expressão difusa de Ber-EP4 em todos os CBC estudados. A expressão deste marcador é negativa nos carcinomas espinocelulares, assim como nos focos de diferenciação escamosa dos CBC. Entretanto, a expressão de Ber-EP4, mesmo que focal, é observada em $80,5 \%$ dos TE. O BCL-2 apresenta positividade com "reforço" na periferia dos blocos epiteliais em 17 dos 21 casos de TE clássico (80,9\%), caracterizados histologicamente pela presença dos grupamentos celulares de aspecto basalóide com diferenciação folicular e cistos córneos em meio a estroma denso e colagenizado. Em cinco dos sete casos de TE desmoplásico $(71,4 \%)$ notam-se grupamentos celulares alongados compostos por duas a três camadas de células, imersos em denso estroma colagenizado; e, em dois de oito TE imaturos $(25,0 \%)$ observa-se um 
predomínio de aglomerados sólidos de células basalóides sem evidências de diferenciação folicular ou cistos córneos. Quarenta e um carcinomas basocelulares dos 45 examinados são positivos difusamente para o BCL-2 (91,1\%). Quatro destes CBC apresentam expressão de BCL-2 mais acentuada nas células epiteliais tumorais periféricas, semelhante ao padrão encontrado nos TE avaliados. Onze dos 13 carcinomas espinocelulares são negativos para o BCL-2 (84,6\%). O CD34 é positivo nos elementos epiteliais de três de 36 TE (8,3\%), assim como em sete dos 43 CBC (16,2\%). Cumpre ressaltar que, dos sete $C B C$ positivos para $O C D 34$, seis são $C B C$ metatípicos. Catorze de 21 TE (66,66\%) apresentam imunomarcação pelo CD34 em células fusiformes peritumorais. Seis dos 43 espécimes de CBC mostram positividade do estroma peritumoral para o CD34 $(13,0 \%)$.

Ainda na tentativa de propor painel de marcadores para diferenciar CBC de TE, Basarab et al. ${ }^{19}$, em 1998, estudam 15 CBC e 10 TE com painel de marcadores compostos por CD34, BCL-2 e aglutinina de amendoim (PNA). Neste estudo, os pesquisadores descrevem a expressão de CD34 no estroma peritumoral de $20,0 \%$ dos TE e em $7,0 \%$ dos CBC. O BCL-2 é observado nas células de camadas periféricas dos agrupamentos epiteliais tumorais em 20,0\% dos TE e 7,0\% dos CBC. Expressão epitelial difusa de BCL-2 é verificada em $30,0 \%$ dos TE e $40,0 \%$ dos CBC. Nota-se a expressão da aglutinina de amendoim no estroma peritumoral de forma contínua (em 10,0\% dos TE e 40,0\% dos CBC) e descontínua (em 80,0\% dos TE e $20,0 \%$ dos $C B C$ ). Os cientistas concluem que não existe um 
padrão ou associação de padrões de imunorreatividade para os marcadores testados que seja útil para diferenciar TE de CBC.

O estudo da expressão de BCL-2 é associado à expressão de marcadores da proliferação celular, ainda na tentativa de diferenciação do TE e CBC. Ao analisarem 40 tumores (20 TE clássicos e 20 CBC), Abdelsayed et al. $^{20}$, em 2000, observam igual expressão de BCL-2 e p53 nos dois grupos de tumores, entretanto com diferença nos índices de proliferação obtidos pelo Ki67 e PCNA.

Ohnishi e Watanabe ${ }^{21}$, em 1999, estudam 13 tumores tricogênicos benignos com um amplo painel de citoqueratinas (19 citoqueratinas e a involucrina). Essa casuística compreende cinco TE clássicos, de apresentação solitária, quatro TE de apresentação múltipla, um tricoblastoma, um tricoblastoma gigante, um tricoblastoma tricogênico e um fibroma tricogênico. Todas as neoplasias estudadas apresenram expressão idêntica de todo painel de citoqueratinas avaliadas. Estes resultados, segundo os autores, reforçam a proposição de que todas as neoplasias das células germinativas do folículo piloso deveriam ser consideradas como uma única entidade.

Poniecka e Alexis ${ }^{22}$, em 1999, submetem 20 CBC e 10 TE a um painel imunoistoquímico composto pelos marcadores CAM 5.2, antígeno carcinoembriônico (CEA), CK-7, CK-20, CD34, BCL-2, CD30, aglutinina do Ullex europeus (UEA) e HAM 5.6. Estes autores descrevem achados semelhantes aos anteriores, como a positividade do BCL-2 difusamente nas células epiteliais tumorais de todos os $\mathrm{CBC}$ e nas células epiteliais 
periféricas de todos os TE, a positividade estromal para o CD34 presente em quatro dos nove tricoepiteliomas avaliados $(44,4 \%)$ e em dois dos 20 CBC avaliados (10,0\%). Neste trabalho não é observada expressão de CK20 nos TE, assim como nos CBC. Expressão de CK7 é encontrada em $100,0 \%$ dos TE e em 20,0\% dos CBC avaliados. Os outros marcadores não exibem diferenças significativas que pudessem justificar a sua utilização como auxiliares no diagnóstico diferencial entre o TE e o CBC.

A expressão de CK15 nos CBC e TE também é estudada por Jih et al. $^{23}$ em 1999. Neste trabalho, são examinados 50 tumores, dentre eles 37 CBC, 12 TE e um tricoepitelioma desmoplásico. A expressão de CK15 é observada em todos TE e em 10 CBC (27,0\%). Entretanto, no mesmo ano, Kanitakis et al. ${ }^{24}$ relatam imunoexpressão de CK15 em 5/8 TE (62,5\%) e ausência de expressão dessa citoqueratina em 17 CBC estudados.

Painel composto por citoqueratinas $34 \beta \mathrm{E} 12$ (citoqueratina de alto peso molecular), CK6, CK7, CK10, CK10-11, CK14, CK17, CK13, CK19, CAM 5.2, involucrina, antígeno de membrana epitelial (EMA), "Gross cystic disease fluid protein-15" (GCDFP-15) e proteína $\$ 100$ é testado por Yamamoto e Asahi ${ }^{25}$, em 1999, na diferenciação do CBC (29 espécimes), TE (sete espécimes) e três tricoblastomas. Segundo o estudo, as três neoplasias demonstram expressão semelhante de citoqueratinas, com exceção do TE que não apresenta expressão para CK7. Os pesquisadores sugerem que a ausência de expressão de CK7 seria indicador de TE na diagnose diferencial deste grupo de neoplasias. Além disso, este fato 
justifica a classificação do TE e do tricoblastoma em dois grupos distintos de neoplasias de origem folicular.

Painel ainda mais amplo contendo citoqueratinas CK10, CK14, CK6, CK6hf, CK8, CK13, CK8-15, CK17, CK19, CK20 e queratinas do pelo humano ("human hair keratin" - hH) composto pelos anticorpos: hHa1, hHa2, hHa3, hHa5, hHa8, hHb1, hHb2, hHb5 e hHb6 é aplicado em 19 tricoblastomas e $13 \mathrm{CBC}^{26}$. Neste trabalho, relata-se a imunoexpressão do CK19 em 69,0\% (9/13) dos tricoblastomas e em 22,2\% (4/18) dos CBC. O antígeno CK15 não é identificado em nenhum CBC e está presente em $38,0 \%(5 / 13)$ dos tricoblastomas. Quanto aos demais marcadores, nenhum deles permite uma clara definição diagnóstica entre as duas neoplasias. Os autores sugerem também que a expressão das citoqueratinas está sujeita a influências externas (citocinas, fatores de crescimento e vitaminas) e que reflete um estado de diferenciação do tumor e não uma característica específica da neoplasia.

Mais recentemente o antígeno CD10 é relatado também como possível marcador para diferenciação de TE e CBC. O antígeno CD10 é uma metaloendopeptidase de superfície celular, envolvida na inativação de uma variedade de peptídeos biologicamente ativos ${ }^{27}$. Este marcador é inicialmente identificado na leucemia linfoblástica aguda. É expresso na superfície de linfócitos normais e neoplásicos. Na pele, a expressão do CD10 é descrita no estroma perianexial e em alguns tumores de linhagem mesenquimal da derme ${ }^{28}$. 
Pham et al. ${ }^{29}$, em 2006, estudam 23 CBC e 13 TE com o marcador CD10 e observam positividade estromal em 92,0\% (12/13) dos TE. No CBC, o componente celular da neoplasia mostra-se imunomarcado em $87,0 \%$ dos casos. Nenhum dos TE exibe positividade epitelial para CD10. Por outro lado, somente três CBC apresentam expressão estromal para este marcador. Segundo os autores, os resultados sugerem ser o CD10 um bom marcador para diferenciar TE de CBC.

A perda da expressão de CK15 e CK20 é observada no tricoblastoma com evidências de transformação/associação com $\mathrm{CBC}$, ao contrário do observado nos tricoblastomas puros ${ }^{30}$

Combinação de técnica de imunoistoquímica com coloração para elementos estromais das neoplasias basalóides também tem sido proposta na tentativa de aprimorar a diagnose diferencial de TE e CBC.

Choi et al. ${ }^{31}$, em 2008, estudam 11 TE e 17 CBC com o marcador CK 15 associado à coloração para fibras elásticas e relatam expressão difusa de CK15 pelas células tumorais de $83,3 \%$ dos CBC e, pelas células da periferia dos blocos tumorais, em $87,5 \%$ dos TE. Descrevem trama de fibras elásticas acentuada ao redor dos blocos celulares do CBC e rarefação da mesma trama no estroma peritumoral do TE.

Painel imunoistoquímico composto pelos marcadores considerados úteis na diferenciação de TE e CBC, como o CD34, CD10, CK20 e BCL-2, é ampliado com marcadores de proliferação celular Ki67, p53 e receptor de estrógeno, e aplicado no estudo de 19 TE desmoplásicos e 18 CBC. Não 
há, entretanto, qualquer associação destes marcadores com poder de identificar claramente as duas neoplasias estudadas ${ }^{32}$.

Retomando a avaliação dos marcadores BCL-2 e CD10 na diferenciação dos tumores tricoblásticos e CBC, Córdoba et al. ${ }^{33}$, em 2008, descrevem padrão de expressão de BCL-2 distinto nos tricoblastomas e CBC nodulares. Entretanto, a imunomarcação observada nos CBC com diferenciação folicular não os distingue dos tricoblastomas. O mesmo ocorre com a imunoexpressão de CD10 de padrão (epitelial e estromal peritumoral) semelhante nos CBC com diferenciação folicular e no grupo de tricoblastomas. Esta variante do CBC representa um problema diagnóstico diferencial com os tricoblastomas.

A podoplanina (D2-40) tem sido descrita como marcador de células de linhagem vascular linfática ${ }^{34}$, que se expressa também nas células da bainha externa do folículo piloso. Liang et al. ${ }^{35}$, em 2007 , sugerem a sua utilidade como marcador de neoplasias anexiais cutâneas em comparação com neoplasias metastáticas para a pele.

Em uma série de 49 tumores (22 TE e 27 CBC), Plaza et al. ${ }^{36}$, em 2010, demonstram a imunomarcação difusa deste antígeno em 95,0\% dos TE. O mesmo padrão de expressão de podoplanina é observado em somente $22,2 \%$ dos CBC. 


\section{Técnica de arranjo em matriz de amostras teciduais - "tissue microarray"}

A técnica do arranjo em matriz de amostras teciduais, o "tissue microarray" (TMA), proposta em $1998^{37}$, veio acrescentar grande praticidade e dinamismo ao estudo imunoistoquímico investigativo, pois, através desta técnica podemos, com apenas uma reação, examinar várias amostras teciduais com a mesma qualidade e sem outros fatores que podem interferir nos resultados obtidos, como, por exemplo, variações de temperatura, controle do $\mathrm{pH}$ dos reagentes, tempos diferentes de revelação das reações, que podem ocorrer em reações realizadas em sessões não concomitantes de procedimento técnico.

A utilização dos arranjos em matriz tecidual é proposta para estudos de hibridação fluorescente in situ (FISH), hibridação in situ de RNA (RNAISH) e imunoistoquímica.

O TMA para estudos de imunoistoquímica tem sido bastante utilizado, pela possibilidade de produzir grandes amostragens com custo reduzido, além de permitir protocolos mais homogêneos, diminuindo problemas técnicos de processamento.

A técnica de TMA consiste na excisão de cilindros pequenos $(0,6$ 1,0 mm de diâmetro) de tecido de vários blocos de parafina "doadores" para construir um bloco "receptor". Esta técnica possibilita coletar em um mesmo bloco receptor centenas de amostras de diferentes espécimes a serem 
estudadas e organizadas de acordo com uma planilha para identificação dos resultados.

Outra vantagem desta técnica é possibilitar a utilização de coleções de tumores ou mesmo de várias amostras de processos teciduais contidas em um bloco receptor (bloco de TMA) para pesquisas futuras com outras abordagens. A manutenção dos TMA, assim como dos cortes histológicos ("em branco") obtidos destes blocos, em ambiente refrigerado, é procedimento que visa à preservação da antigenicidade tecidual ${ }^{38}$.

A técnica de TMA tem sido utilizada no estudo de lesões melanocíticas $^{39,40,41,42}$ e também de $\mathrm{CBC}^{43,44,45,46,47}$. Entretanto, não encontramos estudos utilizando esta técnica em grandes séries, para comparar TE e CBC.

Ao revisar a literatura que aborda os possíveis marcadores ou painel de marcadores úteis para a diagnose diferencial das neoplasias basalóides foliculares, em particular a diferenciação do TE e CBC, podemos observar que os resultados são conflitantes. Autores que utilizam extensos painéis de citoqueratinas justificam estes dados como decorrentes da possibilidade de que as neoplasias de células germinativas do folículo piloso representem estágios diferentes de uma mesma entidade ${ }^{21,25}$.

Por outro lado, esses resultados conflitantes podem estar relacionados ao pequeno número de amostras que compõem a casuística desses trabalhos, geralmente não superior a 50 casos, principalmente de tricoepiteliomas (Tabela 1). Por este motivo, parece-nos interessante 
realizar estudo com painel imunoistoquímico amplo em casuística expressiva de tricoepiteliomas e carcinomas basocelulares com o auxílio da técnica de TMA.

Tabela 1 - Autores, casuística, anticorpos isolados e painéis imunoistoquímicos para o estudo comparativo do tricoepitelioma, tumores derivados do folículo piloso e do carcinoma basocelular

\begin{tabular}{|c|c|c|c|c|c|}
\hline Autores & TE & CBC & $\begin{array}{c}\text { Outros } \\
\text { tumores } \\
\text { foliculares }\end{array}$ & Anticorpos & $\begin{array}{l}\text { Número de } \\
\text { casos }\end{array}$ \\
\hline Kirchmann et al. ${ }^{12}$ & 16 & 19 & - & CD34 & 37 \\
\hline Smoller et al. ${ }^{13}$ & 10 & 10 & - & BCL-2 & 20 \\
\hline Illueca et al. ${ }^{14}$ & - & 7 & $7^{*}$ & CD34 & 14 \\
\hline Schulz; Hartchuh ${ }^{16}$ & - & 205 & $36^{* *}$ & CK20 & 241 \\
\hline Verhaegh et al. ${ }^{17}$ & 9 & 8 & - & BCL-2, CD34, TGF- $\beta$ & 17 \\
\hline Swanson et al. ${ }^{18}$ & 36 & 45 & - & BCL-2 e CD34 & 81 \\
\hline Basarab et al. ${ }^{19}$ & 10 & 15 & - & CD34 & 25 \\
\hline Abdelsayed et al. ${ }^{20}$ & 20 & 20 & - & $\begin{array}{c}\text { BCL-2, Ki67, PCNA e } \\
\text { p53 }\end{array}$ & 40 \\
\hline Ohnishi; Watanabe ${ }^{21}$ & 13 & 0 & 3 & Painel de citoqueratinas & 16 \\
\hline Poniecka; Alexis 22 & 10 & 20 & - & $\begin{array}{l}\text { CD34, BCL-2, CK7 e } \\
\text { CK20 }\end{array}$ & 30 \\
\hline Jih et al. ${ }^{23}$ & 13 & 37 & - & CK15 & 50 \\
\hline Kanitakis et al. ${ }^{24}$ & 8 & 17 & 41 & CK15 & 66 \\
\hline Yamamoto; Asahi ${ }^{25}$ & 7 & 29 & 3 & $\begin{array}{c}\text { Painel de citoqueratinas } \\
\text { e EMA }\end{array}$ & 39 \\
\hline Kurzen et al. ${ }^{26}$ & - & 13 & $19^{* *}$ & Painel de citoqueratinas & 32 \\
\hline Pham et al. ${ }^{29}$ & 13 & 23 & - & CD10 & 36 \\
\hline Misago et al. ${ }^{30}$ & - & 0 & $7^{* *}$ & CK15 e CK20 & 7 \\
\hline Choi et al. ${ }^{31}$ & 11 & 17 & - & CK15 & 28 \\
\hline Costache et al. ${ }^{32}$ & 19 & 18 & - & $\begin{array}{l}\text { CD34, CD10, BCL-2 e } \\
\text { CK20. }\end{array}$ & 37 \\
\hline Cordoba et al..$^{33}$ & - & 19 & $21^{* *}$ & BCL-2, CD10 & 40 \\
\hline Plaza et al. ${ }^{36}$ & 22 & 27 & - & D2 40 & 49 \\
\hline
\end{tabular}

TE - tricoepitelioma; CBC - carcinoma basocelular; "triquilemomas; **tricoblastomas; CK citoqueratinas; EMA - antígeno de membrana epitelial. 
2 OBJETIVOS 


\section{Objetivos gerais:}

Identificar um painel "mínimo" de marcadores que permita distinguir o tricoepitelioma do carcinoma basocelular.

\section{Objetivos específicos:}

1. Construir uma série de casos de tricoepiteliomas e carcinomas basocelulares através da técnica de arranjo em matriz de amostras teciduais ("tissue microarray" - TMA).

2. Analisar e comparar esta amostra com amplo painel imunoistoquímico, composto por marcadores anteriormente testados na literatura, na tentativa de dirimir as inúmeras discrepâncias entre os resultados dos vários estudos já realizados.

3. Verificar através de análise estatística a possibilidade da criação de modelos para conjuntos de marcadores passíveis de diferenciar o tricoepitelioma do carcinoma basocelular. 
3 MATERIAL E MÉTODOS 


\subsection{CASUÍSTICA}

Foram selecionados espécimes de TE clássicos e CBC, provenientes de três laboratórios de patologia, sendo eles:

1. Laboratório de Dermatopatologia da Divisão de Clínica Dermatológica do Hospital das Clínicas da Faculdade de Medicina da Universidade de São Paulo (HC-FMUSP).

2. Laboratório de Dermatopatologia do Serviço de Dermatologia do Complexo Hospitalar Padre Bento de Guarulhos (Guarulhos - SP).

3. Laboratório de Patologia do Serviço de Anatomia Patológica do Hospital do Servidor Público Estadual (São Paulo - SP).

O projeto recebeu anuência dos serviços envolvidos e foi submetido e aprovado pela Comissão de Ética em Pesquisa do HC-FMUSP, protocolo número 340/09.

Todos os espécimes foram revistos por dois patologistas, sendo os critérios utilizados para o diagnóstico os descritos na literatura ${ }^{1,4}$. Foram excluídos da análise os subtipos histológicos de CBC menos frequentes, assim como o TE desmoplásico.

Espécimes com dimensões maiores ou iguais a $0,3 \times 0,3 \mathrm{~cm}$, na face de corte, foram selecionados para análise pela técnica do "tissue microarray" (TMA). 


\subsection{MÉTODOS}

\subsubsection{TÉCNICA DE ARRANJO EM MATRIZ DE AMOSTRAS TECIDUAIS - "TISSUE MICROARRAY"}

Após a seleção dos casos, as respectivas lâminas histológicas foram demarcadas nas áreas mais representativas das neoplasias com caneta para retroprojetor (Figura 1A). Por comparação visual, estas áreas de interesse foram marcadas nos blocos de parafina (blocos doadores) de cada espécime selecionado (Figura 1B).

As amostras para montagem dos TMA foram retiradas, dos blocos "doadores", com agulha de 1,0 mm de diâmetro. Utilizando-se o instrumento "tissue arrayer" MTA-1 (Beecher Instruments, Winscosin, USA), de cada área selecionada no bloco "doador", foram colhidos dois fragmentos (Figura 1C), os quais foram arranjados em dois blocos "receptores" de TMA diferentes (Figura 1 D-G) com posições correspondentes, denominados como bloco "original" e "bloco espelho".

Cada fragmento retirado recebeu uma designação para permitir identificar o respectivo espécime de origem em uma planilha.

A montagem dos blocos "receptores" de TMA foi realizada no Setor Multiusuário do Laboratório de Investigação Médica 14 (LIM 14), do Serviço de Patologia Hepática do Hospital das Clínicas, da Faculdade de Medicina da Universidade de São Paulo. 
Foram construídos quatro blocos e respectivos "blocos espelho", com representação de 162 TE e 328 CBC.

De cada bloco foram obtidos 51 cortes histológicos de $3 \mu \mathrm{m}$, colhidos em lâminas de vidro de 26x76x1 mm "StarFrost-Adhäsiv" (Bad Homburg, Germany), tratadas com solução adesiva de órgano-silano (Figura $1 \mathrm{H}$ ). Quatro lâminas nos níveis inicial (uma lâmina), médio (duas lâminas) e final (uma lâmina) de cada sequência foram coradas pela hematoxilina-eosina para identificar os níveis mais representativos do TMA.

Após a identificação da sequência de cortes em que houve a menor perda tecidual, estes foram submetidos às reações imunoistoquímicas. Os marcadores pesquisados foram aqueles descritos pela literatura, utilizados com maior frequência na rotina da dermatopatologia. 

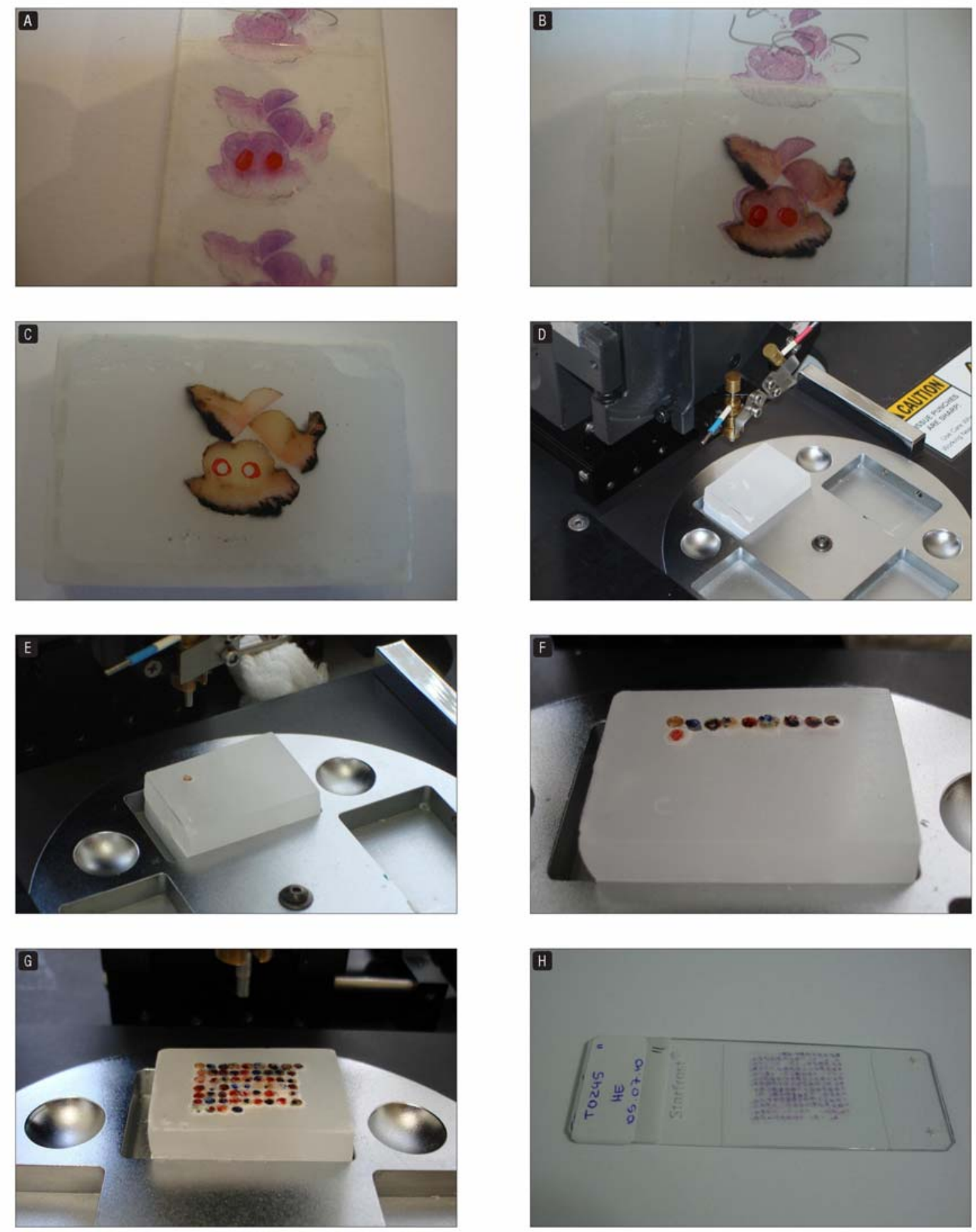

Figura 1 - Técnica de construção do "tissue microarray" (TMA). A) Marcação dos pontos de interesse na lâmina. B) Transposição dos pontos para o bloco de parafina "doador". C) Retirada dos fragmentos do bloco doador. D) Preparação do bloco "receptor". E) introdução do fragmento no bloco "receptor". F) Bloco "receptor" parcialmente montado. G) Bloco "receptor" finalizado. H) Lâmina do bloco "receptor". (D - G - Imagens gentilmente cedidas pelo LIM-14) 


\subsubsection{TÉCNICA DE IMUNOISTOQUÍMICA}

Os cortes histológicos foram submetidos à desparafinização em banho de xilol a $60^{\circ} \mathrm{C}$ por 15 min, seguido de outro banho de xilol à temperatura ambiente por 15 min. Em seguida foram hidratados em cadeia descendente de etanol e água destilada.

Procedeu-se à recuperação antigênica, de acordo com o anticorpo utilizado, conforme explicitado na Tabela 2. A seguir, bloqueou-se a peroxidase endógena com o peróxido de hidrogênio a 6,0\% em etanol v/v, por 10 min, três vezes.

Em seguida, os cortes histológicos foram lavados em água corrente e destilada e em banhos com solução salina tamponada com fosfatos (PBS) $10 \mathrm{mM} \mathrm{pH} \mathrm{7,4} \mathrm{por} 5 \mathrm{~min}$.

Fez-se então o bloqueio de proteínas com Cas Block (Zymed Laboratories, San Francisco, Ca, USA), por 10 min a $37^{\circ} \mathrm{C}$.

Os cortes histológicos foram incubados com os anticorpos primários, diluídos em solução de albumina bovina (BSA) (Sigma Chemical Company, St Louis, MO, EUA) a 1,0\% e azida sódica $\mathrm{NaN}_{3}$ (Inlab, São Paulo) 0,1\% em PBS, em câmara úmida: 30 min a $37^{\circ} \mathrm{C}$ e, em seguida, $18 \mathrm{~h}$ (overnight) a $4^{\circ} \mathrm{C}$ (ver Tabela 2). Após este procedimento, foram realizadas lavagens em PBS com três trocas de 5 min cada. 
A seguir, foram incubados com o bloqueador pós-primário ("Post Primary Block NovoLink Max Polymer Detection System" - Newcastle, UK), por $30 \min$ a $37^{\circ} \mathrm{C}$

Os cortes histológicos foram submetidos a lavagens com PBS, com três trocas de 3 a 5 min cada. Em seguida, foram incubados com o sistema de detecção "NovoLink Polymer" do mesmo kit por 30 min a $37^{\circ} \mathrm{C}$.

Fez-se a revelação das reações com solução de substrato cromogênico contendo diaminobenzidina (Sigma Aldrich, EUA) a 0,10\%, peróxido de hidrogênio a $0,06 \%$, dimetil sulfóxido (Labsynth) a 1,0\% em PBS, em banho de 5 min a $37^{\circ} \mathrm{C}$, seguida de lavagens em água corrente e água destilada.

Os cortes histológicos foram contracorados com Hematoxilina de Harris por 1 min, lavagens em água corrente e água destilada. Imersão rápida em água amoniacal (solução de hidróxido de amônia 0,5\%), seguida de lavagens em água corrente e água destilada.

Procedeu-se à desidratação dos cortes em cadeia ascendente de etanol, diafanização em banhos de xilol e montagem em meio permanente (Entellan®, Merck KGaA, Alemanha) com lamínula.

Todas as reações foram realizadas com controles sabidamente positivos para os anticorpos em estudo. Como controle negativo das reações substituiu-se o anticorpo primário por PBS. 
Tabela 2 - Anticorpos utilizados, código/clone, diluição de uso e procedimento de recuperação antigênica

\begin{tabular}{|c|c|c|c|c|}
\hline Anticorpo & Código/clone & Fabricante & Diluição & Recuperação antigênica \\
\hline CD34 & M7165/clone QBEnd-10 & DAKO Cytomation (Carpinteria, CA,USA) & $1 / 500$ & $10 \mathrm{mM}$ ácido cítrico, $\mathrm{pH}$ 6,0* \\
\hline BCL 2 & 18-0193Z /BCL-2-100 & Zymed (CA, USA) & $1 / 400$ & $10 \mathrm{mM}$ ácido cítrico, $\mathrm{pH}$ 6,0* \\
\hline CD10 & MS-728-S/CALLA Ab-2, clone 56C6 & Thermo Fisher Scientific (USA) & $1 / 100$ & 1 mM EDTA, pH 8,0** \\
\hline EMA & M0613/clone E29 & DAKO Cytomation (Carpinteria, CA,USA) & $1 / 1000$ & $10 \mathrm{mM}$ ácido cítrico, $\mathrm{pH}$ 6,0* \\
\hline CK20 & M7019/KS20.8 & DAKO Cytomation (Carpinteria, CA,USA) & $1 / 800$ & $10 \mathrm{mM}$ ácido cítrico, $\mathrm{pH}$ 6,0* \\
\hline CK15 & NCL-CK15 & Novocastra (Newcastle, UK) & $1 / 50$ & $10 \mathrm{mM}$ ácido cítrico, $\mathrm{pH} 9,0^{*}$ \\
\hline D2-40 & M3619 & DAKO Cytomation (Carpinteria, CA,USA) & $1 / 600$ & $10 \mathrm{mM}$ ácido cítrico, $\mathrm{pH} 6,0^{*}$ \\
\hline $34 \beta$ E12 & M0630 & DAKO Cytomation (Carpinteria, CA,USA) & $1 / 400$ & Ácido cítrico 10 mM, pH 6,0 \\
\hline
\end{tabular}

EMA - antígeno de membrana epitelial; CK - citoqueratina; * uso do forno de micro-ondas; ** uso de panela de pressão 


\subsubsection{ANÁLISE DO MATERIAL}

Os cortes histológicos foram digitalizados no sistema Aperio "ScanScope AT Scanner" para obtenção de lâminas histológicas virtuais. A leitura do material foi realizada com o "software" "ImageScope Viewing", em microcomputador com tela plana de 19 polegadas, com resolução de $1280 \mathrm{x}$ 980 pixels.

Fez-se inicialmente a leitura, para cada um dos marcadores, dos cortes histológicos obtidos do primeiro bloco de TMA composto por 85 TE e 62 CBC. Para a leitura, foram considerados os espécimes com representação de 50,0\% ou mais da área de cada cilindro tecidual ("cores").

A análise foi qualitativa, considerando-se a positividade (expressão de pelo menos $25,0 \%$ da amostra representada) e os padrões de imunomarcação do componente epitelial neoplásico e do estroma tumoral. No componente epitelial, foi verificado se a marcação estava presente de modo difuso ou se as células mais periféricas (da paliçada) dos agrupamentos basalóides, ou basaliomatosos, mostravam-se imunomarcadas. Para o componente estromal das neoplasias, averigou-se se a imunomarcação era observada no componente peritumoral ou difusamente em todo o estroma. 


\subsubsection{ANÁLISE ESTATíSTICA DOS RESULTADOS OBTIDOS DO PRIMEIRO BLOCO DE TMA ANALISADO}

Os resultados obtidos da análise dos casos de TE e CBC, para cada um dos marcadores, foram comparados pelo teste exato de Fisher, considerando-se o nível de significância de 95,0\% ( $p \leq 0,05)$, com o programa "Epi-Info 6.0" (CDC, Atlanta, USA) . A partir desta análise, foram escolhidos para a avaliação de toda a casuística somente os marcadores que apresentaram expressão com diferenças estatisticamente significativas entre os dois grupos de tumores.

\subsubsection{ANÁliSE ESTATíStiCA DOS RESULTADOS DE TODA A CASUÍSTICA CONSIDERANDO-SE OS IMUNOMARCADORES SELECIONADOS}

Os resultados obtidos da leitura de toda a casuística foram submetidos à análise estatística pelos testes de regressão linear multifatorial e regressão logística multifatorial, respectivamente pelos programas "Statistica 7.1 package" (StatSoft Inc, Tulsa, USA) e "Stata SE 10.0". (Stata Corp LP, College Station, USA).

Para a inserção dos dados nos programas estatísticos, os resultados foram transformados em valores de "zero" e "um". 
Ambas as abordagens (logística e linear) foram realizadas para comparação direta dos resultados e, indiretamente, para validação do tamanho da amostra. A partir da seleção de variáveis significativas no modelo múltiplo, foram criados índices de discriminação progressivos pela associação de valores de variáveis significativas, em forma de inclusão e análise do resultado do desfecho ("forward inclusion"). 
4 RESULTADOS 
Os TE foram obtidos de 53 doentes do gênero masculino e 109 do gênero feminino. Dez doentes apresentavam lesões múltiplas. A idade dos pacientes variou de sete a 74 anos (média de 55,8 anos).

As localizações mais frequentes dos TE foram: nasal $(57,3 \%)$, lábio $(12,3 \%)$, pálpebra $(9,55 \%)$, face $(6,1 \%)$ e região malar $(4,4 \%)$.

Os CBC foram obtidos de 176 doentes do gênero masculino e 152 do feminino. A idade dos pacientes com diagnóstico de CBC variou de 27 a 90 anos (média de 66,3 anos).

As localizações mais frequentes dos CBC foram: nasal $(25,47 \%)$, região malar $(9,45 \%)$, fronte $(8,23 \%)$, membro superior $(7,0 \%)$ e dorso $(6,7 \%)$.

Foram analisadas 490 amostras para exame, sendo 162 tricoepiteliomas clássicos e 328 CBC.

Todas as amostras revisadas apresentaram as características microscópicas propostas para a diagnose de TE e CBC respectivamente ${ }^{1,4}$. (Ver Figura 2 A-F).

Os subtipos de CBC examinados foram assim distribuídos: 145 nodulares, 57 micronodulares, 63 esclerodermiformes, 59 do tipo nodular e micronodular, um do tipo micronodular e esclerodermiforme e três do tipo nodular e esclerodermiforme. 


\subsection{EXAME IMUNOISTOQUÍMICO DO PRIMEIRO BLOCO DE TMA COM REPRESENTAÇÃO DE 85 TRICOEPITELIOMAS E 62 CARCINOMAS BASOCELULARES}

A leitura do primeiro bloco de TMA, para os marcadores testados demonstrou:

- CD34

Vinte e dois TE (28,2\%) e 37 CBC (61,7\%) não exibiram imunomarcação para CD34. Cinqüenta e seis TE $(71,8 \%)$ e 23 CBC $(38,3 \%)$ foram positivos para o CD34, independentemente do padrão. Quarenta e três TE $(55,1 \%)$ e 12 CBC $(20,0 \%)$ exibiram marcação do estroma ao redor dos blocos epiteliais tumorais. Oito TE (10,3\%) e 10 CBC (16,7\%) apresentaram expressão de CD34 em todo o estroma. Quatro TE $(5,1 \%)$ exibiram o CD34 somente nas células epiteliais tumorais, aspecto que não foi observado nos CBC. A expressão deste antígeno nas células epiteliais tumorais e no estroma foi observada em apenas um TE $(1,3 \%)$ e um CBC $(1,7 \%)$. (Ver Figuras $2 \mathrm{G}-\mathrm{J}$ e $3 \mathrm{~A}$ e B).

- BCL-2

Todos TE e todos CBC foram positivos para o BCL-2, independentemente do padrão. Sessenta e oito TE $(90,7 \%)$ e 55 CBC $(94,8 \%)$ expressaram o antígeno BCL-2 em todo componente epitelial de modo difuso. Sete TE $(9,3 \%)$ e três CBC $(5,2 \%)$ apresentaram 
imunomarcação somente de células tumorais da periferia dos blocos epiteliais neoplásicos. (Ver Figura 3 C - F).

- CD10

Três TE $(3,9 \%)$ e um CBC $(1,8 \%)$ foram negativos para este marcador. Setenta e quatro TE $(96,1 \%)$ e 54 CBC $(98,2 \%)$ foram imunomarcados pelo anticorpo CD10. Quarenta e quatro TE $(57,1 \%)$ e nove CBC $(16,4 \%)$ exibiram expressão estromal de CD10. Vinte e sete TE $(35,1 \%)$ e 28 CBC $(50,9 \%)$ apresentaram imunomarcação tanto do componente epitelial como do estromal. Três TE (3,9\%) e 17 CBC (30,9\%) exibiram este marcador em toda a extensão do epitélio tumoral. (Ver Figuras $3 \mathrm{G}-\mathrm{J}$ e $4 \mathrm{~A}$ e $\mathrm{B})$.

- Antígeno de membrana epitelial - EMA

Sete TE $(8,2 \%)$ e cinco CBC $(8,9 \%)$ não exibiram marcação com este anticorpo. Expressão de EMA independentemente do padrão foi observada em 78 TE (91,8\%) e 51 (91,1\%) CBC. Cinqüenta e cinco TE $(64,7 \%)$ e 13 CBC $(23,2 \%)$ apresentaram expressão de EMA pelos componentes celular e estromal. A expressão de EMA somente no componente epitelial das neoplasias foi observada em e 23 TE $(27,1 \%)$ e 38 CBC $(67,9 \%)$. (Ver Figura $4 \mathrm{C}-\mathrm{F})$. 


\section{- Citoqueratina 20}

Sessenta TE $(75,0 \%)$ e 49 CBC $(89,1 \%)$ não exibiram células com imunoexpressão de citoqueratina 20. Células isoladas, por entre o componente periférico dos blocos epiteliais das neoplasias, foram observadas em 20 TE $(25,0 \%)$ e seis CBC (10,9\%). (Ver Figuras 4 G e H).

\section{- Citoqueratina 15}

Quatro TE $(5,6 \%)$ e oito CBC $(17,8 \%)$ não apresentaram qualquer imunomarcação com o anticorpo para a citoqueratina 15. Sessenta e sete TE $(94,4 \%)$ e 37 CBC (82,2\%) apresentaram expressão de CK15. Trinta TE $(42,3 \%)$ e 25 CBC (55,5\%) exibiram positividade difusa para CK15. Trinta e sete TE $(52,1 \%)$ e 12 CBC $(26,7 \%)$ apresentaram imunomarcação somente de células tumorais da periferia dos blocos celulares neoplásicos. (Ver Figuras $4 \mathrm{I}$ e $\mathrm{J}$ e $5 \mathrm{~A}$ e $\mathrm{B})$.

\section{- D2-40 (podoplanina)}

Nove TE $(14,3 \%)$ e 42 CBC $(95,4 \%)$ foram negativos para este antígeno. Cinqüenta e quatro TE (85,7\%) apresentaram imunoexpressão para D2-40. Cinqüenta e dois TE (82,5\%) exibiram o antígeno nas células epiteliais da periferia dos blocos basalóides e dois difusamente $(3,2 \%)$. Somente dois CBC $(4,6 \%)$ foram positivos para o D2-40, um difusamente $(2,3 \%)$ e outro com imunomarcação das células epiteliais periféricas $(2,3 \%)$. (Ver Figuras 5 C-F). 
- $\quad 34 \beta E 12$.

Todas as amostras dos dois tumores apresentaram imunomarcação difusa do componente epitelial por este anticorpo. (Ver Figuras $5 \mathrm{G}-\mathrm{H}$ ). 


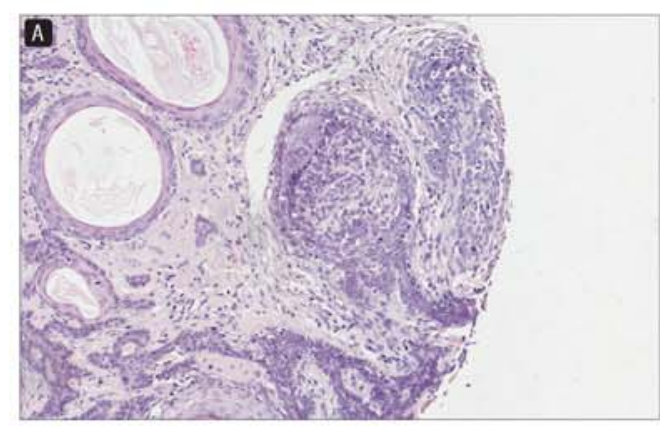

TRICOEPITELIOMA

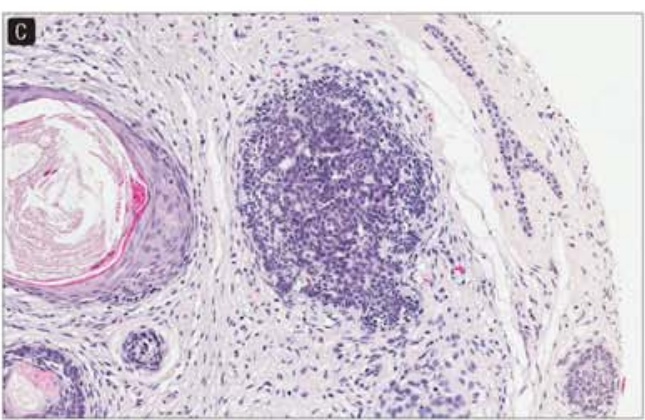

TRICOEPITEUIOMA

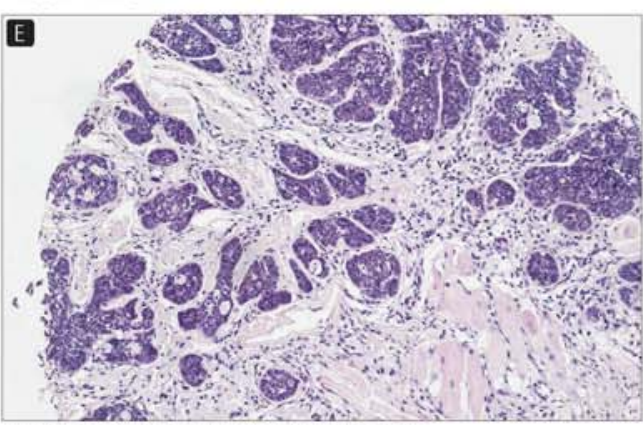

CARCINOMA BASOCELULAR MICRONODULAR

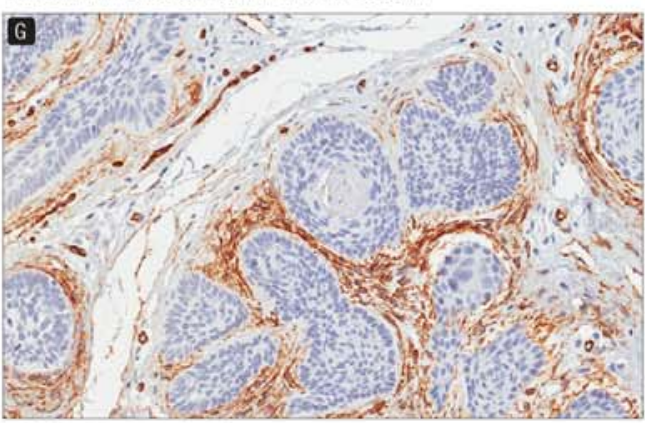

TRICOEPITELIOMA.CD34

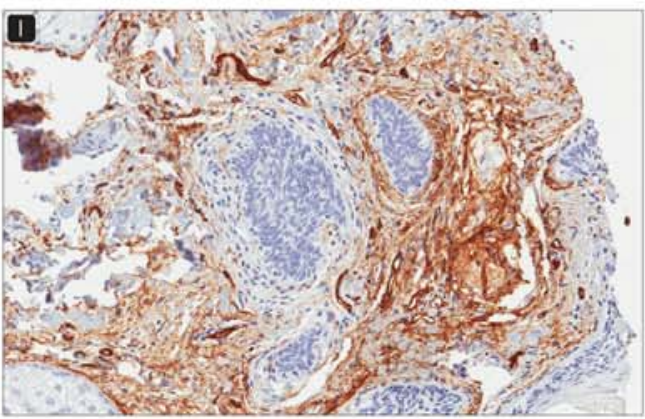

TRICOEPITELIOMA.CD34

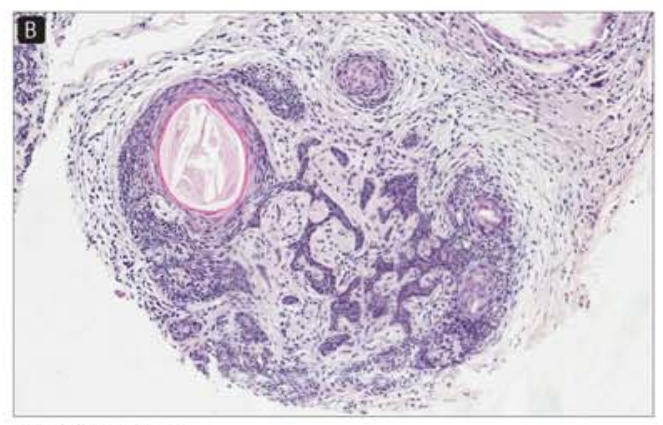

TRICOEPITELIOMA

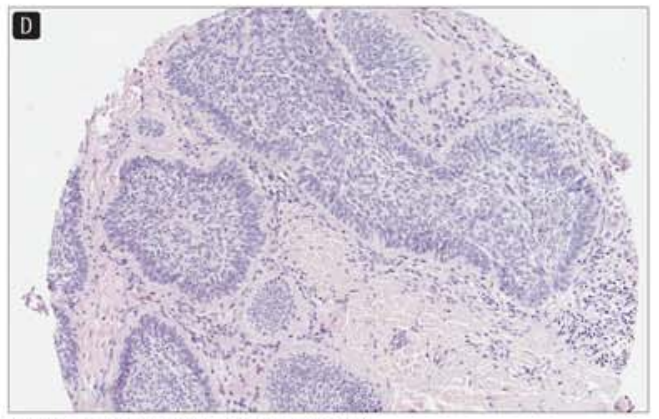

CARCINOMA BASOCELULAR NODULAR

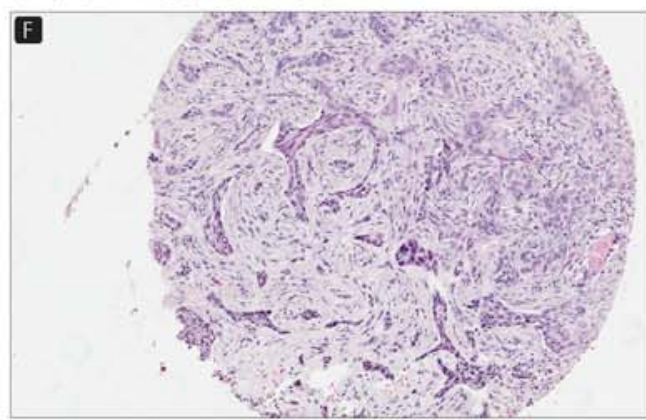

CARCINOMA BASOCELULAR ESCLERODERMIFORME

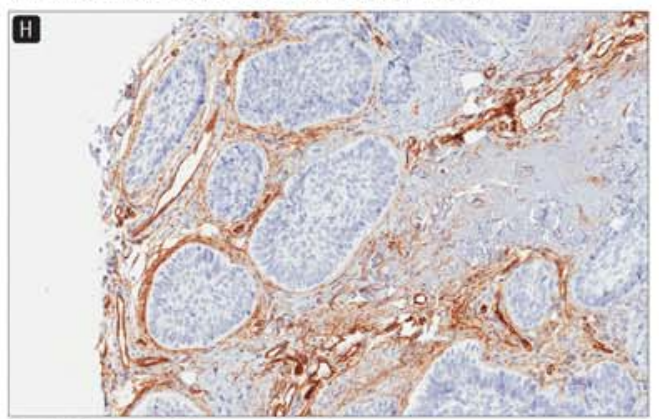

CARCINOMA BASOCELULARCD34

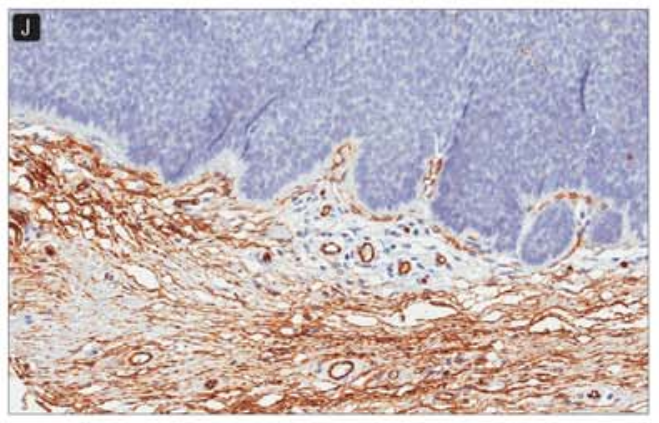

CARCINOMA BASOCELULAR.CD34 
Figura 2 - Tricoepitelioma e carcinoma basocelular: características histopatológicas e expressão do antígeno CD34. A) Tricoepitelioma: nódulos de células basalóides, corpos papilares mesenquimais, fendas entre o estroma tumoral e a derme reticular e cistos de queratina. B) Tricoepitelioma: lóbulos de células basalóides envolvidos por estroma fibrocelular denso. C) Tricoepitelioma: agrupamentos de células basalóides, cistos córneos e fendas estromais. D) Carcinoma basocelular nodular composto por nódulos de células basaliomatosas com paliçada periférica bem formada. E) Carcinoma basocelular micronodular: agrupamentos pequenos de células basaliomatosas. F) Carcinoma basocelular esclerodermiforme com fileiras de células basaliomatosas imersas em estroma denso e hialinizado. (A - F coloração de hematoxilina-eosina). G) Tricoepitelioma com imunomarcação para CD34 nos nódulos celulares e estroma ao redor dos agrupamentos de células basalóides. H) Carcinoma basocelular nodular com expressão de CD34 no estroma ao redor dos nódulos basaliomatosos. I) Tricoepitelioma com expressão estromal difusa de CD34. J) Carcinoma basocelular com expressão estromal difusa de CD34. (G-J - imunoistoquímica com o anticorpo CD34) 


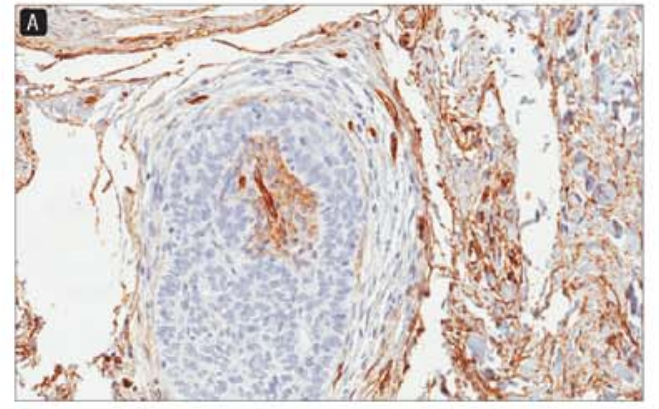

TRICOEPITELIOMA - CD34

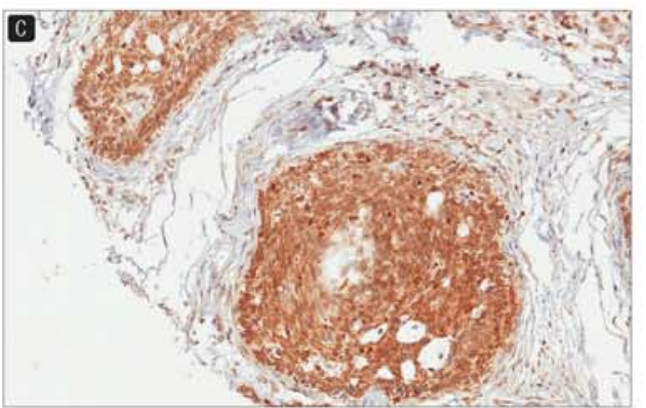

TRICOEPITELIOMA - BCL-2

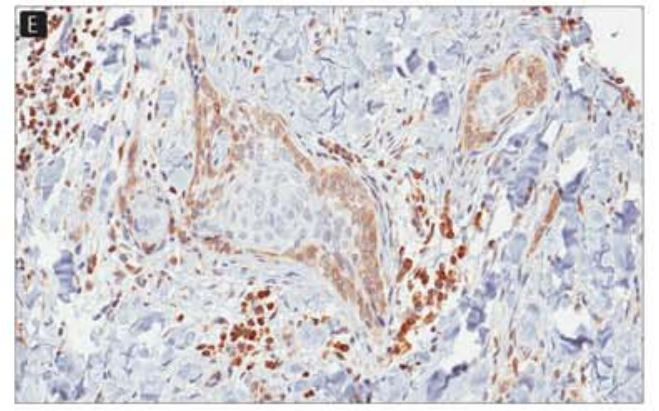

TRICOEPITELIOMA - BCL-2

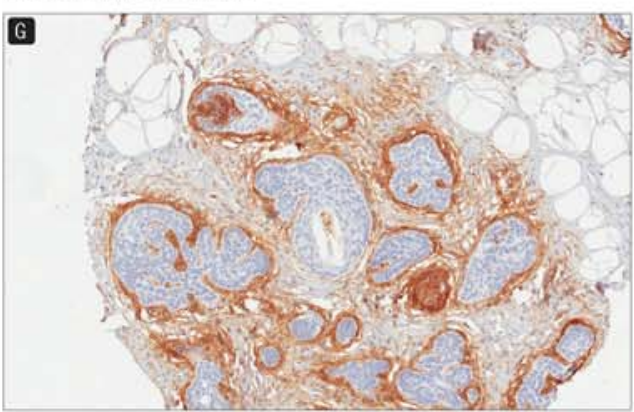

TRICOEPITELIOMA - CD10

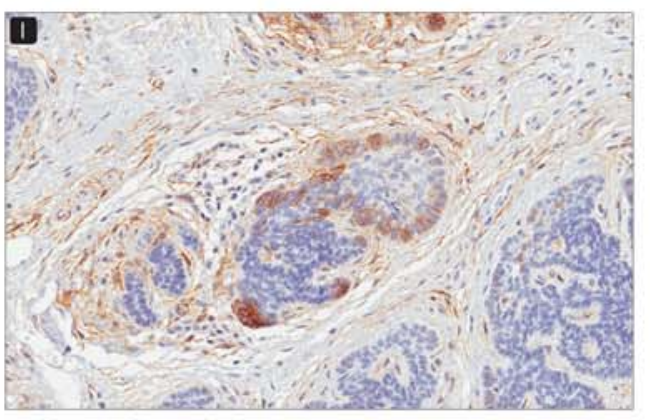

TRICOEPITELIOMA - CD10

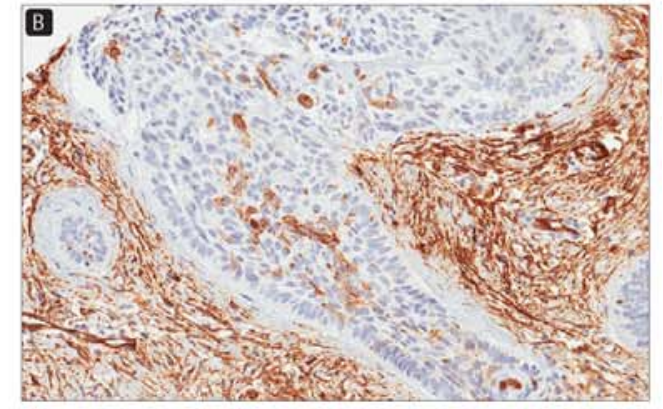

CARCINOMA BASOCELULAR - CD34

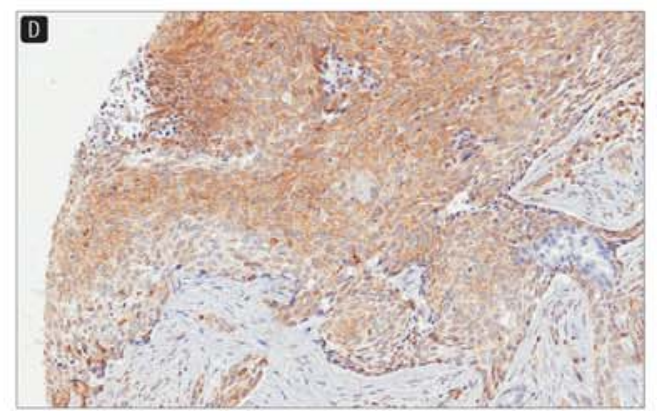

CARCINOMA BASOCELULAR - BCL-2

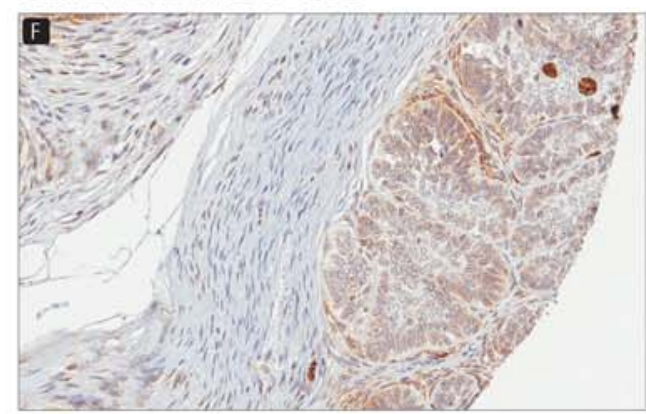

CARCINOMA BASOCELULAR - BCL-2

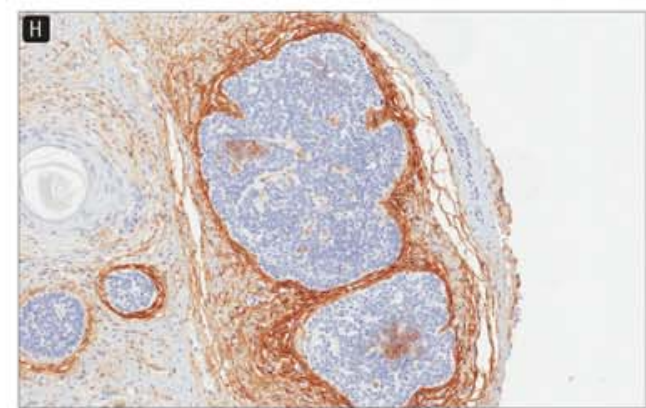

CARCINOMA BASOCELULAR - CD10

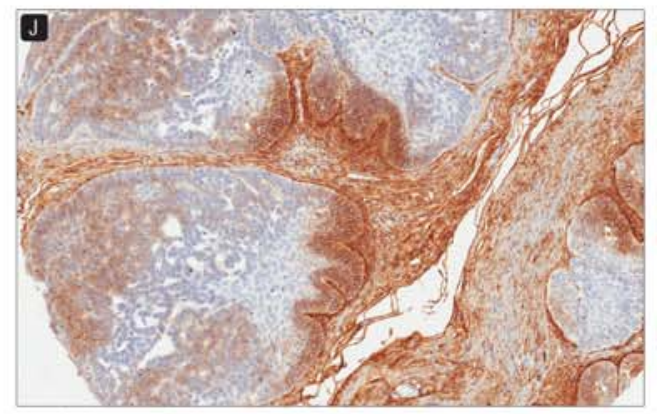

CARCINOMA BASOCELULAR - CD10 
Figura 3 - Tricoepitelioma e carcinoma basocelular: expressão dos antígenos CD34, BCL-2 e CD10. A) Tricoepitelioma com expressão de CD34 nos componentes de células basalóides e estromais. B) Carcinoma basocelular com expressão de CD34 nos componentes de células basalóides e estromais. C) Tricoepitelioma com expressão de BCL-2 difusa nas células basalóides. D) Carcinoma basocelular com expressão de BCL-2 difusa nas células basaliomatosas. E) Tricoepitelioma com imunomarcação para BCL-2 nas células da periferia dos blocos basalóides. F) Carcinoma basocelular com imunomarcação para BCL-2 nas células da periferia dos blocos basalóides. G) Tricoepitelioma apresentando expressão de CD10 no estroma ao redor dos blocos de células basalóides. H) Carcinoma basocelular com o mesmo padrão de expressão de CD10. I) Tricoepitelioma exibindo imunomarcação de CD10 nas células basalóides e no estroma. J) Carcinoma basocelular com expressão de CD10 no epitélio tumoral e no estroma. (A e B - técnica de imunoistoquímica com o anticorpo CD34; C - F técnica de imunoistoquímica com o anticorpo BCL-2. G - J -técnica de imunoistoquímica com o anticorpo CD10) 


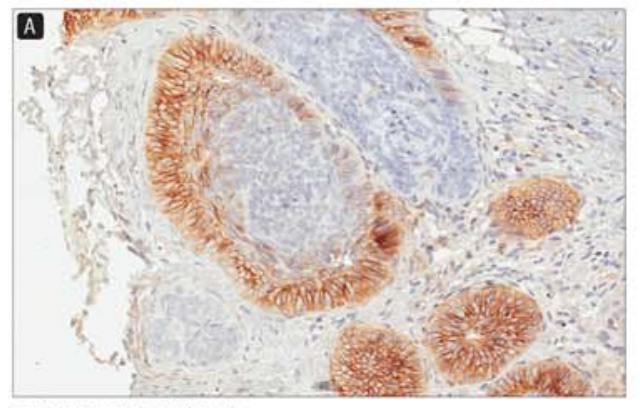

TRICOEPITELIOMA.CD 10

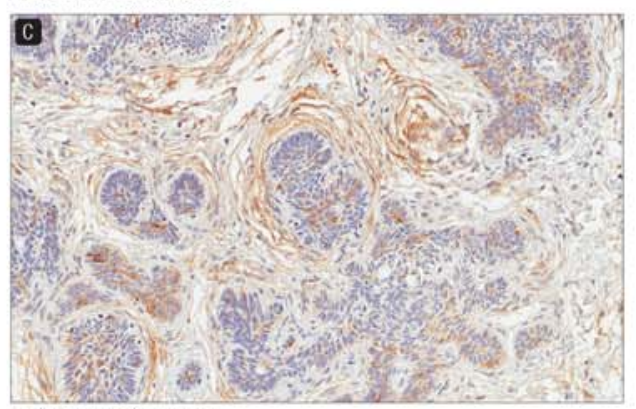

TRICOEPITELIOMA.EMA

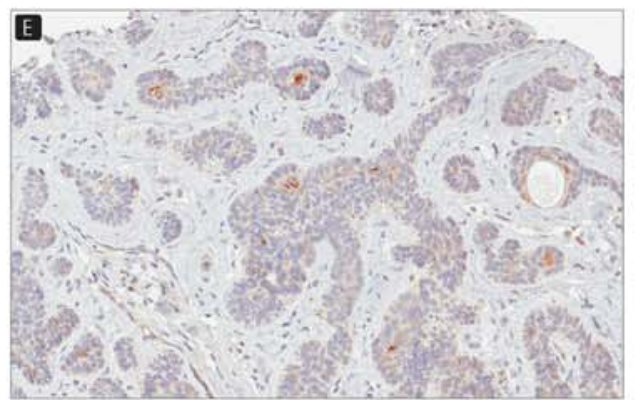

TRICOEPITELIOMA.EMA

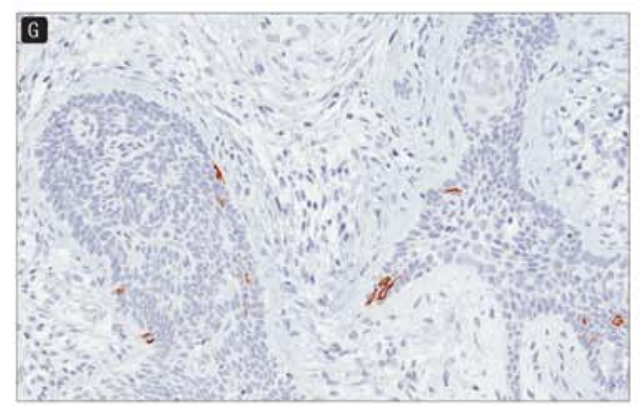

TRICOEPITELIOMA.CK 20

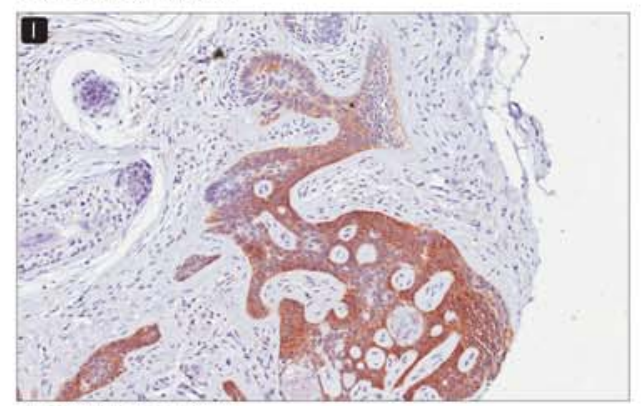

TRICOEPITELIOMA CK 15
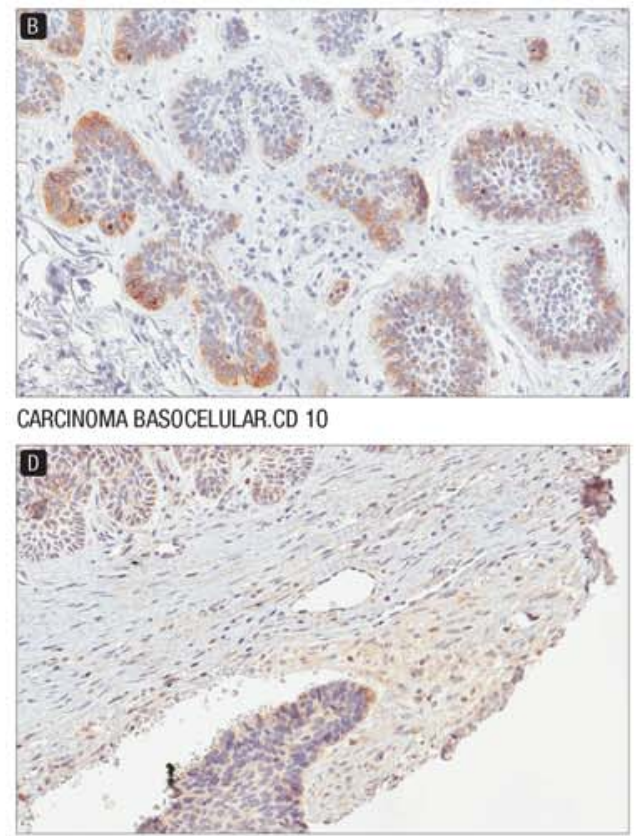

CARCINOMA BASOCELULAR.EMA

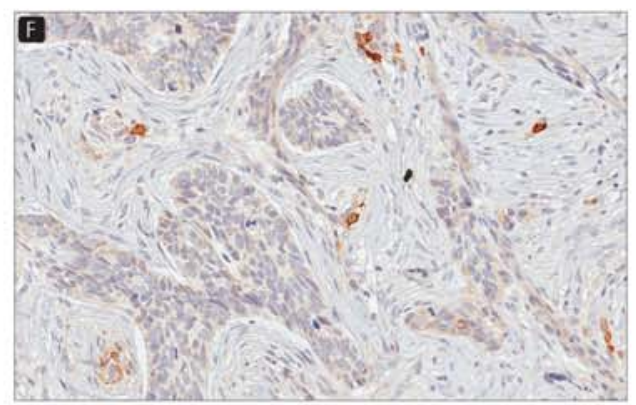

CARCINOMA BASOCELULAR.EMA

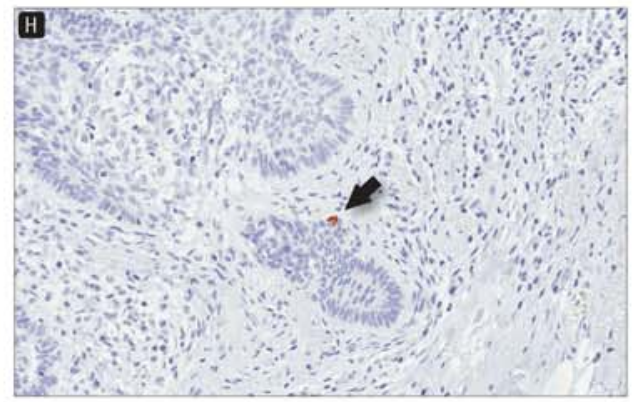

\section{CARCINOMA BASOCELULAR CK 20}

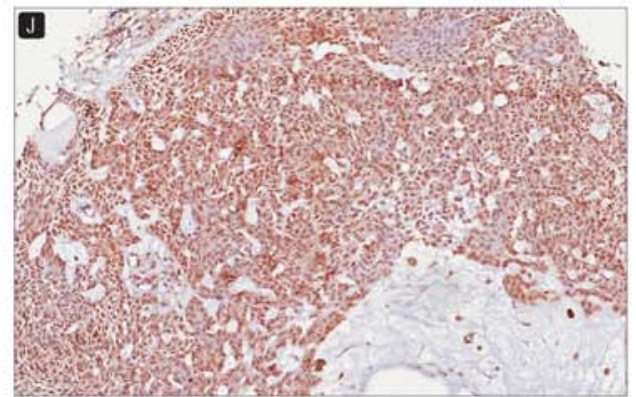

CARCINOMA BASOCELULAR CK 15 
Figura 4 - Tricoepitelioma e carcinoma basocelular: expressão de CD10, antígeno de membrana epitelial (EMA) e citoqueratinas 20 e 15. A) Tricoepitelioma com padrão de imunoexpressão de CD10 difusa e na periferia dos blocos de células basalóides. B) Carcinoma basocelular com expressão de CD10 pelas células da periferia dos blocos celulares basaliomatosos. C) Tricoepitelioma com imunomarcação para EMA dos componentes epitelial e estromal ao redor dos blocos celulares basalóides. D) Carcinoma basocelular apresentando imunomarcação para EMA tanto do componente basaliomatoso como estromal. E) Tricopitelioma com expressão focal de EMA. F) Carcinoma basocelular com expressão focal de EMA. G) Tricoepitelioma apresentando células com expressão de citoqueratina 20 por entre as células das camadas periféricas dos blocos basalóides. H) O mesmo aspecto é observado no carcinoma basocelular (seta). I) Tricoepitelioma com expressão difusa para citoqueratina 15. J) Carcinoma basocelular com imunomarcação difusa de células basaliomatosas. ( $A-B$ - técnica imunoistoquímica com o anticorpo $C D 10$; $\mathrm{C}$ - F- técnica imunoistoquímica com o anticorpo EMA; G e H - técnica imunoistoquímica com anticorpo citoqueratina 20; I - J - técnica imunoistoquímica com o anticorpo citoqueratina 15) 


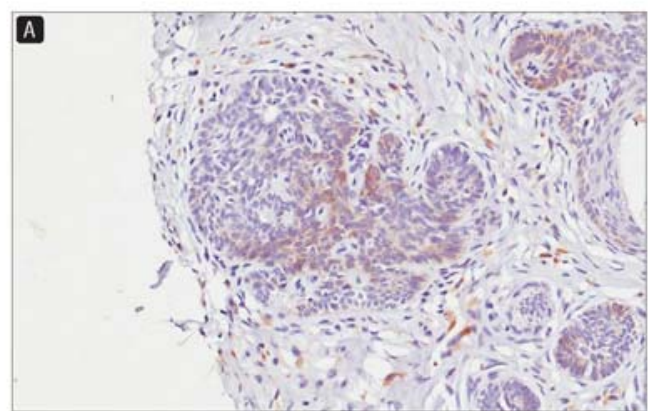

TRICOEPITELIOMA CK 15

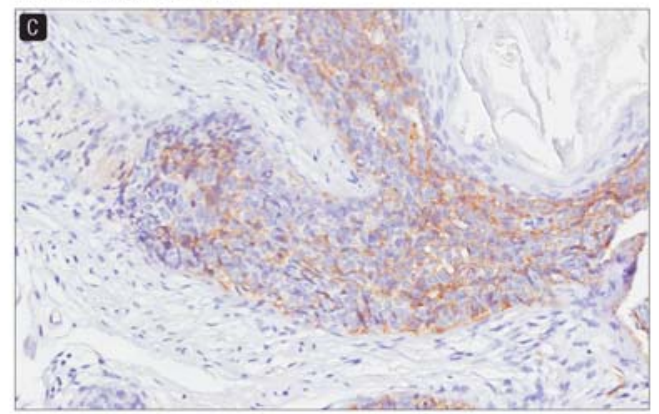

TRICOEPITELIOMA D2 40

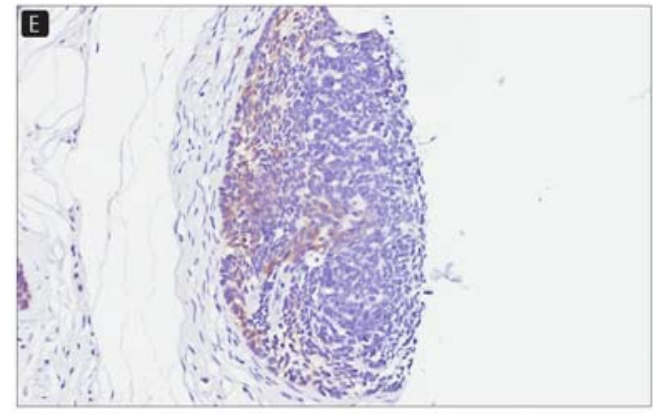

\section{TRICOEPITELIOMA D2 40}

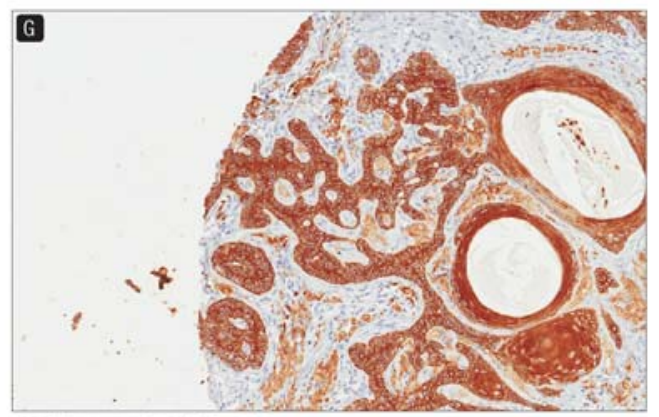

TRICOEPITELIOMA 34B E12

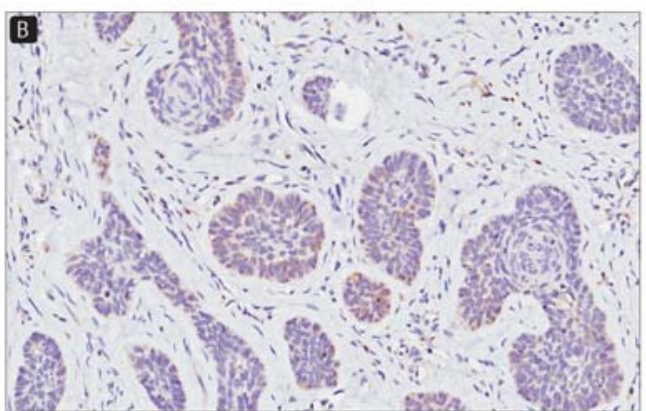

CARCINOMA BASOCELULAR CK 15

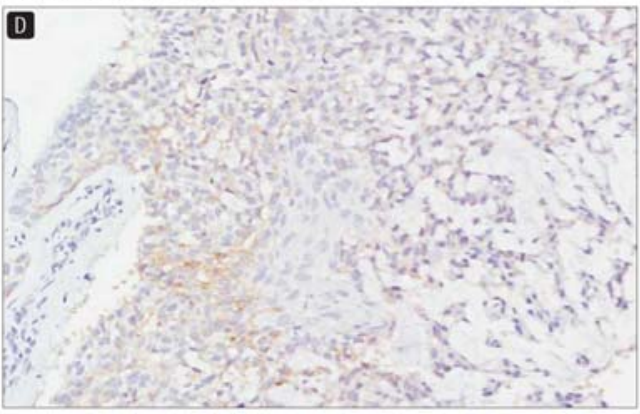

CARCINOMA BASOCELULAR D2 40

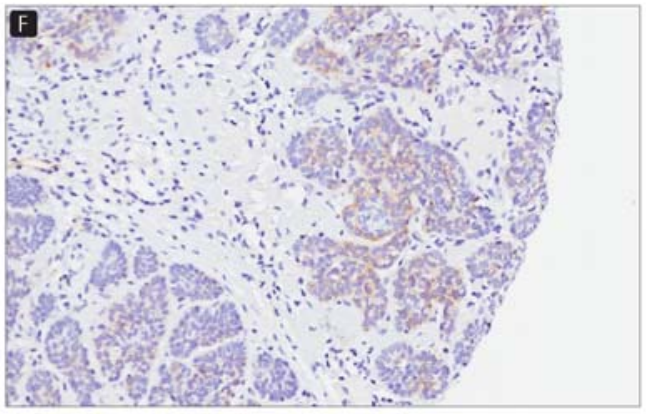

CARCINOMA BASOCELULAR D2 40

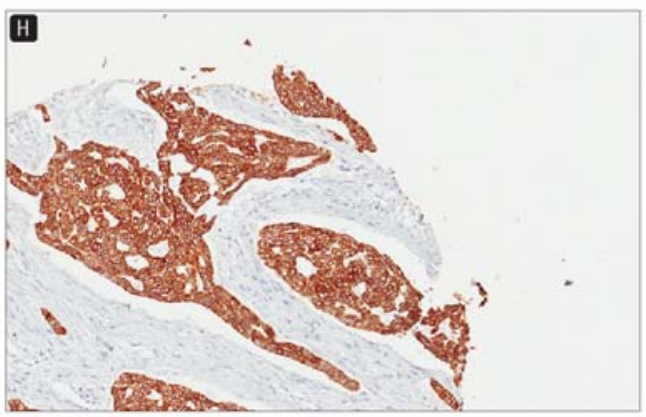

CARCINOMA BASOCELULAR 34B E12 
Figura 5 - Tricoepitelioma e carcinoma basocelular: expressão de citoqueratina 15, D2-40 e $34 \beta$ E12. A) Tricoepitelioma apresentando imunomarcação para citoqueratina 15 das células das camadas periféricas dos blocos basalóides. B) Carcinoma basocelular com o mesmo padrão de imunomarcação. C) Tricoepitelioma com expressão difusa de D2-40 pelas células basalóides. D) Carcinoma basocelular com imunomarcação difusa de D2-40 das células basaliomatosas. E) Tricoepitelioma com imunoexpressão de D2-40 pelas células da periferia dos agrupamentos basalóides. F) Carcinoma basocelular com o mesmo padrão de imunomarcação de D2-40. G) Tricoepitelioma com expressão difusa de citoqueratina $34 \beta$ E12. H) Carcinoma basocelular com imunoexpressão difusa de citoqueratina $34 \beta$ E12. (A e B - imunoistoquímica com o anticorpo citoqueratina 15; C - F - imunoistoquímica com o anticorpo D2-40; G e H imunoistoquímica com o anticorpo $34 \beta$ E12) 


\subsection{ANÁLISE ESTATÍSTICA DOS RESULTADOS OBTIDOS DO PRIMEIRO BLOCO DE TMA ANALISADO}

Fez-se a comparação dos resultados obtidos da análise dos espécimes dos dois grupos de tumores pelo teste exato de Fisher. Os resultados estão apresentados na Tabela 3. 
Tabela 3 - Padrões de expressão dos antígenos CD34, CD10, BCL-2, antígeno de membrana epitelial (EMA), citoqueratina 20, citoqueratina 15, D2-40 e $34 \beta$ E12 em tricoepiteliomas e carcinomas basocelulares agrupados no primeiro bloco analisado de "tissue microarray"

\begin{tabular}{|c|c|c|c|}
\hline Marcador/Padrão de expressão & TE & CBC & valor de $p$ \\
\hline CD34 & $(n=78)$ & $(n=60)$ & \\
\hline Negativo & $22(28,2 \%)$ & $37(61,7 \%)$ & $p<0,0001$ \\
\hline Positivo & $56(71,8 \%)$ & $23(38,3 \%)$ & $p<0,0001$ \\
\hline Estroma e células epiteliais tumorais & $4(5,1 \%)$ & 0 & NS \\
\hline Estroma peritumoral & $43(55,1 \%)$ & $12(20,0 \%)$ & $p<0,0001$ \\
\hline Estroma & $8(10,3 \%)$ & $10(16,7 \%)$ & NS \\
\hline Células epiteliais tumorais & $1(1,3 \%)$ & $1(1,7 \%)$ & NS \\
\hline BCL-2 & $(n=75)$ & $(n=58)$ & \\
\hline Negativo & 0 & 0 & NS \\
\hline Positivo & $75,0(100,0 \%)$ & $58(100,0 \%)$ & NS \\
\hline Difusamente nas células epiteliais tumorais & $68(90,7 \%)$ & $55(94,8 \%)$ & NS \\
\hline Células epiteliais tumorais periféricas & $7(9,3 \%)$ & $3(5,2 \%)$ & NS \\
\hline CD10 & $(n=77)$ & $(n=55)$ & \\
\hline Negativo & $3(3,9 \%)$ & $1(1,8 \%)$ & NS \\
\hline Positivo & $74(96,1 \%)$ & $54(98,2 \%)$ & NS \\
\hline Estroma e células epiteliais tumorais & $27(35,1 \%)$ & $28(50,9 \%)$ & NS \\
\hline Estroma & $44(57,1 \%)$ & $9(16,4 \%)$ & $\mathrm{p}<0,0001$ \\
\hline Células epiteliais tumorais & $3(3,9 \%)$ & $17(30,9 \%)$ & $\mathrm{p}<0,0001$ \\
\hline EMA & $(n=85)$ & $(n=56)$ & \\
\hline Negativo & $7(8,2 \%)$ & $5(8,9 \%)$ & NS \\
\hline Positivo & $78(91,8 \%)$ & $51(91,1 \%)$ & NS \\
\hline Estroma e células epiteliais tumorais & $55(64,7 \%)$ & $13(23,2 \%)$ & $p<0,0001$ \\
\hline Células epiteliais tumorais & $23(27,1 \%)$ & $38(67,9 \%)$ & $p<0,0001$ \\
\hline Citoqueratina 20 & $(n=80)$ & $(n=55)$ & \\
\hline Negativo & $60(75,0 \%)$ & $49(89,1 \%)$ & $p=0,047$ \\
\hline Células tumorais periféricas & $20(25,0 \%)$ & $6(10,9 \%)$ & $p=0,047$ \\
\hline Citoqueratina 15 & $(n=71)$ & $(n=45)$ & \\
\hline Negativo & $4(5,6 \%)$ & $8(17,8 \%)$ & NS \\
\hline Positivo & $67(94,4 \%)$ & $37(82,2 \%)$ & NS \\
\hline Difusamente nas células epiteliais tumorais & $30(42,3 \%)$ & $25(55,5 \%)$ & NS \\
\hline Células epiteliais tumorais periféricas & $37(52,1 \%)$ & $12(26,7 \%)$ & $P=0,0075$ \\
\hline D2-40 & $(n=63)$ & $(n=44)$ & \\
\hline Negativo & $9(14,3 \%)$ & $42(95,4 \%)$ & $\mathrm{p}<0,0001$ \\
\hline Positivo & $54(85,7 \%)$ & $2(4,6 \%)$ & $\mathrm{p}<0,0001$ \\
\hline Células epiteliais tumorais periféricas & $52(82,5 \%)$ & $1(2,3 \%)$ & $p<0,0001$ \\
\hline Difusamente nas células epiteliais tumorais & $2(3,2 \%)$ & $1(2,3 \%)$ & NS \\
\hline $34 \beta E 12$ & $\mathrm{n}=80$ & $n=59$ & \\
\hline Imunorreativos & $80(100,0 \%)$ & $59(100,0 \%)$ & \\
\hline Positivo em todo o epitélio tumoral & $80(100,0 \%)$ & $59(100,0 \%)$ & \\
\hline
\end{tabular}

TE - tricoepitelioma; CBC - carcinoma basocelular; EMA - antígeno de membrana epitelial; ${ }^{*}$ Comparação pelo teste exato de Fisher; NS - não significante 


\subsection{EXAME IMUNOISTOQUÍMICO DE TODA A AMOSTRA}

A análise da amostragem do primeiro bloco de TMA, representando 85 TE e 62 CBC, identificou os marcadores CD34, CD10, EMA, CK15, CK20 e D2-40 como potencialmente diferenciadores de TE e CBC (ver Tabela 3):

A partir desses dados inicialmente obtidos, fez-se a análise de toda a amostragem.

\section{- $\mathrm{CD} 34$}

Cento e quarenta e quatro TE e 302 CBC foram submetidos à pesquisa do antígeno CD34. Trinta e cinco TE $(24,3 \%)$ e 165 CBC (54,6\%) foram negativos para este marcador. Cento e nove TE $(75,7 \%)$ e 137 CBC $(45,4 \%)$ apresentaram-se imunomarcados para CD34. O padrão de imunomarcação mais frequente tanto no TE como no $\mathrm{CBC}$ foi o padrão estromal peritumoral, com 82 casos de TE $(57,0 \%)$ e 90 de CBC $(29,8 \%)$. O segundo padrão mais frequente foi o de imunomarcação de todo o estroma representado, observado em 13 TE $(9,0 \%)$ e 39 CBC $(13,0 \%)$. O terceiro padrão foi a imunoexpressão somente nas células tumorais, presente em quatro $\operatorname{TE}(2,8 \%)$ e quatro $\mathrm{CBC}(1,3 \%)$.

- CD10

Trezentos e dez CBC e 144 TE foram submetidos a este imunomarcador. Somente sete TE $(4,9 \%)$ e três CBC $(0,9 \%)$ foram 
totalmente negativos. Cento e trinta e sete TE $(95,1 \%)$ e 307 CBC $(99,1 \%)$ foram positivos para o CD10, independentemente do padrão apresentado. Trinta e oito TE $(26,4 \%)$ e 159 CBC $(51,3 \%)$ exibiram imunoexpressão pelas células tumorais e estroma peritumoral. Oitenta e sete TE $(60,4 \%)$ e 70 CBC $(22,6 \%)$ foram positivos somente no estroma. Doze TE $(8,3 \%)$ e 78 CBC $(25,2 \%)$ apresentaram imunomarcação somente nas células tumorais.

\section{- Antígeno de membrana epitelial (EMA)}

Cento e cinqüenta e cinco TE e 307 CBC foram submetidos à imunomarcação com EMA. Seis TE (3,9\%) e 15 CBC (4,9\%) não exibiram imunoexpressão deste antígeno. Cento e quarenta e nove TE $(96,1 \%)$ e 292 $(95,1 \%)$ apresentaram imunomarcação para EMA. Cento e quinze TE $(74,2 \%)$ e 170 CBC $(55,4 \%)$ exibiram imunoexpressão nas células tumorais e no estroma. Trinta e quatro TE $(21,9 \%)$ e 122 CBC $(39,7 \%)$ foram imunorreagentes somente nas células tumorais.

\section{- Citoqueratina 20}

Cento e cinqüenta e um TE e 311 CBC foram submetidos à técnica imunoistoquímica com o anticorpo para CK20. Cento e vinte e dois TE $(80,8 \%)$ e 297 CBC $(95,5 \%)$ foram negativos para o marcador CK20. Vinte e nove TE $(19,2 \%)$ e 14 CBC (4,5\%) exibiram imunomarcação de células da periferia dos agrupamentos tumorais. 


\section{- Citoqueratina 15}

Cento e quarenta TE e 304 CBC foram analisados para a CK15. Nove TE $(6,4 \%)$ e 108 CBC $(35,5 \%)$ não expressaram esta citoqueratina. Cento e trinta e um TE (94,0\%) 96 CBC (64,5\%) mostraram-se imunomarcados para CK15. Cinqüenta e seis TE (40,0\%) e 156 CBC $(51,3 \%)$ apresentaram imunomarcação difusa de todas as células tumorais. Setenta e cinco TE $(53,7 \%)$ e 40 CBC $(13,2 \%)$ apresentaram como padrão de imunoexpressão o de células tumorais periféricas.

\section{- $\mathrm{D} 2-40$ (podoplanina)}

Cento e quarenta e três TE e 307 CBC foram examinados com esse imunomarcador. Noventa e um TE (63,6\%) e 18 CBC (5,9\%) apresentaram imunoexpressão de podoplanina. Destes 86 TE $(60,1 \%)$ e 13 CBC (4,2\%) exibiram positividade com o padrão em células tumorais periféricas. Cinco TE $(3,5 \%)$ e cinco CBC (1,7\%) apresentaram expressão difusamente no componente celular neoplásico.

O Anexo 1 demonstra as leituras de todos os casos de TE e CBC para todos os marcadores utilizados. 
4.4 ANÁlise EStATística DOS RESULtAdos DE TODA A CASUÍSTICA CONSIDERANDO-SE OS IMUNOMARCADORES SELECIONADOS

A Tabela 4 demonstra a análise comparativa dos resultados da expressão dos diferentes marcadores de todos os casos de TE e CBC estudados. 
Tabela 4 - Comparação dos padrões de expressão dos casos de tricoepitelioma e de carcinoma basocelular, para os antígenos CD34, CD10, antígeno de membrana epitelial (EMA), citoqueratina 20, citoqueratina 15 e D2-40 em toda a amostra obtida em "tissue microarray"

\begin{tabular}{|c|c|c|c|c|c|}
\hline \multirow[b]{2}{*}{$\begin{array}{l}\text { Antígenol padrão de } \\
\text { expressão }\end{array}$} & \multirow[b]{2}{*}{ TE } & \multirow[b]{2}{*}{ CBC } & \multicolumn{3}{|c|}{ Teste exato de Fisher } \\
\hline & & & $\begin{array}{c}\text { Valor de } \\
p<0,05\end{array}$ & $\begin{array}{l}\text { "Odds } \\
\text { ratio" }\end{array}$ & IC 95\% \\
\hline CD34 & $(n=144)$ & $(n=302)$ & & & \\
\hline \multirow{6}{*}{$\begin{array}{l}\text { Negativo } \\
\text { Positivo } \\
\text { Estroma e células } \\
\text { epiteliais tumorais } \\
\text { Estroma peritumoral } \\
\text { Estroma } \\
\text { Células tumorais }\end{array}$} & $35(24,3 \%)$ & $165(54,6 \%)$ & $p<0,0001$ & 0,26 & $0,1-0,4$ \\
\hline & $109(75,7 \%)$ & $137(45,4 \%)$ & $\mathrm{p}<0,0001$ & 3,7 & $2,4-5,8$ \\
\hline & $10(6,9 \%)$ & $4(1,3 \%)$ & $p=0,0027$ & 5,6 & $1,7-18,0$ \\
\hline & $82(57,0 \%)$ & $90(29,8 \%)$ & $p<0,0001$ & 3,1 & $2,0-4,7$ \\
\hline & $13(9,0 \%)$ & $39(13,0 \%)$ & NS & & \\
\hline & $4(2,8 \%)$ & $4(1,3 \%)$ & NS & & \\
\hline CD10 & $(n=144)$ & $(n=310)$ & & & \\
\hline \multirow{5}{*}{$\begin{array}{l}\text { Negativo } \\
\text { Positivo } \\
\text { Estroma e células } \\
\text { epiteliais tumorais } \\
\text { Estroma } \\
\text { Células epiteliais tumorais }\end{array}$} & $7(4,9 \%)$ & $3(0,9 \%)$ & $p=0,01$ & 5,2 & $1,3-2,0$ \\
\hline & $137(95,1 \%)$ & $307(99,1 \%)$ & $p=0,01$ & 0,2 & $0,05-0,7$ \\
\hline & $38(26,4 \%)$ & $159(51,3 \%)$ & $p<0,0001$ & 0,3 & $0,2-0,5$ \\
\hline & $87(60,4 \%)$ & $70(22,6 \%)$ & $p<0,0001$ & 5,2 & $3,4-8,0$ \\
\hline & $12(8,3 \%)$ & $78(25,2 \%)$ & $\mathrm{p}<0,0001$ & 0,3 & $0,1-0,5$ \\
\hline EMA & $(n=155)$ & $(n=307)$ & & & \\
\hline \multirow{4}{*}{$\begin{array}{l}\text { Negativo } \\
\text { Positivo } \\
\text { Estroma e células } \\
\text { epiteliais tumorais } \\
\text { Células epiteliais tumorais }\end{array}$} & $6(3,9 \%)$ & $15(4,9 \%)$ & NS & & \\
\hline & $149(96,1 \%)$ & $292(95,1 \%)$ & NS & & \\
\hline & $115(74,2 \%)$ & $170(55,4 \%)$ & $\mathrm{p}<0,0001$ & 2,3 & $1,5-3,5$ \\
\hline & $34(21,9 \%)$ & $122(39,7 \%)$ & $p<0,0001$ & 0,4 & $0,3-0,7$ \\
\hline Citoqueratina 20 & $(n=151)$ & $(n=311)$ & & & \\
\hline \multirow{2}{*}{$\begin{array}{l}\text { Negativo } \\
\text { Positivo em células } \\
\text { epiteliais tumorais } \\
\text { periféricas }\end{array}$} & $122(80,8 \%)$ & $297(95,5 \%)$ & $\mathrm{p}<0,0001$ & 0,2 & $0,1-0,3$ \\
\hline & $29(19,2 \%)$ & $14(4,5 \%)$ & $p<0,0001$ & 5,0 & $2,6-9,9$ \\
\hline \multirow{5}{*}{$\begin{array}{l}\text { Citoqueratina } 15 \\
\text { Negativo } \\
\text { Positivo } \\
\text { Difusamente nas células } \\
\text { epiteliais tumorais } \\
\text { Positivo em células } \\
\text { epiteliais tumorais } \\
\text { periféricas }\end{array}$} & $(n=140)$ & $(n=304)$ & & & \\
\hline & $9(6,4 \%)$ & $108(35,5 \%)$ & $p<0,0001$ & 0,1 & $0,1-0,2$ \\
\hline & $131(94,0 \%)$ & $196(64,5 \%)$ & $\mathrm{p}<0,0001$ & 8,0 & $3,9-16,4$ \\
\hline & $56(40,0 \%)$ & $156(51,3 \%)$ & $p=0,03$ & 0,6 & $0,4-0,9$ \\
\hline & $75(53,7 \%)$ & $40(13,2 \%)$ & $p<0,0001$ & 7,6 & $4,8-12,1$ \\
\hline D2-40 & $(n=143)$ & $(n=307)$ & & & \\
\hline Negativo & $52(36,4 \%)$ & $289(94,0 \%)$ & $\mathrm{p}<0,0001$ & 0,02 & $0,008-0,04$ \\
\hline Positivo & $91(63,6 \%)$ & $18(5,9 \%)$ & $\mathrm{p}<0,0001$ & 28,1 & $15,6-50,5$ \\
\hline $\begin{array}{l}\text { Positivo em células } \\
\text { epiteliais tumorais } \\
\text { periféricas }\end{array}$ & $86(60,1 \%)$ & $13(4,2 \%)$ & $\mathrm{p}<0,0001$ & 34,1 & $17,8-65,3$ \\
\hline $\begin{array}{l}\text { Difusamente nas células } \\
\text { epiteliais tumorais }\end{array}$ & $5(3,5 \%)$ & $5(1,7 \%)$ & NS & & \\
\hline
\end{tabular}

NS - não significante. IC 95\%: Intervalo de confiança de 95,0\%. 
Para possibilitar a exploração estatística dos resultados, estes foram transformados em valores de "zero" e "um", recebendo as seguintes designações (ver Tabela 5):

Tricoq - tricoepitelioma.

$\mathrm{CBCq}$ - carcinoma basocelular.

CD34sq - CD34 positivo no estroma periférico.

CD34pq - CD34 positivo no estroma.

CD34 tq - CD34 positivo.

CD10sq - CD10 positivo no estroma.

CD10pq - CD10 positivo nas células epiteliais tumorais.

CD10tq - CD10 positivo no estroma e nas células epiteliais tumorais.

CK15sq - CK15 positivo nas células epiteliais tumorais periféricas.

CK15pq - CK15 positivo em todo tumor.

CK15tq - CK15 negativo.

CK20sq - CK20 positivo.

CK20pq - CK20 negativo.

D2-40sq - D2-40 positivo nas células epiteliais tumorais periféricas.

D2-40pq - D240 negativo.

D240 tq - D2-40 positivo difusamente em todo tumor.

Foram incluídos nos testes somente os casos em que todos os antígenos selecionados puderam ser avaliados, sendo 128 TE e 271 CBC (total de 399 casos). 
Tabela 5 - Tricoepitelioma e carcinoma basocelular: imunomarcação com painel de anticorpos. Exemplo da distribuição dos resultados obtidos e transformados para valores de "zero" e "um"

\begin{tabular}{|c|c|c|c|c|c|c|c|c|c|c|c|c|c|c|c|}
\hline Tricoq & $\mathrm{CBCq}$ & CD34sq & CD34pq & CD34tq & CD10sq & CD10pq & CD10tq & CK15sq & CK15pq & CK15tq & CK20sq & CK20pq & D2-40sq & D2-40pq & D2-40tq \\
\hline 1 & 0 & 0 & 0 & 1 & 0 & 1 & 0 & 0 & 0 & 1 & 0 & 1 & 0 & 1 & 0 \\
\hline 1 & 0 & 0 & 0 & 1 & 1 & 0 & 0 & 0 & 0 & 1 & 0 & 1 & 0 & 1 & 0 \\
\hline 1 & 0 & 0 & 0 & 1 & 1 & 0 & 0 & 0 & 0 & 1 & 0 & 1 & 1 & 0 & 0 \\
\hline 0 & 1 & 0 & 0 & 1 & 0 & 0 & 1 & 0 & 0 & 1 & 0 & 1 & 0 & 1 & 0 \\
\hline 1 & 0 & 0 & 0 & 1 & 1 & 0 & 0 & 0 & 0 & 1 & 0 & 1 & 0 & 1 & 0 \\
\hline 0 & 1 & 0 & 0 & 1 & 1 & 0 & 0 & 0 & 0 & 1 & 0 & 1 & 0 & 1 & 0 \\
\hline 0 & 1 & 0 & 0 & 1 & 0 & 1 & 0 & 0 & 0 & 1 & 0 & 1 & 0 & 1 & 0 \\
\hline 0 & 1 & 0 & 0 & 1 & 0 & 1 & 0 & 0 & 0 & 1 & 0 & 1 & 1 & 0 & 0 \\
\hline 0 & 1 & 0 & 0 & 1 & 0 & 1 & 0 & 0 & 0 & 1 & 0 & 1 & 0 & 1 & 0 \\
\hline 0 & 1 & 0 & 0 & 1 & 0 & 0 & 1 & 0 & 0 & 1 & 0 & 1 & 0 & 1 & 0 \\
\hline 0 & 1 & 0 & 0 & 1 & 0 & 1 & 0 & 0 & 0 & 1 & 0 & 1 & 0 & 1 & 0 \\
\hline 0 & 1 & 0 & 0 & 1 & 1 & 0 & 0 & 0 & 0 & 1 & 0 & 1 & 0 & 1 & 0 \\
\hline 0 & 1 & 0 & 0 & 1 & 0 & 0 & 1 & 0 & 0 & 1 & 0 & 1 & 0 & 1 & 0 \\
\hline 0 & 1 & 0 & 0 & 1 & 0 & 1 & 0 & 0 & 0 & 1 & 0 & 1 & 0 & 1 & 0 \\
\hline 0 & 1 & 0 & 0 & 1 & 1 & 0 & 0 & 0 & 0 & 1 & 0 & 1 & 0 & 1 & 0 \\
\hline 0 & 1 & 0 & 0 & 1 & 0 & 0 & 1 & 0 & 0 & 1 & 0 & 1 & 0 & 1 & 0 \\
\hline 0 & 1 & 0 & 0 & 1 & 0 & 0 & 1 & 0 & 0 & 1 & 0 & 1 & 0 & 1 & 0 \\
\hline 0 & 1 & 0 & 0 & 1 & 0 & 0 & 1 & 0 & 0 & 1 & 0 & 1 & 0 & 1 & 0 \\
\hline 0 & 1 & 0 & 0 & 1 & 0 & 0 & 1 & 0 & 0 & 1 & 0 & 1 & 0 & 1 & 0 \\
\hline 0 & 1 & 0 & 0 & 1 & 0 & 0 & 1 & 0 & 0 & 1 & 0 & 1 & 0 & 1 & 0 \\
\hline 0 & 1 & 0 & 0 & 1 & 1 & 0 & 0 & 0 & 0 & 1 & 0 & 1 & 0 & 1 & 0 \\
\hline
\end{tabular}

Tricoq - tricoepitelioma, CBCq - carcinoma basocelular, CD34sq: CD34 positivo no estroma periférico, CD34pq: CD34 positivo no estroma, CD34tq:positivo, CD10sq: CD10 positivo no estroma, CD10pq: CD10 positivo nas células epiteliais tumorais, CD10tq: CD10 positivo no estroma e nas células epiteliais tumorais, CK15sq: CK15 positivo nas células tumorais periféricas, CK15pq: CK15 positivo em todo tumor, CK 15tq: CK15 negativo,CK20sq: CK20 positivo, CK20pq: CK20 negativo, D2-40sq:D240 positivo nas células epiteliais tumorais periféricas, D2-40pq:D2-40 negativo. D2-40tq:D2-40 positivo difusamente em todo tumor. 0 - padrão ausente, 1 - padrão presente. 


\subsection{ANÁLISE DOS RESULTADOS POR REGRESSÃO LINEAR MULTIFATORIAL}

A regressão linear multifatorial evidenciou seis padrões e marcadores que foram mais eficientes na distinção do tricoepitelioma (ver Tabela 6): D240 positivo em células tumorais periféricas, CK15 positivo em células tumorais periféricas, CD10 positivo no estroma, CK20 positivo em células tumorais periféricas, positividade estromal do CD34 e de EMA no estroma tumoral.

Após a remoção do marcador EMA, por não ter apresentado diferença de expressão estatisticamente significante entre TE e CBC, observou-se uma melhora significativa no valor preditivo ( $R$ 2) que aumentou de 53,0\% para 53,8\% (ver Tabelas 6 e 7 ).

Tabela 6 - Regressão linear multifatorial para a variante dependente "tricoepitelioma - tricoq", dispostos em ordem decrescente de eficiência (ver coluna com valores de Beta). $R=0,73429491 R^{2}=$ $0,53918901 . \underline{R^{2}=0,53093920} . F(7,391)=65,358 p$

\begin{tabular}{lcccccc}
\hline & Beta & $\begin{array}{c}\text { Erro } \\
\text { padrão }\end{array}$ & B & $\begin{array}{c}\text { Erro } \\
\text { padrão }\end{array}$ & t(399) & P \\
\hline Antígeno & & & 1,009396 & 0,030370 & 33,2367 & 0,000000 \\
D2-40sq & $\mathbf{- 0 , 4 6 4 5 2 2}$ & 0,038771 & $-0,500334$ & 0,041760 & $-11,9812$ & 0,000000 \\
CK15sq & $\mathbf{- 0 , 2 3 6 2 0 4}$ & 0,036961 & $-0,250385$ & 0,039180 & $-6,3907$ & 0,000000 \\
CD10sq & $\mathbf{- 0 , 1 7 6 4 5 6}$ & 0,036305 & $-0,172875$ & 0,035568 & $-4,8604$ & 0,000002 \\
CK20sq & $\mathbf{- 0 , 1 1 9 0 6 5}$ & 0,036011 & $-0,191610$ & 0,057953 & $-3,3063$ & 0,001033 \\
CD34sq & $\mathbf{- 0 , 0 9 6 7 9 0}$ & 0,036128 & $-0,092281$ & 0,034445 & $-2,6791$ & 0,007694 \\
EMAsq & $-\mathbf{0 , 0 3 2 1 2 5}$ & 0,035650 & $-0,031271$ & 0,034702 & $-0,9011$ & 0,368072 \\
\hline
\end{tabular}

CD34sq - CD34 positivo no estroma peritumoral; CD10sq: CD10 positivo no estroma; CK15sq: CK15 positivo nas células epiteliais tumorais periféricas, CK20sq: CK20 positivo em células epiteliais tumorais periféricas, D2-40sq: D2-40 positivo positivo em células epiteliais tumorais periféricas, EMAsq - antígeno epitelial de membrana (EMA) positivo no estroma. 
Os valores de "Beta" obtidos com a exclusão de EMA são demonstrados na Tabela 7.

Tabela 7 - Regressão linear multifatorial para a variante dependente "tricoepitelioma - tricoq", após a exclusão do padrão EMAsq, dispostos em ordem decrescente de eficiência de acordo com os valores de Beta. $R=0,73759864 . R^{2}=0,54405175 . \quad R^{2}=$ 0,53835240 . $F(5,400)=95,459 p$

\begin{tabular}{lcccccc}
\hline & Beta & $\begin{array}{c}\text { Erro } \\
\text { padrão }\end{array}$ & $\mathbf{B}$ & $\begin{array}{c}\text { Erro } \\
\text { padrão }\end{array}$ & $\mathbf{t ( 3 9 9 )}$ & Valor de $\mathbf{p}$ \\
\hline Antígeno & & & 0,990876 & 0,023798 & 41,6374 & 0,000000 \\
D2-40sq & $\mathbf{- 0 , 4 6 9 3 3 6}$ & 0,038097 & $-0,504863$ & 0,040981 & $-12,3195$ & 0,000000 \\
CK15sq & $\mathbf{- 0 , 2 3 7 4 5 7}$ & 0,036316 & $-0,252231$ & 0,038576 & $-6,5386$ & 0,000000 \\
CD10sq & $\mathbf{- 0 , 1 8 2 5 0 4}$ & 0,035701 & $-0,178841$ & 0,034985 & $-5,1120$ & 0,000000 \\
CK20sq & $\mathbf{- 0 , 1 1 9 6 2 2}$ & 0,034841 & $-0,193920$ & 0,056481 & $-3,4333$ & 0,000658 \\
CD34sq & $\mathbf{- 0 , 1 0 2 0 6 1}$ & 0,034934 & $-0,097340$ & 0,033318 & $-2,9216$ & 0,003680 \\
\hline
\end{tabular}

CD34sq - CD34 positivo no estroma peritumoral; CD10sq: CD10 positivo no estroma; CK15sq: CK15 positivo nas células epiteliais tumorais periféricas, CK20sq: CK20 positivo em células epiteliais tumorais periféricas, D2-40sq: D2-40 positivo em células epiteliais tumorais periféricas.

\subsection{ANÁlisE DOS RESULTADOS POR REGRESSÃO LOGÍSTICA MULTIFATORIAL}

Os padrões/marcadores observados foram então selecionados para a exploração pela técnica da regressão logística multifatorial, com o objetivo de identificar um painel e uma sequência de marcadores, mais eficazes possíveis, na distinção do tricoepitelioma.

O exame dos resultados pela regressão logística multifatorial confirmou os achados do estudo prévio com a regressão linear, mantendo a 
mesma sequência de eficácia na distinção do tricoepitelioma (D2-40, CK15, CD10, CK20, CD34) (Ver Tabela 8).

Tabela 8 - Comparação entre os achados obtidos com a exploração dos resultados pelas técnicas de regressão linear múltipla e regressão logística múltipla para o diagnóstico do tricoepitelioma, de acordo com os perfis imunoistoquímicos de expressão antigênica, dispostos em ordem decrescente de eficácia

\begin{tabular}{lcccc}
\hline Modelo & \multicolumn{2}{c}{ Linear } & \multicolumn{2}{c}{ Logística } \\
\hline Correlação completa & $r^{2}=0,5309$ & & Pseudo ${ }^{2}=0,4856$ & \\
Antígeno & Beta & $P$ & Odds ratio & $p$ \\
D2-40sq & $-0,46$ & $<0,0001$ & 3,01 & $<0,0001$ \\
CK15sq & $-0,23$ & $<0,001$ & 1,86 & $<0,001$ \\
CD10sq & $-0,18$ & $<0,001$ & 1,45 & $<0,001$ \\
CK20sq & $-0,12$ & $<0,01$ & 1,42 & $<0,01$ \\
CD34sq & $-0,097$ & $<0,01$ & 0,85 & $<0,05$ \\
EMA * & $-0,032$ & NS & 0,30 & NS \\
*Somente marcadores & $r^{2}=0,538$ & & Pseudo $r^{2}=0,4889$ & \\
significativos. & & & & \\
\hline
\end{tabular}

CD34: CD34 positivo no estroma peritumoral; CD10: CD10 positivo no estroma; CK15: CK15 positivo nas células epiteliais tumorais periféricas, CK20: CK20 positivo em células epiteliais tumorais periféricas, D2-40: D240 positivo em células epiteliais tumorais periféricas; NS - Não significativo.

A seguir os resultados foram agrupados em conjuntos de um, dois, três, quatro e cinco marcadores, mantendo a sequência observada, acrescentando um marcador a cada grupo, designado como LIG ("labelling immunostaining group") (ver Tabela 9).

O grupo "LIG 0" é composto pelos resultados da análise do D2-40. Este marcador isoladamente não foi capaz de distinguir o tricoepitelioma, independentemente do resultado se positivo ou negativo. 
O painel do grupo "LIG 1", composto pelos resultados do D2-40 e da CK15, também não contribuiu para a distinção do TE.

O painel imunoistoquímico do grupo "LIG 2" é composto pelos padrões do D2-40, CK15 e CD10. Este painel mostrou-se capaz de distinguir o TE em 25,0\% dos casos, quando a expressão dos três marcadores era positiva. Nenhuma outra combinação de resultados dos três marcadores apresentou capacidade de discriminação do TE.

O grupo "LIG 3", composto pelos mesmos marcadores do grupo "LIG 2", acrescido da CK20, identificou uma população de 3,9 \% dos TE quando ocorria imunoexpressão dos quatro marcadores. A combinação de três resultados positivos propiciou a distinção de 32,0\% TE. Este grupo identificou um perfil imunoistoquímico (de três ou mais marcadores) discriminativo de $35,9 \%$ dos TE da casuística estudada.

O painel do grupo "LIG 4", composto pelos mesmos marcadores do grupo "LIG 3", acrescido do CD34, identificou uma população de 2,3\% dos TE com expressão positiva de todos os cinco marcadores, e $25,0 \%$ dos TE com expressão concomitante de quatro marcadores. A capacidade máxima de distinção deste painel foi de $27,3 \%$ dos TE, com três ou mais resultados positivos. 
Tabela 9 - Discriminação entre tricoepitelioma e carcinoma basocelular pela imunoistoquímica. Associação de marcadores de acordo com a sua significância em estudo com regressão logística múltipla

\begin{tabular}{|c|c|c|c|c|c|}
\hline \multicolumn{3}{|c|}{ Marcadores } & \multirow{2}{*}{$\begin{array}{l}\text { Tricoepitelioma } \\
84 / 128(65,6 \%)\end{array}$} & \multirow{2}{*}{$\begin{array}{c}\begin{array}{c}\text { Carcinoma } \\
\text { basocelular }\end{array} \\
16 / 271(5,9 \%)\end{array}$} & \multirow{2}{*}{$\frac{\text { Discriminação }}{\text { Não }}$} \\
\hline ㄴIG 0 & & Positivo & & & \\
\hline & D2-40 & Negativo & $44 / 128(34,4 \%)$ & $255 / 27(94,1 \%)$ & Não \\
\hline \multirow{3}{*}{ 니G 1} & & Dois positivos & 48/128 (37,5\%) & $2 / 271(0,7 \%)$ & Não \\
\hline & D2-40 & $\begin{array}{l}\text { Positivo e negativo } \\
\text { /Negativo e positivo }\end{array}$ & 59/128(46,1\%) & 46/271(17,0\%) & Não \\
\hline & $C A$ & Dois negativos & $21 / 128(16,4 \%)$ & 223/271(82,3\%) & Não \\
\hline \multirow[t]{4}{*}{ 니G 2} & & Três positivos & $32 / 128(25,0 \%)$ & $0 / 271$ * $(0 \%)$ & $25,0 \%$ dos TE \\
\hline & $\mathrm{D} 2-40$ & Dois positivos & $54 / 128(42,2 \%)$ & $10 / 271(3,7 \%)$ & Não \\
\hline & CK15 & Um positivo & 29/128(22,7\%) & $91 / 271(33,6 \%)$ & Não \\
\hline & CD10 & Três negativos & $13 / 128(10,1 \%)$ & $170 / 271(62,7 \%)$ & Não \\
\hline \multirow{6}{*}{ 니G 3} & & Quatro positivos & $5 / 128(3,9 \%)$ & $0 / 271 *(0 \%)$ & 3,9\% dos TE \\
\hline & & Três positivos & $41 / 128(32,0 \%)$ & $0 / 271$ * $(0 \%)$ & $32,0 \%$ dos TE \\
\hline & $\begin{array}{l}\text { D2-40 } \\
\text { CK15 }\end{array}$ & $\begin{array}{l}\text { Três ou mais } \\
\text { positivos }\end{array}$ & $46 / 128(35,9 \%)$ & $0 / 271 *(0 \%)$ & $35,9 \%$ dos TE \\
\hline & CD10 & Dois positivos & 47/128(36,7\%) & $16 / 271(5,9 \%)$ & Não \\
\hline & CK20 & Um positivo & 23/128(18,0\%) & 89/271(32,9\%) & Não \\
\hline & & Quatro negativos & $12 / 128(9,4 \%)$ & $166 / 271(61,2 \%)$ & Não \\
\hline \multirow{7}{*}{ 니G 4} & & Cinco positivos & $3 / 128(2,3 \%)$ & $0 / 271 *(0 \%)$ & 2,3\% dos TE \\
\hline & & Quatro positivos & $32 / 128(25,0 \%)$ & $0 / 271$ * $(0 \%)$ & $25,0 \%$ dos TE \\
\hline & $\begin{array}{l}\text { D2-40 } \\
\text { CK15 }\end{array}$ & $\begin{array}{l}\text { Quatro ou mais } \\
\text { positivos }\end{array}$ & $35 / 162(27,36 \%)$ & $0 / 271$ * $(0 \%)$ & $27,3 \%$ dos TE \\
\hline & CD10/ & Três positivos & 38/128(29,7\%) & $3 / 271(1,1 \%)$ & Não \\
\hline & CK20 & Dois positivos & 31/128(24,2\%) & $34 / 271(12,5 \%)$ & Não \\
\hline & CD34 & Um positivo & 16/128(12,5\%) & $128 / 271(47,2 \%)$ & Não \\
\hline & & Cinco negativos & $8 / 128(6,3 \%)$ & $106 / 271(39,2 \%)$ & Não \\
\hline
\end{tabular}

CD34:CD34 positivo no estroma peritumoral; CD10: CD10 positivo no estroma; CK 15: CK15 positivo nas células epiteliais tumorais periféricas, CK20: CK20 positivo em células epiteliais tumorais periféricas, D2-40: D2-40 positivo em células epiteliais tumorais periféricas. LIG: "Labelling immunostaining group"; *Combinação de marcadores exclusiva de TE. 
5 DISCUSSÃO 
O diagnóstico diferencial histopatológico entre o TE e O $C B C$ ocasionalmente torna-se difícil, particularmente em amostras pequenas. Esta dificuldade se deve a várias semelhanças entre os aspectos microscópicos das duas proliferações neoplásicas ${ }^{12,13,19,20,22}$.

Este tema tem sido abordado por vários autores, devido à importância da certeza diagnóstica das duas neoplasias, uma vez que o TE tem comportamento biológico benigno. O CBC, por outro lado, é uma neoplasia maligna. Os CBC que se localizam na região centro-facial, local de maior incidência dos TE, geralmente podem evoluir com maior agressividade e, por isso, o planejamento terapêutico envolve excisão com margens de segurança ${ }^{2}$.

A partir do ano de 1994, surgem trabalhos que buscam diferenciar essas duas neoplasias, por meio do uso da técnica de imunoistoquímica, inicialmente, com propostas de uso de um marcador ${ }^{12,13,19,23,26,29}$ e, a seguir, com a proposição de painéis contendo vários marcadores ${ }^{18,22,32}$. Os resultados destes estudos, entretanto, são conflitantes.

As casuísticas que compõem os trabalhos comparativos do $\mathrm{CBC}$ com o TE e outros tumores derivados do folículo piloso raramente excedem 50 amostras, principalmente de tricoepiteliomas. Indagamos se este fato poderia estar relacionado à obtenção dos resultados conflitantes dos estudos. 
No presente trabalho propusemos a montagem de blocos de TMA que permitiu uma amostragem maior de casos (162 TE e 328 CBC) e propiciou analisar toda a amostra, com os sete marcadores propostos.

Ao se fazer um estudo com a técnica do TMA, há que se considerar a possibilidade das perdas teciduais. Estas perdas podem ocorrer na fase dos cortes histológicos dos blocos, quando amostras ("cores") com representações diferentes podem se esgotar antes do que outras, ou mesmo por descolamento durante os inúmeros banhos que compõem os procedimentos técnicos de imunoistoquímica.

As perdas observadas no presente estudo variaram de $3,7 \%$ a $11,7 \%$ dos TE (6 a 19 amostras em 162 casos) e 3,3\% a 7,9\% (11 a 26 amostras em 328 casos) de CBC.

Com a finalidade de minimizar as possíveis perdas de casos foram utilizados os "blocos espelho", onde outra amostra da mesma neoplasia foi colocada na mesma posição do bloco original. No nosso estudo, os "blocos espelho" também foram submetidos às reações de imunoistoquímica. Este procedimento reduziu em $40,0 \%$ as perdas de ambos os grupos de neoplasias estudados.

As vantagens da técnica do TMA consistem em aumentar a quantidade de casos analisados e homogeneizar os resultados pela possibilidade de obter séries amplas de amostras submetidas a uma mesma reação imunoistoquímica. Além destas vantagens, a técnica possibilita 
redução de custos, principalmente de reagentes e de trabalho técnico especializado.

No presente estudo, o TMA propiciou a simulação da leitura e interpretação de reações de imunoistoquímica em amostras pequenas, como ocorre na prática da dermatopatologia, principalmente quanto aos espécimes incisionais de TE e CBC.

Ampliou-se o uso de TMA em dermatopatologia na literatura mundial, sendo encontrados inicialmente trabalhos com lesões melanocíticas ${ }^{39,40,41,42}$ e, recentemente, estudos que enfocam grandes séries de $\mathrm{CBC}^{43,44,45,46,47}$.

Ao analisarmos os resultados dos marcadores utilizados no presente estudo, verificamos resultados conflitantes, como os relatados na literatura, considerando-se individualmente os marcadores e seus padrões de expressão nos dois grupos de tumores. Como o nosso estudo compreendeu casuística expressiva, propusemo-nos a realizar as análises estatísticas com os testes de regressão linear múltipla e regressão logística múltipla, com o objetivo de determinar um painel de imunomarcadores que fosse útil para a diferenciação do TE do CBC.

Discutiremos a seguir os resultados obtidos de cada um dos imunomarcadores e sua influência no(s) painel(éis) de marcadores testados.

\section{CD34}

Em análise individual, a expressão estromal de CD34 foi mais frequente no TE $(75,7 \%$ dos casos $)$ do que no CBC $(45,4 \%$ dos casos). Se 
considerarmos este resultado isoladamente, ele é concordante com relato da literatura ${ }^{12}$. A imunoexpressão estromal no TE relaciona-se com a maior celularidade do estroma desta neoplasia folicular, onde são abundantes as células dendríticas CD34+. Os dendrócitos CD34+ são encontrados na pele normal entre os feixes de colágeno da derme reticular e ao redor de anexos cutâneos $^{48}$. É justificada, por esta característica, a esperada imunoexpressão estromal de CD34 no TE. Entretanto, outros autores não puderam demonstrar o valor de CD34 como marcador de distinção do $\mathrm{TE}^{14,18,32}$.

Apesar da diferença de expressão de CD34 entre TE e CBC, no estudo individual de cada marcador, já se observa um baixo valor da "odds ratio" $(3,7)$ para a imunomarcação de CD34 que, em comparação com os outros estudados, na tentativa de distinção entre TE e CBC, só não foi inferior ao EMA (como demonstrado na Tabela 4).

No estudo por regressão linear multifatorial, após a exclusão do EMA (Tabela 6), a expressão estromal de CD34 passou a ser o último padrão de imunomarcação mais significativo. A análise dos resultados pela regressão logística multifatorial manteve a posição do CD34 no painel imunoistoquímico proposto.

No estudo com a agregação de resultados em grupos (Tabela 9 grupo LIG 4), observa-se que a introdução de CD34 como mais um marcador, reduziu o número de TE identificáveis com três ou mais resultados positivos de 46 para 35 , no painel "D2-40 positivo em células epiteliais tumorais periféricas, CK15 positivo em células epiteliais tumorais 
periféricas e CD10 positivo no estroma e CK 20 positivo em células epiteliais tumorais periféricas" do grupo LIG 3. Este procedimento, portanto, levou à perda de casos distinguíveis de TE, pela combinação de resultados imunoistoquímicos. Desse modo, esta queda na capacidade de distinção do painel desfavoreceu a inclusão da positividade estromal do CD34 como marcador para diferenciar o TE do CBC.

A expressão de CD34 pelo componente epitelial das duas neoplasias não contribuiu para a distinção entre esses dois tumores no nosso estudo. A expressão de CD34 pelas células neoplásicas é frequentemente observada no triquilemoma e descrita como ausente no $\mathrm{CBC}^{14}$. A expressão epitelial de CD34 no nosso estudo foi de $2,8 \%$ dos TE e $1,3 \%$ dos $C B C$, inferior a que foi observada por Swanson et al. em $1998^{18}$. Estes autores encontraram este padrão de imunomarcação em 8,33\% dos TE e $16 \%$ dos CBC.

A combinação de expressão de CD34 epitelial e estromal foi observada em 6,9\% e 1,3\% dos TE e CBC respectivamente. Este padrão de expressão foi relatado por outros autores ${ }^{14,18}$.

\section{10}

Em análise isolada e sem considerar o tipo de padrão de imunomarcação, o CD10 foi expresso em 95,1\% dos TE e 99,1\% dos CBC. Comparando-se, entretanto, os padrões de imunomarcação nas duas neoplasias, verificamos que a expressão de CD10 no epitélio tumoral (presente em $8,3 \%$ dos TE e $25,2 \%$ dos CBC) e no epitélio tumoral e estroma (observada em $26,4 \%$ dos TE e $51,3 \%$ dos CBC) apresentou 
diferenças significativas entre as duas neoplasias. A expressão de CD10 estromal apresentou a maior relevância, estando presente em $60,4 \%$ dos TE e 22,6\% dos CBC. A imunomarcação de CD10 foi mais acentuada ao redor dos agrupamentos de células basalóides do TE. A relevância da expressão estromal do CD10, como marcador característico do TE, foi relatada previamente por Pham et al. em $2006{ }^{29}$.

Entretanto, trabalho mais recente não considera que o CD10, isolado ou associado a outros anticorpos, seja suficiente para aprimorar o diagnóstico diferencial entre TE (variante desmoplásica) e CBC esclerodermiforme ${ }^{32}$. A positividade estromal do CD10 é considerada como possível indicador de invasão estromal, além de ser um marcador de diferenciação folicular ${ }^{49}$.

A análise isolada da expressão de CD10 revelou uma "odds ratio" de 5,2. Representa a terceira em ordem de significância dentre os marcadores selecionados. Esta posição foi mantida mesmo nas avaliações por regressão linear e logística.

Na Tabela 9, observa-se que a introdução do CD10 no painel LIG 2 D2-40 positivo nas células epiteliais tumorais periféricas, CK15 positivo nas células tumorais epiteliais periféricas e CD10 positivo no estroma, promoveu a identificação de $25,0 \%$ da população dos TE e exclusão de todos os CBC.

Esse resultado reforça a importância da utilização de painéis imunoistoquímicos passíveis de imunomarcações do epitélio tumoral e do estroma na distinção dessas duas neoplasias, visto que os dois marcadores 
com expressão epitelial (D2-40 e CK15 - grupo LIG 2), por eles mesmos, não foram capazes de excluir todos os casos de CBC (Tabela 9).

\section{ANTÍGENO EPITELIAL DE MEMBRANA (EMA)}

Em análise isolada e, independentemente do padrão de imunomarcação, EMA foi expresso na maioria dos TE $(96,1 \%)$ e em $95,1 \%$ dos CBC. Embora a expressão de EMA, tanto no componente epitelial, quanto no estroma tumoral, tenha sido mais frequente nos TE $(74,2 \%)$ que nos CBC $(55,4 \%)$, sendo estatisticamente significativa, este padrão obteve uma "odds ratio" de 2,3, inferior à observada na avaliação do CD34. A expressão de EMA, somente nas células epiteliais das neoplasias, foi observada, tanto no TE $(21,0 \%)$ como no CBC $(13,0 \%)$. O EMA é um marcador pouco explorado pelos autores na diferenciação entre TE e CBC. Carr et al. em $2007^{50}$ relataram a marcação de células de Merkel pelo EMA em neoplasias basalóides, como o tricoblastoma. Entretanto, este marcador não foi observado no TE variante desmoplásica ${ }^{51}$. Por outro lado, a expressão de EMA foi descrita no linfadenoma cutâneo, que é considerado uma variante de tricoblastoma ${ }^{1,52}$.

Em nosso trabalho, embora a expressão positiva de EMA, sem considerarmos os seus padrões de imunoexpressão, diferiu entre TE e $\mathrm{CBC}$, tanto a análise de regressão linear multifatorial, quanto a regressão logística (ver Tabela 6), demonstraram que o EMA não é um marcador eficiente para a diferenciação de TE do CBC (ver Tabela 8). 


\section{CK 20}

$\mathrm{Na}$ análise isolada desse marcador, a presença de células com expressão de CK20 foi observada em 19,0\% dos TE e 4,5\% dos CBC. Estas células estavam dispostas na periferia dos blocos celulares tumorais e provavelmente representassem células de Merkel, que acompanham as células basalóides e basaliomatosas ${ }^{53,54}$. Embora a frequência de células imunomarcadas pela CK20 tenha sido maior no TE do que no CBC, o número de casos que apresentaram células de Merkel intratumorais foi muito pequeno em relação à amostra (14 em 151 TE). Este resultado já estava evidente na análise preliminar do primeiro bloco de TMA (ver Tabela 3). Entretanto, na análise de toda a amostra, a frequência de células CK20 positivas foi significativa para a distinção do TE, com o valor da "odds ratio" de 5,0 (Tabela 4).

Essas observações reforçam a necessidade de grandes amostragens para esse tipo de estudo, uma vez que existem disparidades relatadas em pesquisas com amostragens pequenas, ora favorecendo a CK20 como marcador de valia para a diagnose de $\mathrm{TE}^{32,51}$, ora a desfavorecendo ${ }^{22,55}$.

A frequência de células imunomarcadas pela CK20 no CBC é pequena. Em estudo com amostragem expressiva, com 205 casos de CBC, foram encontradas células CK20 positivas em somente $8,0 \%$ dos $\operatorname{casos}^{16}$.

Quanto ao valor de CK20 como marcador no contexto de um painel para a discriminação do TE, pudemos observar o incremento na capacidade diagnóstica do painel proposto com a introdução deste marcador (ver Tabela 9). Após esta inclusão, verificamos que o poder de discriminação 
passou de 25,0\% (com o grupo LIG 2 - três resultados positivos) para 35,9\% (grupo LIG 3 - três ou mais resultados positivos), configurando o painel com maior capacidade discriminatória neste estudo.

Apesar da frequência geral da CK20 ter sido baixa nos TE da amostra estudada, os resultados indicam que a introdução do padrão positivo deste marcador no painel imunoistoquímico favorece o diagnóstico de TE.

\section{CK 15}

Em análise isolada e independentemente do padrão de expressão, a frequência de imunomarcação por CK15 foi diferente nos dois tumores. Os dois padrões de expressão de CK15 nas células epiteliais periféricas (observada em 40,0\% dos TE e 51,3\% dos CBC) e difusamente no epitélio tumoral (presente em 53,7\% dos TE e 13,2\% dos CBC) --, bem como a imunoexpressão independentemente do padrão (presente em 94,0\% dos TE e $64,5 \%$ dos $\mathrm{CBC}$ ), analisados isoladamente, também demonstraram diferenças estatisticamente significantes. Resultados semelhantes foram descritos na literatura ${ }^{23,24,31}$.

A CK15 é considerada um marcador de células tronco foliculares ${ }^{24}$. No folículo piloso maduro sua expressão estaria restrita às células da bainha folicular externa. A CK15 no processo de tumorigênese pode apresentar alterações em sua expressão, até mesmo com a supressão de sua expressão ${ }^{56}$. Estas características poderiam justificar os diferentes padrões de expressão de CK15 observados no TE e CBC. 
A expressão da CK15 nas células epiteliais tumorais periféricas foi o padrão selecionado na exploração dos resultados pela regressão linear multifatorial, pois se mostrou o mais significativo dentre os padrões deste marcador (ver Tabelas 7 e 8), corroborando também o valor da "odds ratio" do teste de Fisher que foi de 7,6 (ver Tabela 4). Observou-se um aumento importante na capacidade de distinção do painel de imunomarcadores com a adição do padrão "CK15 positivo em células periféricas". A presença de dois resultados positivos distinguiu 50 dos 162 TE e excluiu 325 dos 328 $(99,0 \%)$ tumores da amostra de CBC.

\section{D2 40}

Cento e quarenta e três TE e 307 CBC foram submetidos à imunomarcação com o anticorpo D2-40. O anticorpo D2-40 foi inicialmente proposto na literatura como marcador de endotélio linfático ${ }^{57}$ e é expresso pelas células basais do epitélio da bainha externa de folículos pilosos ${ }^{35}$. Recentemente, foi proposto como o melhor imunomarcador do $\mathrm{TE}^{36}$.

Em nossa casuística, 91 TE (63,6\%) e 18 CBC (5,9\%) apresentaram imunorreatividade ao D2-40, independentemente do padrão de imunomarcação observado. Oitenta e seis TE $(60,1 \%)$ e 13 CBC (4,2\%) exibiram positividade em células tumorais periféricas. Imunoexpressão difusa pelas células epiteliais neoplásicas foi observada somente em cinco TE $(3,5 \%)$ e cinco CBC $(1,7 \%)$.

O D2-40 pela análise estatística inicial mostrou-se o mais eficiente na distinção do TE com uma "odds ratio" de 28,1 para a imunoexpressão 
independentemente do padrão e de 34,1 para a imunoexpressão em células epiteliais periféricas (ver Tabela 4), corroborando os achados de Plaza et al. em 2010. Mesmo assim, na análise do toda a casuística, encontramos 18 entre 328 CBC positivos para este marcador, indicando que não há, dentre os marcadores e seus padrões de expressão estudados, um que seja totalmente eficiente no diagnóstico diferencial entre TE e CBC.

Entretanto, na avaliação dos resultados pelos testes de regressão linear e logística, observou-se a manutenção da capacidade do D2-40 como marcador para a distinção do diagnóstico de TE.

Os resultados das análises pelas técnicas de regressão linear múltipla e de regressão logística multifatorial foram muito semelhantes entre si e identificaram o mesmo painel de marcadores/padrões como possíveis caracterizadores do TE. Esta semelhança entre os dados das duas análises de regressão, bem como a manutenção da ordem de significância observada nos valores da "odds ratio" dos estudos preliminares como o teste de Fisher (Tabela 4), validam o tamanho da amostra estudada.

O painel proposto de três ou mais imunomarcadores positivos no painel do grupo LIG 3 mostrou-se uma ferramenta de auxílio ao diagnóstico diferencial entre o TE e o CBC. Este painel foi capaz de identificar 35,9\% dos TE (grupo LIG3 da Tabela 9) numa amostra ampla de tumores (128 casos). Além disso, o perfil de imunomarcadores que compuseram este grupo foi capaz de excluir/desfavorecer 271 casos de CBC do diagnóstico de TE. 
Como a proposta inicial do estudo foi a de trabalhar com amostras de proporções reduzidas, simulando as dimensões das biópsias incisionais, fez-se a análise de disposição ordenada dos marcadores nos painéis estudados, para sugerir também a sequência ideal de reações a ser realizada na prática diagnóstica. Este procedimento é importante para a realização do exame imunoistoquímico, uma vez que as amostras incisionais são geralmente de pequenas dimensões e passíveis de esgotamento do material contido no bloco.

Os resultados por nós obtidos, ao estudar ampla casuística de TE e CBC propiciada pela técnica de TMA, não permitiram caracterizar um marcador ou painel de imunomarcadores que pudesse discriminar o TE de modo absoluto. Alguns dos marcadores e/ou conjunto de marcadores mostraram-se promissores, entretanto, com capacidade máxima de discriminação de $35,9 \%$ dos casos de TE. Justificamos estes dados pelo fato de que os tumores basalóides foliculares benignos e malignos devem representar um espectro contínuo cujas características imunofenotípicas podem se mesclar $21,25,31,58$.

É importante salientar que o "padrão ouro" do nosso trabalho foi o exame histopatológico convencional das amostras teciduais coradas pela hematoxilina-eosina. As variáveis que foram estabelecidas como fixas (diagnóstico de TE e CBC) dos testes estatísticos foram determinadas pelo diagnóstico histopatológico dos casos selecionados para o estudo.

A importância do exame histopatológico associado à aplicação dos critérios descritos para o correto diagnóstico diferencial entre essas duas 
neoplasias foi concordante com o de trabalhos científicos que também abordaram esta questão ${ }^{22,36}$. Os marcadores e/ou painel de imunomarcadores obtidos por técnicas imunoistoquímicas, portanto, podem auxiliar, mas não substituem o exame histopatológico convencional realizado pelo patologista. Este exame deve ser embasado nos critérios histopatológicos propostos na literatura. 
6 CONCLUSÕES 
1. A técnica de "tissue microarray" possibilitou a análise de 162 casos de tricoepitelioma e 328 carcinomas basocelulares, com poucas perdas teciduais, que puderam ser avaliadas com painel imunoistoquímico de sete marcadores.

2. Os marcadores BCL-2 e antígeno epitelial de membrana, dentre os sete analisados, não foram adequados para auxiliar na diagnose diferencial entre o tricoepitelioma e o carcinoma basocelular.

3. As análises de regressão linear múltipla e de regressão logística multifatorial identificaram painel composto pelos imunomarcadores D2-40, citoqueratina 15, CD10 e citoqueratina 20, que foi expresso somente pelo tricoepitelioma em $35,9 \%$ dos casos. 
7 ANEXOS 
Anexo A - Resultados das reações de com posição e número do bloco de arranjo tecidual para 328 carcinomas basocelulares e 162 tricoepiteliomas, com os marcadores CD34, CD10, CK15, D2-40, EMA

\begin{tabular}{|c|c|c|c|c|c|c|c|c|}
\hline $\begin{array}{c}\text { Posição no } \\
\text { bloco }\end{array}$ & $\begin{array}{c}\text { Número do } \\
\text { bloco }\end{array}$ & Diagnóstico & CD 34 & $C D 10$ & CK 15 & CK 20 & D2 40 & EMA \\
\hline A5 & 246 & TRICOEPITELIOMA & neg & pos todo epit & pos epi perif & pos cel epit isol & neg & pos todo epit \\
\hline A6 & 246 & TRICOEPITELIOMA & neg & pos todo epit & neg & neg & neg & pos estroma/epit \\
\hline B1 & 246 & TRICOEPITELIOMA & neg & pos todo epit & pos epi perif & neg & neg & pos estroma/epit \\
\hline B2 & 246 & TRICOEPITELIOMA & pos estroma/epit & pos estroma & pos epi perif & pos cel epit isol & neg & pos estroma/epit \\
\hline B3 & 246 & TRICOEPITELIOMA & pos estrom perif & pos estroma/epit & pos epi perif & neg & neg & pos estroma/epit \\
\hline B4 & 246 & TRICOEPITELIOMA & pos estrom perif & perda & neg & neg & neg & pos estroma/epit \\
\hline C1 & 246 & TRICOEPITELIOMA & pos estrom perif & pos estroma & pos todo epit & neg & pos epi perif & pos estroma/epit \\
\hline C4 & 246 & TRICOEPITELIOMA & pos estrom perif & pos estroma & pos todo epit & neg & pos epi perif & pos estroma/epit \\
\hline $\mathrm{C} 6$ & 246 & TRICOEPITELIOMA & pos estroma & pos todo epit & pos epi perif & neg & neg & pos estroma/epit \\
\hline C7 & 246 & TRICOEPITELIOMA & perda & perda & perda & neg & perda & perda \\
\hline D1 & 246 & TRICOEPITELIOMA & perda & perda & perda & perda & perda & pos todo epit \\
\hline D2 & 246 & TRICOEPITELIOMA & pos todo epit & neg & pos todo epit & neg & neg & pos todo epit \\
\hline D3 & 246 & TRICOEPITELIOMA & pos estroma/epit & pos estroma/epit & pos todo epit & pos cel epit isol & pos epi perif & pos todo epit \\
\hline D6 & 246 & TRICOEPITELIOMA & pos estrom perif & pos estroma & pos epi perif & neg & neg & pos estroma/epit \\
\hline E2 & 246 & TRICOEPITELIOMA & pos estrom perif & neg & pos epi perif & neg & neg & pos todo epit \\
\hline E5 & 246 & TRICOEPITELIOMA & pos estrom perif & pos estroma & pos epi perif & neg & pos epi perif & pos estroma/epit \\
\hline E6 & 246 & TRICOEPITELIOMA & neg & pos estroma & neg & neg & neg & pos estroma/epit \\
\hline E7 & 246 & TRICOEPITELIOMA & pos estrom perif & neg & pos todo epit & neg & neg & pos estroma/epit \\
\hline F4 & 246 & TRICOEPITELIOMA & pos estrom perif & pos estroma & pos epi perif & neg & pos epi perif & pos estroma/epit \\
\hline $\mathrm{F} 7$ & 246 & TRICOEPITELIOMA & neg & perda & perda & perda & neg & perda \\
\hline G1 & 246 & TRICOEPITELIOMA & pos estrom perif & pos estroma & pos todo epit & neg & neg & pos estroma/epit \\
\hline G2 & 246 & TRICOEPITELIOMA & pos estrom perif & pos estroma & pos todo epit & neg & neg & pos estroma/epit \\
\hline G3 & 246 & TRICOEPITELIOMA & neg & pos estroma & pos epi perif & neg & pos epi perif & pos estroma/epit \\
\hline G4 & 246 & TRICOEPITELIOMA & pos estrom perif & pos estroma & pos epi perif & neg & neg & pos estroma/epit \\
\hline G5 & 246 & TRICOEPITELIOMA & pos estrom perif & pos estroma & pos epi perif & pos cel epit isol & neg & pos estroma/epit \\
\hline G6 & 246 & TRICOEPITELIOMA & pos estroma/epit & pos estroma & pos todo epit & neg & neg & pos estroma/epit \\
\hline G7 & 246 & TRICOEPITELIOMA & pos todo epit & neg & pos todo epit & pos cel epit isol & pos todo epit & pos todo epit \\
\hline $\mathrm{H} 1$ & 246 & TRICOEPITELIOMA & pos estrom perif & pos estroma & pos todo epit & neg & pos epi perif & pos estroma/epit \\
\hline $\mathrm{H} 2$ & 246 & TRICOEPITELIOMA & pos estrom perif & pos todo epit & pos epi perif & neg & neg & pos estroma/epit \\
\hline H3 & 246 & TRICOEPITELIOMA & pos estrom perif & pos estroma & pos todo epit & neg & pos epi perif & pos estroma/epit \\
\hline $\mathrm{H} 4$ & 246 & TRICOEPITELIOMA & pos estrom perif & pos estroma & pos todo epit & neg & pos epi perif & pos todo epit \\
\hline
\end{tabular}


Anexo A - Resultados das reações de com posição e número do bloco de arranjo tecidual para 328 carcinomas basocelulares e 162 tricoepiteliomas, com os marcadores CD34, CD10, CK15, D2-40, EMA. (continuação)

\begin{tabular}{|c|c|c|c|c|c|c|c|c|}
\hline $\begin{array}{l}\text { Posição no } \\
\text { bloco }\end{array}$ & $\begin{array}{l}\text { Número do } \\
\text { bloco }\end{array}$ & Diagnóstico & CD 34 & $C D 10$ & CK 15 & CK 20 & D2 40 & EMA \\
\hline H5 & 246 & TRICOEPITELIOMA & pos estrom perif & pos estroma & pos epi perif & neg & pos epi perif & pos estroma/epit \\
\hline $\mathrm{H} 7$ & 246 & TRICOEPITELIOMA & pos estrom perif & pos estroma & pos todo epit & neg & perda & pos estroma/epit \\
\hline I1 & 246 & TRICOEPITELIOMA & neg & pos estroma & neg & neg & pos epi perif & pos todo epit \\
\hline 12 & 246 & TRICOEPITELIOMA & pos estrom perif & pos estroma & pos epi perif & neg & pos epi perif & pos estroma/epit \\
\hline 13 & 246 & TRICOEPITELIOMA & pos estroma/epit & perda & pos epi perif & neg & pos epi perif & pos estroma/epit \\
\hline 15 & 246 & TRICOEPITELIOMA & pos estrom perif & pos todo epit & pos todo epit & pos cel epit isol & pos epi perif & pos estroma/epit \\
\hline J5 & 246 & TRICOEPITELIOMA & perda & perda & perda & perda & perda & perda \\
\hline $\mathrm{J} 7$ & 246 & CBCESCLEROD & neg & pos estroma/epit & neg & neg & neg & pos estroma/epit \\
\hline A6 & 240 & CBCNOD & neg & pos estroma/epit & perda & pos cel epit isol & neg & perda \\
\hline A8 & 240 & TRICOEPITELIOMA & neg & pos estroma/epit & pos todo epit & neg & pos epi perif & pos todo epit \\
\hline A9 & 240 & TRICOEPITELIOMA & neg & pos estroma/epit & pos todo epit & neg & pos epi perif & pos estroma/epit \\
\hline A11 & 240 & TRICOEPITELIOMA & pos estroma/epit & pos estroma/epit & pos epi perif & neg & pos epi perif & pos estroma/epit \\
\hline A13 & 240 & TRICOEPITELIOMA & neg & pos estroma/epit & pos epi perif & neg & pos epi perif & pos estroma/epit \\
\hline A15 & 240 & TRICOEPITELIOMA & neg & pos estroma/epit & pos todo epit & neg & neg & pos estroma/epit \\
\hline B5 & 240 & TRICOEPITELIOMA & neg & pos estroma & pos todo epit & neg & pos epi perif & pos estroma/epit \\
\hline B9 & 240 & TRICOEPITELIOMA & pos estrom perif & pos estroma/epit & pos todo epit & neg & pos epi perif & pos estroma/epit \\
\hline B11 & 240 & CBCNOD & neg & pos estroma/epit & pos epi perif & neg & neg & pos estroma/epit \\
\hline B12 & 240 & TRICOEPITELIOMA & pos estrom perif & pos estroma & pos epi perif & neg & pos epi perif & pos estroma/epit \\
\hline B14 & 240 & TRICOEPITELIOMA & neg & pos estroma & pos epi perif & neg & neg & pos estroma/epit \\
\hline B15 & 240 & TRICOEPITELIOMA & neg & pos estroma & pos epi perif & neg & neg & pos estroma/epit \\
\hline C1 & 240 & TRICOEPITELIOMA & pos estrom perif & pos estroma & pos todo epit & neg & pos epi perif & pos estroma/epit \\
\hline C2 & 240 & TRICOEPITELIOMA & pos estrom perif & pos estroma & pos epi perif & neg & pos epi perif & pos estroma/epit \\
\hline C3 & 240 & TRICOEPITELIOMA & pos estrom perif & pos estroma & pos epi perif & neg & pos epi perif & pos estroma/epit \\
\hline C6 & 240 & TRICOEPITELIOMA & neg & pos estroma & neg & neg & neg & pos todo epit \\
\hline C8 & 240 & TRICOEPITELIOMA & pos estrom perif & pos estroma & pos epi perif & neg & pos epi perif & pos estroma/epit \\
\hline C10 & 240 & TRICOEPITELIOMA & pos estroma & pos estroma & pos epi perif & neg & pos epi perif & pos estroma/epit \\
\hline C11 & 240 & TRICOEPITELIOMA & pos estrom perif & pos estroma & pos todo epit & neg & pos epi perif & pos estroma/epit \\
\hline C12 & 240 & TRICOEPITELIOMA & pos estroma & pos estroma & pos epi perif & neg & pos epi perif & pos estroma/epit \\
\hline C13 & 240 & TRICOEPITELIOMA & pos estrom perif & pos estroma/epit & perda & neg & pos epi perif & pos estroma/epit \\
\hline C14 & 240 & TRICOEPITELIOMA & neg & pos todo epit & pos epi perif & neg & pos epi perif & pos todo epit \\
\hline C15 & 240 & TRICOEPITELIOMA & pos estrom perif & pos estroma/epit & pos epi perif & neg & pos epi perif & pos estroma/epit \\
\hline
\end{tabular}


Anexo A - Resultados das reações de com posição e número do bloco de arranjo tecidual para 328 carcinomas basocelulares e 162 tricoepiteliomas, com os marcadores CD34, CD10, CK15, D2-40, EMA. (continuação)

\begin{tabular}{|c|c|c|c|c|c|c|c|c|}
\hline $\begin{array}{l}\text { Posição no } \\
\text { bloco }\end{array}$ & $\begin{array}{c}\text { Número do } \\
\text { bloco }\end{array}$ & Diagnóstico & CD 34 & $C D 10$ & CK 15 & CK 20 & D2 40 & EMA \\
\hline D2 & 240 & TRICOEPITELIOMA & pos estrom perif & pos estroma/epit & pos epi perif & neg & pos epi perif & pos estroma/epit \\
\hline D3 & 240 & TRICOEPITELIOMA & perda & perda & perda & perda & perda & perda \\
\hline D4 & 240 & TRICOEPITELIOMA & neg & pos estroma & pos epi perif & neg & pos epi perif & pos estroma/epit \\
\hline D5 & 240 & TRICOEPITELIOMA & pos estrom perif & pos estroma & pos todo epit & pos cel epit isol & pos epi perif & pos estroma/epit \\
\hline D8 & 240 & TRICOEPITELIOMA & pos estrom perif & pos estroma & pos epi perif & pos cel epit isol & neg & pos todo epit \\
\hline D9 & 240 & TRICOEPITELIOMA & pos estrom perif & pos estroma/epit & pos epi perif & neg & neg & pos todo epit \\
\hline D10 & 240 & TRICOEPITELIOMA & pos estroma/epit & pos estroma/epit & pos epi perif & pos cel epit isol & pos epi perif & pos estroma/epit \\
\hline D11 & 240 & TRICOEPITELIOMA & perda & perda & perda & perda & perda & perda \\
\hline D12 & 240 & CBCNOD & neg & pos estroma & pos epi perif & neg & neg & pos todo epit \\
\hline D13 & 240 & CBCNODMICRO & pos estrom perif & pos todo epit & neg & neg & neg & pos estroma/epit \\
\hline E1 & 240 & CBCMICRO & pos estrom perif & pos todo epit & pos todo epit & neg & neg & pos todo epit \\
\hline D15 & 240 & CBCNOD & pos estroma & pos todo epit & perda & neg & neg & pos todo epit \\
\hline E2 & 240 & CBCNOD & neg & pos estroma/epit & perda & neg & neg & pos todo epit \\
\hline E3 & 240 & CBCNOD & pos estrom perif & pos estroma/epit & pos todo epit & neg & neg & pos todo epit \\
\hline E4 & 240 & CBCMICRO & pos estroma & pos estroma/epit & neg & neg & neg & pos todo epit \\
\hline E5 & 240 & CBCMICRO & pos estrom perif & pos estroma/epit & pos todo epit & neg & neg & pos todo epit \\
\hline E6 & 240 & TRICOEPITELIOMA & pos estrom perif & pos estroma & pos todo epit & neg & pos epi perif & pos estroma/epit \\
\hline E7 & 240 & TRICOEPITELIOMA & neg & pos estroma & pos todo epit & neg & neg & pos todo epit \\
\hline E8 & 240 & TRICOEPITELIOMA & pos estrom perif & pos estroma & pos todo epit & pos cel epit isol & pos epi perif & pos estroma/epit \\
\hline E9 & 240 & TRICOEPITELIOMA & pos estrom perif & pos estroma & pos todo epit & neg & pos epi perif & pos estroma/epit \\
\hline E10 & 240 & TRICOEPITELIOMA & pos estrom perif & pos estroma & pos todo epit & neg & pos epi perif & pos estroma/epit \\
\hline E12 & 240 & TRICOEPITELIOMA & neg & pos estroma/epit & pos todo epit & pos cel epit isol & pos epi perif & pos estroma/epit \\
\hline E13 & 240 & TRICOEPITELIOMA & pos estrom perif & pos estroma & pos todo epit & neg & pos epi perif & pos estroma/epit \\
\hline E14 & 240 & TRICOEPITELIOMA & neg & pos estroma & pos todo epit & neg & pos epi perif & pos todo epit \\
\hline E15 & 240 & TRICOEPITELIOMA & neg & neg & pos todo epit & neg & neg & pos todo epit \\
\hline $\mathrm{F} 2$ & 240 & TRICOEPITELIOMA & neg & pos estroma/epit & pos todo epit & neg & pos epi perif & pos todo epit \\
\hline F3 & 240 & TRICOEPITELIOMA & pos estroma & pos estroma/epit & pos todo epit & pos cel epit isol & neg & pos estroma/epit \\
\hline F4 & 240 & TRICOEPITELIOMA & pos estroma & pos estroma/epit & pos todo epit & neg & pos epi perif & pos todo epit \\
\hline F5 & 240 & TRICOEPITELIOMA & neg & pos estroma & pos todo epit & neg & pos epi perif & pos estroma/epit \\
\hline F6 & 240 & TRICOEPITELIOMA & pos estroma/epit & pos estroma & pos todo epit & neg & pos epi perif & pos estroma/epit \\
\hline F7 & 240 & TRICOEPITELIOMA & perda & perda & perda & perda & perda & perda \\
\hline
\end{tabular}


Anexo A - Resultados das reações de com posição e número do bloco de arranjo tecidual para 328 carcinomas basocelulares e 162 tricoepiteliomas, com os marcadores CD34, CD10, CK15, D2-40, EMA. (continuação)

\begin{tabular}{|c|c|c|c|c|c|c|c|c|}
\hline $\begin{array}{l}\text { Posição no } \\
\text { bloco }\end{array}$ & $\begin{array}{l}\text { Número do } \\
\text { bloco }\end{array}$ & Diagnóstico & CD 34 & $C D 10$ & CK 15 & CK 20 & D2 40 & EMA \\
\hline F9 & 240 & TRICOEPITELIOMA & pos estrom perif & pos estroma & pos todo epit & neg & pos epi perif & pos estroma/epit \\
\hline F11 & 240 & TRICOEPITELIOMA & pos estroma & pos estroma & pos epi perif & neg & pos epi perif & pos estroma/epit \\
\hline F12 & 240 & TRICOEPITELIOMA & pos estroma/epit & pos estroma/epit & perda & neg & pos epi perif & pos estroma/epit \\
\hline F14 & 240 & TRICOEPITELIOMA & neg & pos estroma & pos epi perif & pos cel epit isol & pos epi perif & pos estroma/epit \\
\hline F15 & 240 & TRICOEPITELIOMA & pos estrom perif & pos estroma & pos todo epit & pos cel epit isol & pos epi perif & pos todo epit \\
\hline G1 & 240 & TRICOEPITELIOMA & pos estrom perif & pos estroma & pos epi perif & pos cel epit isol & pos epi perif & pos estroma/epit \\
\hline G2 & 240 & TRICOEPITELIOMA & pos estrom perif & pos estroma/epit & pos epi perif & pos cel epit isol & pos epi perif & pos todo epit \\
\hline G3 & 240 & TRICOEPITELIOMA & pos estrom perif & pos estroma & pos todo epit & pos cel epit isol & pos epi perif & pos estroma/epit \\
\hline G4 & 240 & TRICOEPITELIOMA & pos estrom perif & pos estroma & pos epi perif & neg & pos epi perif & pos estroma/epit \\
\hline G5 & 240 & TRICOEPITELIOMA & pos estrom perif & pos estroma & pos epi perif & neg & neg & pos estroma/epit \\
\hline G6 & 240 & TRICOEPITELIOMA & perda & perda & perda & perda & perda & perda \\
\hline G7 & 240 & TRICOEPITELIOMA & pos estrom perif & pos estroma & pos epi perif & pos cel epit isol & pos epi perif & pos estroma/epit \\
\hline G8 & 240 & TRICOEPITELIOMA & pos estrom perif & pos estroma & pos epi perif & neg & pos epi perif & pos estroma/epit \\
\hline G9 & 240 & TRICOEPITELIOMA & pos estrom perif & pos estroma & pos epi perif & neg & pos epi perif & pos estroma/epit \\
\hline G10 & 240 & TRICOEPITELIOMA & pos estrom perif & pos estroma & pos epi perif & pos cel epit isol & pos epi perif & pos estroma/epit \\
\hline G11 & 240 & TRICOEPITELIOMA & neg & pos estroma/epit & pos todo epit & neg & neg & pos estroma/epit \\
\hline G13 & 240 & TRICOEPITELIOMA & pos estrom perif & pos estroma/epit & perda & neg & neg & pos estroma/epit \\
\hline G15 & 240 & TRICOEPITELIOMA & pos todo epit & pos estroma & neg & pos cel epit isol & pos todo epit & pos todo epit \\
\hline $\mathrm{H} 1$ & 240 & TRICOEPITELIOMA & pos estrom perif & neg & pos epi perif & neg & neg & pos todo epit \\
\hline H3 & 240 & TRICOEPITELIOMA & neg & pos estroma/epit & pos epi perif & pos cel epit isol & neg & pos todo epit \\
\hline H5 & 240 & TRICOEPITELIOMA & pos estrom perif & pos estroma & pos todo epit & neg & pos todo epit & perda \\
\hline $\mathrm{H} 6$ & 240 & CBCMICRO & pos estrom perif & pos estroma/epit & pos todo epit & neg & neg & perda \\
\hline $\mathrm{H} 7$ & 240 & CBCESCLEROD & neg & pos estroma & pos todo epit & neg & neg & pos estroma/epit \\
\hline $\mathrm{H} 8$ & 240 & CBCNOD & neg & pos estroma/epit & pos epi perif & neg & neg & pos estroma/epit \\
\hline $\mathrm{H} 9$ & 240 & CBCMICRO & pos estroma & pos todo epit & neg & neg & neg & pos todo epit \\
\hline $\mathrm{H} 10$ & 240 & CBCMICRO & pos estroma & pos estroma/epit & pos todo epit & pos cel epit isol & neg & pos estroma/epit \\
\hline $\mathrm{H} 11$ & 240 & CBCNOD & neg & pos estroma & neg & neg & neg & neg \\
\hline $\mathrm{H} 12$ & 240 & CBCNOD & neg & pos todo epit & perda & neg & neg & pos todo epit \\
\hline H13 & 240 & CBCMICRO & pos estrom perif & pos todo epit & pos todo epit & neg & neg & pos todo epit \\
\hline $\mathrm{H} 14$ & 240 & CBCMICRO & pos estroma & pos estroma/epit & pos epi perif & neg & neg & pos todo epit \\
\hline $\mathrm{H} 15$ & 240 & CBCNOD & pos estrom perif & pos estroma/epit & pos todo epit & neg & neg & pos todo epit \\
\hline
\end{tabular}


Anexo A - Resultados das reações de com posição e número do bloco de arranjo tecidual para 328 carcinomas basocelulares e 162 tricoepiteliomas, com os marcadores CD34, CD10, CK15, D2-40, EMA. (continuação)

\begin{tabular}{|c|c|c|c|c|c|c|c|c|}
\hline $\begin{array}{l}\text { Posição no } \\
\text { bloco }\end{array}$ & $\begin{array}{l}\text { Número do } \\
\text { bloco }\end{array}$ & Diagnóstico & CD 34 & $C D 10$ & CK 15 & CK 20 & D2 40 & EMA \\
\hline I1 & 240 & CBCMICRO & pos estroma & pos todo epit & pos epi perif & neg & neg & pos todo epit \\
\hline 13 & 240 & CBCNOD & neg & pos estroma/epit & pos todo epit & neg & neg & pos todo epit \\
\hline 14 & 240 & CBCNOD & neg & pos estroma/epit & pos todo epit & neg & neg & pos estroma/epit \\
\hline 15 & 240 & CBCNOD & neg & perda & perda & perda & neg & perda \\
\hline 16 & 240 & CBCNOD & neg & pos todo epit & neg & neg & neg & pos todo epit \\
\hline 17 & 240 & CBCESCLEROD & neg & pos estroma & pos todo epit & neg & neg & pos estroma/epit \\
\hline 18 & 240 & CBCMICRO & neg & pos estroma/epit & pos todo epit & neg & neg & pos todo epit \\
\hline 19 & 240 & CBCMICRO & pos estrom perif & pos estroma & perda & neg & neg & neg \\
\hline 110 & 240 & CBCNOD & neg & pos estroma/epit & pos todo epit & neg & neg & pos estroma/epit \\
\hline I11 & 240 & CBCESCLEROD & neg & pos estroma/epit & pos epi perif & neg & neg & pos todo epit \\
\hline 112 & 240 & CBCNOD & pos estroma & pos estroma/epit & pos todo epit & pos cel epit isol & neg & pos todo epit \\
\hline I13 & 240 & CBCNODESCLEROD & pos estrom perif & pos estroma/epit & pos epi perif & neg & neg & pos estroma/epit \\
\hline I14 & 240 & CBCMICRO & neg & perda & pos epi perif & perda & pos epi perif & pos todo epit \\
\hline I15 & 240 & CBCMICRO & pos estroma & perda & perda & neg & perda & pos todo epit \\
\hline $\mathrm{J} 1$ & 240 & CBCNOD & pos estroma & pos estroma & pos todo epit & neg & neg & pos estroma/epit \\
\hline $\mathrm{J} 2$ & 240 & CBCNODMICRO & pos estrom perif & pos estroma/epit & pos epi perif & neg & neg & pos todo epit \\
\hline J3 & 240 & CBCESCLEROD & neg & pos estroma/epit & pos todo epit & neg & neg & pos todo epit \\
\hline J4 & 240 & CBCNOD & pos estroma & pos estroma/epit & pos todo epit & neg & neg & pos estroma/epit \\
\hline J5 & 240 & CBCNOD & pos estrom perif & pos todo epit & perda & neg & neg & neg \\
\hline J6 & 240 & CBCMICRO & perda & perda & perda & perda & perda & perda \\
\hline $\mathrm{J} 7$ & 240 & CBCNODMICRO & neg & pos estroma & pos todo epit & pos cel epit isol & neg & neg \\
\hline J8 & 240 & CBCNOD & neg & pos estroma/epit & pos epi perif & neg & neg & pos estroma/epit \\
\hline J9 & 240 & CBCNOD & neg & pos todo epit & pos todo epit & neg & neg & pos todo epit \\
\hline $\mathrm{J} 10$ & 240 & CBCNOD & neg & pos todo epit & neg & neg & pos todo epit & pos todo epit \\
\hline $\mathrm{J} 11$ & 240 & CBCMICRO & neg & pos todo epit & neg & neg & neg & pos estroma/epit \\
\hline J12 & 240 & CBCNOD & neg & pos estroma/epit & pos todo epit & neg & neg & pos todo epit \\
\hline $\mathrm{J} 13$ & 240 & CBCNOD & neg & pos estroma/epit & pos todo epit & neg & neg & pos todo epit \\
\hline J14 & 240 & CBCMICRO & neg & pos estroma/epit & neg & neg & neg & pos todo epit \\
\hline J15 & 240 & CBCMICRO & pos estrom perif & pos todo epit & pos todo epit & neg & neg & pos todo epit \\
\hline K1 & 240 & CBCMICRO & perda & perda & perda & perda & perda & perda \\
\hline K2 & 240 & TRICOEPITELIOMA & pos estrom perif & pos estroma/epit & pos epi perif & neg & pos epi perif & pos estroma/epit \\
\hline
\end{tabular}


Anexo A - Resultados das reações de com posição e número do bloco de arranjo tecidual para 328 carcinomas basocelulares e 162 tricoepiteliomas, com os marcadores CD34, CD10, CK15, D2-40, EMA. (continuação)

\begin{tabular}{|c|c|c|c|c|c|c|c|c|}
\hline $\begin{array}{l}\text { Posição no } \\
\text { bloco }\end{array}$ & $\begin{array}{l}\text { Número do } \\
\text { bloco }\end{array}$ & Diagnóstico & CD 34 & $C D 10$ & CK 15 & CK 20 & D2 40 & EMA \\
\hline K5 & 240 & TRICOEPITELIOMA & pos estrom perif & pos estroma & pos epi perif & neg & pos epi perif & pos estroma/epit \\
\hline K8 & 240 & TRICOEPITELIOMA & perda & perda & neg & perda & perda & perda \\
\hline K9 & 240 & TRICOEPITELIOMA & perda & perda & perda & neg & perda & perda \\
\hline K10 & 240 & TRICOEPITELIOMA & pos estrom perif & pos estroma & perda & neg & pos epi perif & pos estroma/epit \\
\hline K12 & 240 & TRICOEPITELIOMA & pos estrom perif & pos estroma/epit & pos epi perif & pos cel epit isol & pos epi perif & pos todo epit \\
\hline K13 & 240 & TRICOEPITELIOMA & pos estrom perif & pos estroma & pos epi perif & neg & pos epi perif & pos estroma/epit \\
\hline K14 & 240 & TRICOEPITELIOMA & pos estroma & pos estroma & pos epi perif & neg & neg & pos todo epit \\
\hline K15 & 240 & TRICOEPITELIOMA & pos estrom perif & pos estroma & pos epi perif & neg & pos epi perif & pos estroma/epit \\
\hline L1 & 240 & TRICOEPITELIOMA & pos estrom perif & pos estroma/epit & pos epi perif & neg & pos epi perif & pos estroma/epit \\
\hline L2 & 240 & TRICOEPITELIOMA & pos estroma & pos estroma/epit & pos todo epit & neg & neg & pos todo epit \\
\hline L3 & 240 & TRICOEPITELIOMA & pos estrom perif & pos estroma & pos epi perif & pos cel epit isol & neg & pos todo epit \\
\hline L4 & 240 & TRICOEPITELIOMA & perda & perda & perda & neg & perda & pos estroma/epit \\
\hline L5 & 240 & TRICOEPITELIOMA & neg & pos todo epit & perda & neg & neg & pos todo epit \\
\hline L6 & 240 & TRICOEPITELIOMA & pos estroma & pos todo epit & pos todo epit & pos cel epit isol & pos epi perif & pos todo epit \\
\hline L7 & 240 & TRICOEPITELIOMA & pos estrom perif & pos estroma/epit & perda & neg & pos epi perif & pos estroma/epit \\
\hline L10 & 240 & TRICOEPITELIOMA & neg & perda & perda & pos cel epit isol & perda & pos todo epit \\
\hline L12 & 240 & TRICOEPITELIOMA & neg & neg & perda & neg & perda & pos todo epit \\
\hline L14 & 240 & TRICOEPITELIOMA & pos estrom perif & pos estroma & pos todo epit & neg & neg & pos estroma/epit \\
\hline M1 & 240 & TRICOEPITELIOMA & pos estrom perif & pos estroma/epit & neg & neg & neg & pos estroma/epit \\
\hline M4 & 240 & CBCNOD & pos todo epit & pos estroma & pos todo epit & neg & neg & pos todo epit \\
\hline M5 & 240 & CBCNOD & neg & pos todo epit & pos todo epit & neg & neg & pos todo epit \\
\hline M6 & 240 & CBCNODMICRO & neg & neg & pos epi perif & pos cel epit isol & neg & pos todo epit \\
\hline M7 & 240 & CBCNOD & neg & pos todo epit & pos todo epit & neg & neg & pos todo epit \\
\hline M8 & 240 & CBCNOD & neg & pos estroma & perda & perda & perda & pos todo epit \\
\hline M9 & 240 & CBCNOD & neg & pos estroma/epit & perda & pos cel epit isol & neg & pos todo epit \\
\hline M10 & 240 & CBCMICRO & neg & pos estroma/epit & perda & neg & perda & perda \\
\hline M11 & 240 & CBCNOD & neg & perda & perda & perda & perda & pos todo epit \\
\hline M12 & 240 & CBCNOD & neg & pos todo epit & perda & pos cel epit isol & neg & pos todo epit \\
\hline M13 & 240 & CBCNOD & neg & pos todo epit & perda & neg & neg & pos todo epit \\
\hline M14 & 240 & CBCNOD & neg & pos estroma/epit & perda & neg & neg & neg \\
\hline M15 & 240 & CBCESCLEROD & neg & perda & perda & perda & neg & pos todo epit \\
\hline
\end{tabular}


Anexo A - Resultados das reações de com posição e número do bloco de arranjo tecidual para 328 carcinomas basocelulares e 162 tricoepiteliomas, com os marcadores CD34, CD10, CK15, D2-40, EMA. (continuação)

\begin{tabular}{|c|c|c|c|c|c|c|c|c|}
\hline $\begin{array}{l}\text { Posição no } \\
\text { bloco }\end{array}$ & $\begin{array}{l}\text { Número do } \\
\text { bloco }\end{array}$ & Diagnóstico & CD 34 & $C D 10$ & CK 15 & CK 20 & D2 40 & EMA \\
\hline A6 & 242 & CBCNODMICRO & pos estrom perif & pos todo epit & pos todo epit & neg & neg & pos estroma/epit \\
\hline A7 & 242 & CBCNOD & pos estroma/epit & pos todo epit & pos todo epit & neg & neg & pos estroma/epit \\
\hline A8 & 242 & CBCNOD & neg & pos estroma & pos todo epit & neg & neg & pos todo epit \\
\hline A9 & 242 & CBCNOD & pos estrom perif & pos estroma/epit & pos todo epit & neg & neg & pos estroma/epit \\
\hline A11 & 242 & CBCESCLEROD & pos estrom perif & pos estroma/epit & neg & neg & neg & pos estroma/epit \\
\hline A12 & 242 & CBCESCLEROD & perda & pos estroma/epit & perda & neg & neg & pos estroma \\
\hline A13 & 242 & CBCNODMICRO & pos estrom perif & pos estroma/epit & neg & neg & neg & pos estroma/epit \\
\hline A14 & 242 & CBCNOD & neg & pos estroma & pos todo epit & neg & neg & pos estroma/epit \\
\hline A15 & 242 & CBCESCLEROD & pos estrom perif & pos estroma/epit & pos todo epit & neg & neg & pos estroma/epit \\
\hline B1 & 242 & CBCNOD & pos estrom perif & pos todo epit & pos todo epit & neg & neg & pos todo epit \\
\hline B2 & 242 & CBCNOD & neg & pos estroma & pos todo epit & neg & neg & pos todo epit \\
\hline B3 & 242 & CBCNOD & neg & pos estroma/epit & pos todo epit & neg & neg & pos todo epit \\
\hline B4 & 242 & CBCNOD & neg & pos estroma/epit & pos todo epit & neg & neg & pos todo epit \\
\hline B5 & 242 & CBCNODMICRO & pos estrom perif & pos todo epit & pos todo epit & neg & neg & pos todo epit \\
\hline B6 & 242 & CBCMICRO & pos estrom perif & pos estroma/epit & pos todo epit & neg & neg & pos estroma/epit \\
\hline B7 & 242 & CBCMICRO & perda & perda & perda & perda & neg & perda \\
\hline B8 & 242 & CBCNOD & pos estrom perif & pos estroma/epit & neg & neg & neg & pos estroma/epit \\
\hline B9 & 242 & CBCNOD & neg & pos estroma/epit & pos todo epit & neg & neg & pos estroma/epit \\
\hline B10 & 242 & CBCNODMICRO & neg & pos estroma & pos todo epit & neg & neg & pos todo epit \\
\hline B11 & 242 & CBCMICRO & pos estrom perif & pos todo epit & pos todo epit & neg & neg & pos estroma/epit \\
\hline B13 & 242 & CBCNODMICRO & neg & pos estroma/epit & pos todo epit & neg & neg & pos estroma/epit \\
\hline B14 & 242 & CBCNODMICRO & perda & pos estroma/epit & pos epi perif & neg & perda & perda \\
\hline B15 & 242 & CBCMICRO & perda & pos estroma/epit & pos todo epit & neg & perda & perda \\
\hline $\mathrm{C} 1$ & 242 & CBCNOD & pos estrom perif & pos todo epit & pos todo epit & neg & neg & pos estroma/epit \\
\hline $\mathrm{C} 2$ & 242 & CBCNOD & pos estrom perif & pos todo epit & pos todo epit & neg & neg & pos estroma/epit \\
\hline $\mathrm{C} 3$ & 242 & CBCESCLEROD & perda & perda & perda & perda & perda & perda \\
\hline C4 & 242 & CBCNOD & pos estrom perif & pos estroma/epit & pos todo epit & neg & neg & pos estroma/epit \\
\hline C5 & 242 & CBCNODMICRO & pos estrom perif & pos estroma/epit & pos todo epit & neg & neg & pos estroma/epit \\
\hline C6 & 242 & CBCMICRO & pos estrom perif & pos estroma/epit & pos todo epit & neg & neg & pos estroma/epit \\
\hline C7 & 242 & CBCNOD & neg & pos todo epit & pos todo epit & neg & neg & pos estroma/epit \\
\hline $\mathrm{C} 8$ & 242 & CBCNOD & neg & pos estroma & pos todo epit & neg & neg & pos estroma/epit \\
\hline
\end{tabular}


Anexo A - Resultados das reações de com posição e número do bloco de arranjo tecidual para 328 carcinomas basocelulares e 162 tricoepiteliomas, com os marcadores CD34, CD10, CK15, D2-40, EMA. (continuação)

\begin{tabular}{|c|c|c|c|c|c|c|c|c|}
\hline $\begin{array}{c}\text { Posição no } \\
\text { bloco }\end{array}$ & $\begin{array}{c}\text { Número do } \\
\text { bloco }\end{array}$ & Diagnóstico & CD 34 & $C D 10$ & CK 15 & CK 20 & D2 40 & EMA \\
\hline C9 & 242 & CBCNODMICRO & neg & pos todo epit & neg & neg & neg & neg \\
\hline C11 & 242 & CBCMICRO & neg & pos estroma/epit & pos todo epit & neg & neg & pos estroma/epit \\
\hline C13 & 242 & CBCNODMICRO & perda & pos estroma/epit & pos todo epit & neg & perda & pos todo epit \\
\hline C14 & 242 & CBCNODMICRO & pos estrom perif & pos todo epit & pos todo epit & neg & neg & pos estroma/epit \\
\hline C15 & 242 & CBCNODMICRO & pos estrom perif & pos estroma/epit & pos todo epit & neg & neg & pos estroma/epit \\
\hline D1 & 242 & CBCNODMICRO & pos estroma & pos estroma/epit & pos todo epit & neg & neg & pos estroma/epit \\
\hline D2 & 242 & CBCNOD & neg & pos estroma & neg & neg & neg & pos estroma/epit \\
\hline D3 & 242 & CBCESCLEROD & neg & pos estroma/epit & pos todo epit & neg & neg & pos estroma/epit \\
\hline D4 & 242 & CBCESCLEROD & neg & pos estroma & pos todo epit & neg & neg & pos estroma/epit \\
\hline D5 & 242 & CBCNODMICRO & neg & pos estroma/epit & pos todo epit & neg & neg & pos estroma/epit \\
\hline D6 & 242 & CBCNOD & neg & pos estroma/epit & pos todo epit & neg & neg & pos estroma/epit \\
\hline D7 & 242 & CBCMICRO & pos estrom perif & pos todo epit & pos epi perif & neg & neg & pos estroma/epit \\
\hline D8 & 242 & CBCNOD & pos estrom perif & pos todo epit & pos todo epit & neg & neg & pos todo epit \\
\hline D9 & 242 & CBCESCLEROD & neg & perda & pos todo epit & neg & neg & perda \\
\hline D10 & 242 & CBCESCLEROD & perda & pos estroma & pos todo epit & perda & neg & pos estroma/epit \\
\hline D11 & 242 & CBCNODMICRO & perda & perda & pos epi perif & perda & neg & pos estroma \\
\hline D12 & 242 & CBCESCLEROD & perda & perda & pos todo epit & pos cel epit isol & neg & pos estroma \\
\hline D13 & 242 & CBCNODMICRO & neg & pos estroma & pos todo epit & neg & neg & pos estroma/epit \\
\hline D14 & 242 & CBCMICRO & pos estrom perif & pos todo epit & pos todo epit & neg & neg & pos estroma/epit \\
\hline D15 & 242 & CBCMICRO & pos estrom perif & pos estroma/epit & pos todo epit & neg & neg & pos estroma/epit \\
\hline E1 & 242 & CBCMICRO & pos estroma & pos estroma/epit & pos todo epit & neg & neg & pos estroma/epit \\
\hline E2 & 242 & CBCNODMICRO & neg & pos estroma/epit & pos todo epit & neg & neg & pos estroma/epit \\
\hline E3 & 242 & CBCNODMICRO & perda & perda & pos todo epit & perda & perda & perda \\
\hline E4 & 242 & CBCNODMICRO & pos estrom perif & pos estroma/epit & pos todo epit & neg & neg & pos estroma/epit \\
\hline E5 & 242 & CBCNOD & neg & pos estroma & pos todo epit & neg & neg & pos todo epit \\
\hline E6 & 242 & CBCNODMICRO & neg & pos estroma & pos todo epit & neg & neg & pos todo epit \\
\hline E7 & 242 & CBCNOD & neg & pos estroma & pos todo epit & neg & neg & pos estroma/epit \\
\hline E8 & 242 & CBCNOD & neg & pos estroma & pos todo epit & neg & neg & pos estroma/epit \\
\hline E9 & 242 & TRICOEPITELIOMA & neg & pos estroma & perda & neg & neg & pos estroma/epit \\
\hline E11 & 242 & TRICOEPITELIOMA & neg & pos todo epit & pos todo epit & neg & pos epi perif & pos todo epit \\
\hline E12 & 242 & TRICOEPITELIOMA & pos estroma & pos estroma/epit & pos epi perif & neg & pos epi perif & pos estroma/epit \\
\hline
\end{tabular}


Anexo A - Resultados das reações de com posição e número do bloco de arranjo tecidual para 328 carcinomas basocelulares e 162 tricoepiteliomas, com os marcadores CD34, CD10, CK15, D2-40, EMA. (continuação)

\begin{tabular}{|c|c|c|c|c|c|c|c|c|}
\hline $\begin{array}{c}\text { Posição no } \\
\text { bloco }\end{array}$ & $\begin{array}{c}\text { Número do } \\
\text { bloco }\end{array}$ & Diagnóstico & CD 34 & $C D 10$ & CK 15 & CK 20 & D2 40 & EMA \\
\hline E14 & 242 & TRICOEPITELIOMA & neg & pos estroma & pos todo epit & neg & pos todo epit & pos estroma/epit \\
\hline E15 & 242 & TRICOEPITELIOMA & perda & perda & perda & perda & perda & perda \\
\hline F2 & 242 & TRICOEPITELIOMA & pos estrom perif & pos estroma & pos epi perif & neg & neg & pos estroma/epit \\
\hline F3 & 242 & TRICOEPITELIOMA & pos estrom perif & pos estroma & pos epi perif & neg & pos epi perif & pos estroma/epit \\
\hline F6 & 242 & CBCMICRO & pos estrom perif & pos estroma/epit & pos todo epit & neg & neg & pos estroma/epit \\
\hline F7 & 242 & TRICOEPITELIOMA & perda & perda & pos todo epit & perda & perda & perda \\
\hline F8 & 242 & TRICOEPITELIOMA & pos estrom perif & pos estroma/epit & pos todo epit & neg & neg & pos estroma/epit \\
\hline F11 & 242 & TRICOEPITELIOMA & pos estrom perif & pos todo epit & pos todo epit & neg & pos todo epit & pos todo epit \\
\hline F12 & 242 & CBCMICRO & neg & pos estroma/epit & pos todo epit & neg & neg & pos estroma/epit \\
\hline F13 & 242 & CBCMICRO & neg & pos estroma/epit & pos todo epit & neg & neg & pos todo epit \\
\hline F14 & 242 & CBCNOD & pos estrom perif & pos estroma/epit & pos todo epit & neg & neg & pos estroma/epit \\
\hline F15 & 242 & CBCNOD & neg & pos todo epit & pos epi perif & neg & neg & pos todo epit \\
\hline G3 & 242 & CBCESCLEROD & perda & pos estroma & pos todo epit & neg & neg & pos estroma/epit \\
\hline G2 & 242 & CBCNOD & pos estrom perif & pos estroma & pos todo epit & neg & neg & pos todo epit \\
\hline G4 & 242 & CBCNOD & pos todo epit & pos estroma & pos todo epit & neg & neg & pos estroma/epit \\
\hline G5 & 242 & CBCMICRO & neg & pos todo epit & pos todo epit & neg & pos epi perif & pos todo epit \\
\hline G7 & 242 & CBCESCLEROD & pos estrom perif & pos estroma & pos todo epit & neg & neg & pos estroma/epit \\
\hline G8 & 242 & CBCESCLEROD & neg & pos estroma/epit & pos todo epit & neg & neg & pos estroma/epit \\
\hline G11 & 242 & CBCMICRO & neg & pos todo epit & pos todo epit & neg & neg & pos todo epit \\
\hline G12 & 242 & CBCMICRO & neg & pos estroma/epit & pos todo epit & neg & neg & pos estroma/epit \\
\hline G13 & 242 & CBCMICRO & pos estroma & pos todo epit & pos todo epit & neg & neg & pos todo epit \\
\hline G14 & 242 & CBCNODMICRO & perda & pos todo epit & pos todo epit & perda & neg & pos todo epit \\
\hline G15 & 242 & CBCESCLEROD & neg & pos todo epit & pos epi perif & neg & perda & pos estroma/epit \\
\hline $\mathrm{H} 1$ & 242 & CBCNOD & neg & pos estroma/epit & pos todo epit & neg & neg & pos todo epit \\
\hline $\mathrm{H} 2$ & 242 & CBCNOD & pos estrom perif & pos estroma/epit & pos todo epit & neg & neg & pos todo epit \\
\hline $\mathrm{H} 3$ & 242 & CBCESCLEROD & neg & pos estroma & pos todo epit & neg & neg & pos todo epit \\
\hline $\mathrm{H} 4$ & 242 & CBCNOD & pos estroma & pos todo epit & pos todo epit & neg & neg & pos estroma/epit \\
\hline H5 & 242 & CBCNOD & pos estroma & pos todo epit & pos epi perif & neg & neg & pos todo epit \\
\hline $\mathrm{H} 6$ & 242 & CBCNOD & pos estrom perif & pos todo epit & pos todo epit & neg & neg & pos todo epit \\
\hline $\mathrm{H} 7$ & 242 & CBCMICRO & pos estroma & pos todo epit & pos todo epit & neg & neg & pos estroma/epit \\
\hline $\mathrm{H} 8$ & 242 & CBCNOD & perda & perda & perda & perda & perda & perda \\
\hline
\end{tabular}


Anexo A - Resultados das reações de com posição e número do bloco de arranjo tecidual para 328 carcinomas basocelulares e 162 tricoepiteliomas, com os marcadores CD34, CD10, CK15, D2-40, EMA. (continuação)

\begin{tabular}{|c|c|c|c|c|c|c|c|c|}
\hline $\begin{array}{l}\text { Posição no } \\
\text { bloco }\end{array}$ & $\begin{array}{l}\text { Número do } \\
\text { bloco }\end{array}$ & Diagnóstico & CD 34 & $C D 10$ & CK 15 & CK 20 & D2 40 & EMA \\
\hline H9 & 242 & CBCNOD & neg & pos todo epit & pos todo epit & neg & pos epi perif & pos estroma/epit \\
\hline H11 & 242 & TRICOEPITELIOMA & pos estroma & pos estroma & pos todo epit & neg & pos epi perif & pos estroma/epit \\
\hline H13 & 242 & TRICOEPITELIOMA & pos estrom perif & pos estroma/epit & pos epi perif & neg & pos epi perif & pos estroma/epit \\
\hline H14 & 242 & CBCNOD & neg & pos todo epit & pos todo epit & neg & neg & neg \\
\hline H15 & 242 & CBCNODMICRO & pos estrom perif & pos estroma/epit & pos todo epit & neg & neg & pos todo epit \\
\hline I1 & 242 & CBCESCLEROD & neg & pos estroma & pos todo epit & neg & neg & pos todo epit \\
\hline 12 & 242 & CBCNOD & pos estroma & pos todo epit & pos todo epit & neg & neg & pos todo epit \\
\hline 13 & 242 & CBCNOD & neg & pos estroma/epit & neg & neg & neg & pos todo epit \\
\hline 14 & 242 & CBCNODMICRO & neg & pos estroma/epit & pos epi perif & neg & neg & pos estroma/epit \\
\hline 15 & 242 & CBCNODMICRO & pos estrom perif & pos estroma/epit & neg & neg & neg & pos estroma/epit \\
\hline 16 & 242 & CBCNODMICRO & neg & pos todo epit & neg & neg & neg & pos todo epit \\
\hline 17 & 242 & CBCNOD & neg & pos estroma & neg & neg & neg & pos todo epit \\
\hline 18 & 242 & CBCNODMICRO & pos estrom perif & pos estroma & pos todo epit & neg & neg & pos estroma \\
\hline 19 & 242 & CBCESCLEROD & perda & pos estroma & pos todo epit & neg & neg & pos estroma/epit \\
\hline 112 & 242 & TRICOEPITELIOMA & perda & pos estroma & pos epi perif & neg & neg & pos estroma/epit \\
\hline I13 & 242 & TRICOEPITELIOMA & perda & perda & perda & perda & neg & perda \\
\hline 114 & 242 & TRICOEPITELIOMA & pos todo epit & pos estroma/epit & pos todo epit & neg & neg & pos estroma/epit \\
\hline J4 & 242 & CBCESCLEROD & pos estrom perif & pos todo epit & pos todo epit & neg & neg & pos estroma/epit \\
\hline J5 & 242 & CBCESCLEROD & pos estrom perif & pos estroma & pos todo epit & neg & neg & pos estroma/epit \\
\hline J6 & 242 & CBCESCLEROD & pos estrom perif & pos estroma/epit & pos todo epit & neg & neg & pos estroma/epit \\
\hline $\mathrm{J} 7$ & 242 & CBCNODMICRO & pos estrom perif & pos todo epit & neg & neg & neg & neg \\
\hline J8 & 242 & CBCNODMICRO & neg & pos estroma/epit & pos todo epit & neg & neg & neg \\
\hline $\mathrm{J} 10$ & 242 & CBCESCLEROD & neg & pos estroma & pos epi perif & neg & neg & pos estroma/epit \\
\hline $\mathrm{J} 11$ & 242 & CBCNODMICRO & neg & pos estroma/epit & neg & neg & neg & pos estroma/epit \\
\hline $\mathrm{J} 12$ & 242 & CBCNODMICRO & neg & pos estroma/epit & neg & neg & neg & pos estroma/epit \\
\hline J13 & 242 & CBCMICRO & neg & pos estroma & pos todo epit & neg & neg & pos estroma/epit \\
\hline J14 & 242 & CBCNODMICRO & pos estroma & pos todo epit & neg & neg & pos epi perif & pos estroma/epit \\
\hline J15 & 242 & CBCNODMICRO & neg & pos todo epit & pos todo epit & neg & neg & perda \\
\hline K1 & 242 & CBCNOD & neg & pos todo epit & pos todo epit & neg & neg & pos todo epit \\
\hline K2 & 242 & CBCESCLEROD & pos estroma & pos estroma & pos todo epit & neg & neg & pos estroma/epit \\
\hline K3 & 242 & CBCNOD & neg & pos todo epit & pos todo epit & neg & neg & pos todo epit \\
\hline
\end{tabular}


Anexo A - Resultados das reações de com posição e número do bloco de arranjo tecidual para 328 carcinomas basocelulares e 162 tricoepiteliomas, com os marcadores CD34, CD10, CK15, D2-40, EMA. (continuação)

\begin{tabular}{|c|c|c|c|c|c|c|c|c|}
\hline $\begin{array}{l}\text { Posição no } \\
\text { bloco }\end{array}$ & $\begin{array}{l}\text { Número do } \\
\text { bloco }\end{array}$ & Diagnóstico & CD 34 & $C D 10$ & CK 15 & CK 20 & D2 40 & EMA \\
\hline K5 & 242 & CBCNODMICRO & neg & pos estroma/epit & pos todo epit & neg & neg & pos estroma/epit \\
\hline K6 & 242 & CBCNOD & neg & pos estroma/epit & pos todo epit & neg & neg & pos todo epit \\
\hline K7 & 242 & CBCNOD & neg & pos estroma/epit & pos todo epit & neg & neg & pos todo epit \\
\hline K8 & 242 & CBCNODMICRO & perda & pos estroma & pos todo epit & neg & neg & pos todo epit \\
\hline K9 & 242 & CBCNODMICRO & pos estrom perif & pos todo epit & pos todo epit & neg & neg & pos todo epit \\
\hline K10 & 242 & CBCNOD & pos estrom perif & pos estroma/epit & pos todo epit & neg & neg & pos estroma/epit \\
\hline K11 & 242 & CBCNOD & neg & pos todo epit & pos todo epit & neg & neg & pos todo epit \\
\hline K12 & 242 & CBCNOD & pos estroma & pos estroma/epit & pos todo epit & neg & pos todo epit & pos estroma/epit \\
\hline K13 & 242 & CBCNOD & neg & pos estroma & pos todo epit & neg & neg & pos todo epit \\
\hline K14 & 242 & CBCNOD & neg & pos todo epit & pos todo epit & neg & neg & pos todo epit \\
\hline K15 & 242 & CBCESCLEROD & neg & pos estroma/epit & neg & neg & neg & pos estroma/epit \\
\hline L1 & 242 & CBCNOD & neg & pos estroma/epit & pos todo epit & neg & neg & pos estroma/epit \\
\hline L2 & 242 & CBCNOD & neg & pos estroma/epit & neg & neg & neg & pos estroma/epit \\
\hline L3 & 242 & CBCMICRO & pos estroma & pos estroma/epit & neg & neg & neg & pos estroma/epit \\
\hline L4 & 242 & CBCNODMICRO & pos estroma & pos estroma/epit & neg & neg & neg & neg \\
\hline L5 & 242 & CBCNOD & neg & pos estroma/epit & neg & neg & neg & pos estroma/epit \\
\hline L6 & 242 & CBCNODMICRO & neg & pos estroma/epit & pos epi perif & neg & neg & pos estroma/epit \\
\hline L7 & 242 & CBCNOD & pos estrom perif & pos todo epit & pos todo epit & neg & neg & pos todo epit \\
\hline L8 & 242 & CBCMICRO & pos estrom perif & pos estroma & neg & neg & neg & pos estroma/epit \\
\hline L9 & 242 & CBCNODMICRO & pos todo epit & pos estroma & neg & neg & neg & pos todo epit \\
\hline L10 & 242 & CBCNODMICRO & neg & pos todo epit & pos todo epit & neg & neg & pos todo epit \\
\hline L11 & 242 & CBCNOD & pos estroma & perda & pos todo epit & neg & pos epi perif & pos todo epit \\
\hline L12 & 242 & CBCMICRO & neg & pos estroma/epit & pos todo epit & neg & neg & pos estroma/epit \\
\hline L13 & 242 & CBCNODMICRO & pos estroma/epit & pos estroma/epit & neg & neg & neg & pos todo epit \\
\hline L14 & 242 & CBCNODMICRO & perda & perda & perda & perda & perda & perda \\
\hline M1 & 242 & CBCESCLEROD & pos estroma/epit & pos estroma/epit & pos epi perif & neg & neg & pos todo epit \\
\hline M2 & 242 & CBCNOD & neg & pos estroma & neg & neg & neg & pos todo epit \\
\hline M3 & 242 & CBCESCLEROD & pos estrom perif & pos estroma/epit & pos epi perif & neg & neg & pos todo epit \\
\hline M4 & 242 & CBCNODMICRO & neg & pos estroma/epit & pos todo epit & neg & neg & pos estroma/epit \\
\hline M5 & 242 & CBCESCLEROD & neg & pos estroma & pos todo epit & neg & neg & pos estroma/epit \\
\hline M6 & 242 & CBCNODMICRO & neg & pos estroma & pos todo epit & neg & neg & pos todo epit \\
\hline
\end{tabular}


Anexo A - Resultados das reações de com posição e número do bloco de arranjo tecidual para 328 carcinomas basocelulares e 162 tricoepiteliomas, com os marcadores CD34, CD10, CK15, D2-40, EMA. (continuação)

\begin{tabular}{|c|c|c|c|c|c|c|c|c|}
\hline $\begin{array}{l}\text { Posição no } \\
\text { bloco }\end{array}$ & $\begin{array}{l}\text { Número do } \\
\text { bloco }\end{array}$ & Diagnóstico & CD 34 & $C D 10$ & CK 15 & CK 20 & D2 40 & EMA \\
\hline M7 & 242 & CBCNOD & neg & pos estroma/epit & pos todo epit & neg & neg & pos todo epit \\
\hline M8 & 242 & CBCESCLEROD & neg & pos estroma & pos todo epit & neg & neg & pos todo epit \\
\hline M9 & 242 & CBCNOD & pos estroma & pos estroma/epit & pos todo epit & neg & neg & pos estroma/epit \\
\hline M10 & 242 & CBCNOD & pos estroma & pos estroma/epit & pos todo epit & neg & neg & pos estroma/epit \\
\hline M11 & 242 & CBCNODMICRO & pos estrom perif & pos estroma/epit & pos todo epit & neg & neg & pos estroma/epit \\
\hline M12 & 242 & CBCNODMICRO & pos estrom perif & pos estroma/epit & pos todo epit & neg & neg & pos estroma/epit \\
\hline M13 & 242 & CBCNOD & neg & pos todo epit & pos todo epit & neg & neg & pos estroma/epit \\
\hline M14 & 242 & CBCMICRO & neg & pos estroma/epit & pos todo epit & neg & neg & pos todo epit \\
\hline M15 & 242 & CBCNODMICRO & pos estrom perif & pos estroma/epit & pos todo epit & neg & pos todo epit & pos estroma/epit \\
\hline A6 & 244 & CBCMICRO & neg & pos estroma & pos todo epit & neg & pos epi perif & pos todo epit \\
\hline A7 & 244 & CBCNOD & neg & pos todo epit & pos todo epit & neg & neg & perda \\
\hline A8 & 244 & CBCNODMICRO & neg & pos estroma/epit & neg & neg & neg & pos estroma/epit \\
\hline A9 & 244 & CBCMICRO & neg & pos estroma & neg & neg & perda & pos todo epit \\
\hline A10 & 244 & CBCNOD & neg & pos estroma/epit & pos todo epit & neg & perda & pos todo epit \\
\hline A11 & 244 & CBCNODMICRO & neg & pos estroma/epit & neg & neg & perda & pos todo epit \\
\hline A12 & 244 & CBCESCLEROD & pos estrom perif & pos estroma/epit & neg & neg & neg & pos todo epit \\
\hline A13 & 244 & CBCESCLEROD & perda & pos estroma & neg & neg & perda & pos estroma/epit \\
\hline A14 & 244 & CBCNOD & perda & pos estroma & neg & neg & neg & pos todo epit \\
\hline A15 & 244 & CBCNOD & neg & pos todo epit & neg & neg & neg & pos todo epit \\
\hline B1 & 244 & CBCNOD & pos estrom perif & pos todo epit & neg & neg & neg & pos estroma/epit \\
\hline B2 & 244 & CBCNOD & pos estrom perif & pos estroma/epit & pos todo epit & neg & neg & pos estroma/epit \\
\hline B3 & 244 & CBCNOD & pos estroma & pos todo epit & pos todo epit & neg & neg & pos todo epit \\
\hline B5 & 244 & CBCESCLEROD & neg & pos estroma & pos todo epit & neg & pos epi perif & pos estroma/epit \\
\hline B6 & 244 & CBCNOD & neg & pos estroma & neg & neg & neg & pos estroma/epit \\
\hline B7 & 244 & CBCESCLEROD & pos estroma & pos estroma & neg & neg & neg & pos estroma/epit \\
\hline B8 & 244 & CBCNOD & neg & pos todo epit & neg & neg & neg & pos estroma/epit \\
\hline B9 & 244 & CBCMICRO & pos estrom perif & pos estroma/epit & neg & neg & neg & pos estroma/epit \\
\hline B11 & 244 & CBCMICRO & neg & pos todo epit & pos epi perif & neg & neg & pos todo epit \\
\hline B12 & 244 & TRICOEPITELIOMA & perda & perda & perda & neg & perda & perda \\
\hline B13 & 244 & CBCMICRO & pos estrom perif & pos todo epit & neg & neg & pos epi perif & pos estroma/epit \\
\hline B14 & 244 & TRICOEPITELIOMA & pos estrom perif & pos estroma/epit & pos epi perif & neg & pos epi perif & pos estroma/epit \\
\hline
\end{tabular}


Anexo A - Resultados das reações de com posição e número do bloco de arranjo tecidual para 328 carcinomas basocelulares e 162 tricoepiteliomas, com os marcadores CD34, CD10, CK15, D2-40, EMA. (continuação)

\begin{tabular}{|c|c|c|c|c|c|c|c|c|}
\hline $\begin{array}{c}\text { Posição no } \\
\text { bloco }\end{array}$ & $\begin{array}{c}\text { Número do } \\
\text { bloco }\end{array}$ & Diagnóstico & CD 34 & $C D 10$ & CK 15 & CK 20 & D2 40 & EMA \\
\hline B15 & 244 & CBCNOD & neg & pos todo epit & neg & neg & neg & pos todo epit \\
\hline C1 & 244 & CBCESCLEROD & neg & pos estroma/epit & neg & neg & neg & pos estroma/epit \\
\hline C2 & 244 & CBCNOD & neg & pos estroma & neg & neg & neg & pos estroma/epit \\
\hline C3 & 244 & CBCNODMICRO & neg & pos estroma/epit & neg & neg & neg & pos estroma/epit \\
\hline C5 & 244 & CBCESCLEROD & neg & pos estroma/epit & neg & pos cel epit isol & pos epi perif & pos estroma/epit \\
\hline C11 & 244 & TRICOEPITELIOMA & neg & pos estroma & pos epi perif & neg & pos epi perif & perda \\
\hline C12 & 244 & CBCNOD & pos estrom perif & pos estroma/epit & neg & neg & neg & pos estroma/epit \\
\hline $\mathrm{C} 13$ & 244 & CBCNOD & pos estrom perif & pos estroma/epit & neg & neg & neg & pos estroma/epit \\
\hline C14 & 244 & CBCNOD & perda & perda & pos epi perif & neg & neg & pos todo epit \\
\hline C15 & 244 & CBCNODMICRO & neg & neg & neg & neg & neg & pos todo epit \\
\hline D1 & 244 & CBCNOD & neg & pos estroma & pos epi perif & neg & neg & pos estroma/epit \\
\hline D2 & 244 & CBCNODMICRO & pos estrom perif & pos todo epit & pos epi perif & perda & neg & pos estroma/epit \\
\hline D4 & 244 & CBCNOD & pos estroma & pos estroma/epit & neg & neg & neg & pos estroma/epit \\
\hline D5 & 244 & CBCNOD & neg & pos estroma/epit & neg & neg & neg & pos todo epit \\
\hline D6 & 244 & CBCNOD & neg & pos todo epit & neg & neg & neg & pos todo epit \\
\hline D7 & 244 & CBCNODMICRO & neg & pos estroma/epit & neg & neg & neg & pos estroma/epit \\
\hline D8 & 244 & CBCESCLEROD & neg & pos estroma/epit & neg & neg & neg & pos estroma/epit \\
\hline D9 & 244 & CBCESCLEROD & pos estrom perif & pos estroma/epit & neg & neg & neg & pos estroma/epit \\
\hline D11 & 244 & CBCNODMICRO & pos estrom perif & pos estroma/epit & neg & neg & neg & pos estroma/epit \\
\hline D13 & 244 & CBCNODMICRO & pos todo epit & pos estroma/epit & pos epi perif & pos cel epit isol & neg & pos estroma/epit \\
\hline D14 & 244 & CBCMICRO & neg & pos estroma/epit & neg & neg & neg & pos estroma/epit \\
\hline D15 & 244 & CBCMICRO & pos estroma & pos estroma/epit & pos todo epit & neg & neg & pos estroma/epit \\
\hline E1 & 244 & CBCESCLEROD & pos estrom perif & pos estroma & neg & neg & neg & neg \\
\hline E2 & 244 & CBCMICRO & pos estrom perif & pos estroma/epit & neg & neg & neg & pos todo epit \\
\hline E3 & 244 & CBCNODMICRO & neg & pos todo epit & neg & neg & pos epi perif & pos todo epit \\
\hline E4 & 244 & CBCNOD & pos estroma & pos estroma/epit & neg & neg & neg & pos estroma/epit \\
\hline E5 & 244 & CBCNOD & perda & perda & neg & perda & perda & perda \\
\hline E6 & 244 & CBCNODMICRO & neg & pos estroma & pos todo epit & neg & neg & pos estroma/epit \\
\hline E7 & 244 & CBCNODMICRO & pos estroma & pos todo epit & neg & neg & neg & pos estroma/epit \\
\hline E9 & 244 & CBCESCLEROD & perda & pos estroma/epit & neg & neg & neg & pos estroma/epit \\
\hline E10 & 244 & CBCNOD & neg & pos estroma/epit & neg & neg & neg & pos estroma/epit \\
\hline
\end{tabular}


Anexo A - Resultados das reações de com posição e número do bloco de arranjo tecidual para 328 carcinomas basocelulares e 162 tricoepiteliomas, com os marcadores CD34, CD10, CK15, D2-40, EMA. (continuação)

\begin{tabular}{|c|c|c|c|c|c|c|c|c|}
\hline $\begin{array}{c}\text { Posição no } \\
\text { bloco }\end{array}$ & $\begin{array}{c}\text { Número do } \\
\text { bloco }\end{array}$ & Diagnóstico & CD 34 & $C D 10$ & CK 15 & CK 20 & D2 40 & EMA \\
\hline E11 & 244 & CBCESCLEROD & perda & pos estroma & neg & neg & neg & pos estroma/epit \\
\hline E12 & 244 & CBCNODMICRO & pos estrom perif & pos estroma/epit & neg & neg & perda & pos estroma/epit \\
\hline E13 & 244 & CBCNODMICRO & pos estroma & pos estroma/epit & neg & neg & neg & pos todo epit \\
\hline E14 & 244 & CBCNODMICRO & pos estroma & pos estroma/epit & pos epi perif & neg & neg & pos todo epit \\
\hline E15 & 244 & CBCNODMICRO & pos estrom perif & pos estroma/epit & neg & neg & neg & pos estroma/epit \\
\hline F1 & 244 & CBCNODMICRO & neg & pos estroma/epit & pos epi perif & neg & pos todo epit & pos estroma \\
\hline $\mathrm{F} 2$ & 244 & CBCESCLEROD & pos estroma & pos estroma/epit & neg & neg & neg & pos estroma/epit \\
\hline F3 & 244 & CBCNODMICRO & neg & pos estroma/epit & neg & neg & neg & pos todo epit \\
\hline F4 & 244 & CBCESCLEROD & neg & pos estroma/epit & neg & neg & neg & pos estroma/epit \\
\hline F5 & 244 & CBCMICRO & pos estroma & pos estroma/epit & neg & neg & neg & pos estroma/epit \\
\hline F6 & 244 & CBCNODMICRO & neg & pos estroma/epit & pos epi perif & neg & neg & pos estroma/epit \\
\hline F7 & 244 & CBCNOD & pos estroma & pos estroma/epit & pos todo epit & neg & neg & pos todo epit \\
\hline F8 & 244 & CBCNOD & neg & pos estroma & pos todo epit & neg & pos todo epit & pos todo epit \\
\hline F9 & 244 & CBCNODMICRO & pos estrom perif & pos estroma & neg & neg & neg & pos estroma/epit \\
\hline F10 & 244 & TRICOEPITELIOMA & pos estrom perif & pos estroma & pos todo epit & neg & neg & pos estroma/epit \\
\hline F11 & 244 & TRICOEPITELIOMA & pos estrom perif & pos estroma & pos epi perif & neg & pos epi perif & pos estroma/epit \\
\hline F12 & 244 & CBCNOD & neg & pos estroma/epit & neg & neg & neg & pos todo epit \\
\hline F13 & 244 & CBCMICRO & pos estrom perif & pos todo epit & pos epi perif & neg & neg & pos todo epit \\
\hline F14 & 244 & CBCMICROESCLEROD & pos estrom perif & pos todo epit & neg & neg & neg & pos estroma/epit \\
\hline F15 & 244 & TRICOEPITELIOMA & pos estrom perif & pos estroma & pos epi perif & neg & neg & pos todo epit \\
\hline G1 & 244 & CBCNOD & neg & pos estroma & pos todo epit & neg & neg & pos todo epit \\
\hline G2 & 244 & CBCNOD & pos estrom perif & pos estroma/epit & neg & neg & neg & pos estroma/epit \\
\hline G3 & 244 & CBCNOD & neg & pos todo epit & neg & neg & neg & pos todo epit \\
\hline G4 & 244 & CBCNOD & neg & pos estroma & pos todo epit & neg & neg & pos todo epit \\
\hline G5 & 244 & CBCESCLEROD & neg & pos estroma/epit & pos epi perif & neg & neg & pos estroma/epit \\
\hline G6 & 244 & CBCESCLEROD & pos estrom perif & pos estroma/epit & pos epi perif & neg & neg & pos estroma/epit \\
\hline G7 & 244 & CBCESCLEROD & pos estroma & pos todo epit & neg & neg & neg & pos estroma/epit \\
\hline G8 & 244 & CBCMICRO & pos estrom perif & neg & neg & neg & neg & pos estroma/epit \\
\hline G9 & 244 & TRICOEPITELIOMA & pos estrom perif & pos estroma & pos epi perif & neg & pos epi perif & pos estroma/epit \\
\hline G10 & 244 & CBCNODMICRO & neg & pos estroma & neg & neg & neg & pos estroma/epit \\
\hline G11 & 244 & CBCNODESCLEROD & pos estrom perif & pos estroma/epit & pos todo epit & neg & neg & pos estroma/epit \\
\hline
\end{tabular}


Anexo A - Resultados das reações de com posição e número do bloco de arranjo tecidual para 328 carcinomas basocelulares e 162 tricoepiteliomas, com os marcadores CD34, CD10, CK15, D2-40, EMA. (continuação)

\begin{tabular}{|c|c|c|c|c|c|c|c|c|}
\hline $\begin{array}{l}\text { Posição no } \\
\text { bloco }\end{array}$ & $\begin{array}{l}\text { Número do } \\
\text { bloco }\end{array}$ & Diagnóstico & CD 34 & $C D 10$ & CK 15 & CK 20 & D2 40 & EMA \\
\hline G12 & 244 & CBCMICRO & neg & pos estroma & neg & neg & neg & pos todo epit \\
\hline G13 & 244 & CBCNODMICRO & pos estrom perif & pos estroma & neg & neg & neg & pos estroma/epit \\
\hline G14 & 244 & CBCNOD & pos estrom perif & pos estroma/epit & neg & neg & neg & pos estroma/epit \\
\hline G15 & 244 & CBCNOD & neg & pos estroma/epit & neg & neg & neg & pos estroma/epit \\
\hline $\mathrm{H} 1$ & 244 & CBCMICRO & neg & pos estroma & neg & neg & neg & pos todo epit \\
\hline $\mathrm{H} 2$ & 244 & CBCNOD & neg & pos estroma/epit & pos todo epit & neg & neg & pos todo epit \\
\hline $\mathrm{H} 3$ & 244 & CBCESCLEROD & perda & pos estroma/epit & neg & neg & neg & pos estroma/epit \\
\hline $\mathrm{H} 4$ & 244 & CBCESCLEROD & neg & pos estroma & neg & neg & neg & pos estroma/epit \\
\hline H5 & 244 & CBCNODMICRO & neg & pos estroma/epit & neg & neg & neg & pos estroma/epit \\
\hline $\mathrm{H} 6$ & 244 & CBCESCLEROD & neg & pos estroma & neg & neg & neg & pos estroma/epit \\
\hline $\mathrm{H} 7$ & 244 & CBCNOD & neg & pos estroma & pos epi perif & neg & neg & pos todo epit \\
\hline $\mathrm{H} 8$ & 244 & CBCNODESCLEROD & neg & pos estroma/epit & pos todo epit & pos cel epit isol & neg & pos todo epit \\
\hline H9 & 244 & CBCNOD & perda & pos estroma/epit & neg & neg & neg & pos estroma/epit \\
\hline $\mathrm{H} 10$ & 244 & CBCESCLEROD & neg & pos estroma & pos todo epit & neg & neg & pos todo epit \\
\hline H11 & 244 & CBCESCLEROD & neg & pos estroma & neg & pos cel epit isol & neg & pos estroma/epit \\
\hline $\mathrm{H} 12$ & 244 & CBCNOD & neg & pos estroma/epit & neg & neg & neg & pos estroma/epit \\
\hline $\mathrm{H} 13$ & 244 & CBCNOD & pos estroma/epit & pos estroma/epit & pos todo epit & neg & neg & pos estroma/epit \\
\hline $\mathrm{H} 14$ & 244 & CBCNODMICRO & pos estrom perif & pos estroma/epit & pos epi perif & neg & neg & pos estroma/epit \\
\hline $\mathrm{H} 15$ & 244 & CBCESCLEROD & neg & pos estroma/epit & neg & neg & neg & pos estroma/epit \\
\hline 12 & 244 & CBCESCLEROD & neg & pos estroma/epit & neg & neg & neg & pos estroma/epit \\
\hline 14 & 244 & CBCNOD & pos estrom perif & pos estroma/epit & neg & neg & neg & pos estroma/epit \\
\hline 15 & 244 & CBCNOD & pos estroma & pos estroma/epit & neg & neg & neg & pos estroma/epit \\
\hline 16 & 244 & CBCNOD & pos estrom perif & pos todo epit & pos todo epit & pos cel epit isol & neg & pos estroma/epit \\
\hline 17 & 244 & CBCNOD & neg & pos estroma/epit & pos todo epit & neg & neg & pos todo epit \\
\hline 19 & 244 & CBCESCLEROD & neg & pos estroma/epit & pos todo epit & neg & neg & pos estroma/epit \\
\hline $\mathrm{I} 10$ & 244 & CBCNOD & pos estrom perif & pos todo epit & neg & neg & neg & pos todo epit \\
\hline J3 & 244 & CBCESCLEROD & pos estroma & pos estroma/epit & neg & neg & neg & pos estroma/epit \\
\hline J4 & 244 & CBCESCLEROD & pos estrom perif & pos estroma & neg & neg & pos epi perif & pos estroma/epit \\
\hline J6 & 244 & CBCMICRO & pos estrom perif & pos todo epit & neg & neg & neg & pos todo epit \\
\hline $\mathrm{J} 7$ & 244 & CBCESCLEROD & pos estrom perif & pos estroma/epit & neg & neg & pos epi perif & pos estroma/epit \\
\hline J8 & 244 & CBCMICRO & pos estrom perif & pos estroma/epit & pos epi perif & neg & neg & pos estroma/epit \\
\hline
\end{tabular}


Anexo A - Resultados das reações de com posição e número do bloco de arranjo tecidual para 328 carcinomas basocelulares e 162 tricoepiteliomas, com os marcadores CD34, CD10, CK15, D2-40, EMA. (conclusão)

\begin{tabular}{|c|c|c|c|c|c|c|c|c|}
\hline $\begin{array}{c}\text { Posição no } \\
\text { bloco }\end{array}$ & $\begin{array}{c}\text { Número do } \\
\text { bloco }\end{array}$ & Diagnóstico & CD 34 & $C D 10$ & CK 15 & CK 20 & D2 40 & EMA \\
\hline J9 & 244 & CBCNOD & neg & pos estroma & neg & neg & neg & pos todo epit \\
\hline J10 & 244 & TRICOEPITELIOMA & perda & pos estroma/epit & pos epi perif & pos cel epit isol & perda & perda \\
\hline $\mathrm{J} 14$ & 244 & TRICOEPITELIOMA & pos estrom perif & pos estroma/epit & pos epi perif & neg & pos epi perif & pos estroma/epit \\
\hline K2 & 244 & TRICOEPITELIOMA & pos estroma & pos estroma & pos epi perif & neg & pos epi perif & pos estroma/epit \\
\hline K3 & 244 & CBCNOD & pos estrom perif & pos todo epit & pos epi perif & neg & pos epi perif & pos todo epit \\
\hline K6 & 244 & TRICOEPITELIOMA & pos estrom perif & pos estroma & pos epi perif & neg & neg & pos estroma/epit \\
\hline K7 & 244 & CBCNODMICRO & pos estrom perif & pos estroma/epit & pos epi perif & pos cel epit isol & neg & pos estroma/epit \\
\hline K8 & 244 & CBCESCLEROD & neg & pos estroma/epit & neg & neg & neg & pos estroma/epit \\
\hline K9 & 244 & CBCESCLEROD & neg & pos estroma/epit & pos epi perif & neg & neg & pos estroma/epit \\
\hline K10 & 244 & CBCNOD & perda & pos estroma/epit & perda & neg & perda & pos todo epit \\
\hline K11 & 244 & CBCESCLEROD & pos estrom perif & pos todo epit & pos epi perif & neg & neg & pos estroma/epit \\
\hline K12 & 244 & TRICOEPITELIOMA & pos estrom perif & pos estroma & pos epi perif & neg & pos epi perif & pos estroma/epit \\
\hline K13 & 244 & CBCESCLEROD & neg & pos estroma & neg & neg & neg & pos estroma/epit \\
\hline K14 & 244 & TRICOEPITELIOMA & neg & pos estroma & pos todo epit & neg & perda & pos todo epit \\
\hline L1 & 244 & TRICOEPITELIOMA & pos estrom perif & pos todo epit & pos epi perif & pos cel epit isol & pos epi perif & pos todo epit \\
\hline L2 & 244 & TRICOEPITELIOMA & pos estrom perif & pos estroma/epit & neg & neg & neg & pos estroma/epit \\
\hline L6 & 244 & TRICOEPITELIOMA & pos estrom perif & pos estroma/epit & pos epi perif & neg & pos epi perif & pos estroma/epit \\
\hline L7 & 244 & TRICOEPITELIOMA & neg & pos estroma/epit & pos todo epit & neg & neg & pos estroma/epit \\
\hline L8 & 244 & TRICOEPITELIOMA & perda & pos estroma & pos todo epit & neg & perda & pos estroma/epit \\
\hline L9 & 244 & TRICOEPITELIOMA & pos estrom perif & pos estroma & pos epi perif & neg & pos epi perif & pos estroma/epit \\
\hline M2 & 244 & TRICOEPITELIOMA & pos estroma/epit & pos estroma & pos epi perif & pos cel epit isol & neg & pos estroma/epit \\
\hline M4 & 244 & TRICOEPITELIOMA & pos estroma/epit & pos estroma & pos epi perif & pos cel epit isol & pos epi perif & pos estroma/epit \\
\hline M5 & 244 & TRICOEPITELIOMA & perda & pos estroma & pos todo epit & neg & neg & pos estroma/epit \\
\hline M7 & 244 & TRICOEPITELIOMA & pos estrom perif & pos estroma & pos epi perif & neg & pos epi perif & pos estroma/epit \\
\hline M8 & 244 & TRICOEPITELIOMA & pos estroma & pos estroma & pos epi perif & neg & pos epi perif & pos estroma/epit \\
\hline
\end{tabular}


Anexo B - Aprovação do Comitê de Ética para Análise de Projetos de Pesquisa - CAPPesq da Diretoria Clínica do Hospital das Clínicas e da Faculdade de Medicina da Universidade de São Paulo

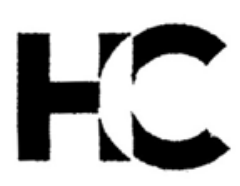

\section{APROVAÇĀO}

A Comissão de Ética para Análise de Projetos de Pesquisa CAPPesq da Diretoria Clínica do Hospital das Clínicas e da Faculdade de Medicina da Universidade de São Paulo, em sessão de 03/06/2009. APROVOU o Protocolo de Pesquisa n 0340/09, intitulado: "AVALIAÇAOO DO PERFIL IMUNOHISTOQUIMICO DOS CARCINOMAS BASOCELULARES E DAS NEOPLASIAS basalóIDES (BENIGNAS E MALIGNAS) DO APARATO PILOSEBÁCEO, PELA TÉCNICA dO "TISSUE MICRO-ARRAY", apresentado pelo Departamento de DERMATOLOGIA.

Cabe ao pesquisador elaborar e apresentar d CAPPesq, os relatórios parciais e final sobre a pesquisa (Resolução do Conselho Nacional de Saúde no 196, de 10/10/1996, inciso IX.2, letra "c").

Pesquisador (a) Responsável: PROFA. DRA. MIRIAM NACAGAMI SOTTO Pesquisador (a) Executante: ANTONIO JOSÉ TEBCHERANI

CAPPesq, 03 de junho de 2009.

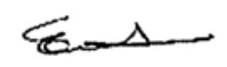

PROF. DR. EDUARDO MASSAD

Presidente

Comissāo de Ética para Anólise de Projetos de Pesquisa

Comissáo de Etica para Analise de Projetos de Pesquisa do HCFMUSP e da FMUSP Diretoria Clinica do Hospital das Clinicas da Faculdade de Medicina da Universidade de Såo Paulo Rua Ovidio Pires de Campos, 225, $5^{\circ}$ andar - CEP 05403010 - Sáo Paulo - SP Fone: 01130696442 Fax. 01130696492 e-mail: cappesqOhonet usp.br / secretariacappesq2@hcnet.usp.br 
REFERÊNCIAS 
1. Carr RA, Taijbee SM, Sanders DAS. Basaloid skin tumours: Basal cell carcinoma. Curr Diagn Pathol. 2007; 13:252-72.

2. Wolff K, Goldsmith LA, Katz SI, Gilchrest BA, Paller AS, Leffell DJ. Fitzpatrick's. Dermatology in General Medicine. $7^{\text {th }}$ ed. New York: MacGraw-Hill; 2008. Chap 117. p.1040.

3. Headington JT. Tumours of the hair follicle $-\mathrm{A}$ review. Am J Pathol. 1977; 85: 480-515.

4. Ackerman AB; Viragh PV; Chongchitnant N. Neoplasms with follicular differentiation. Philadelphia: Lea\&Febbiger; 1993. Chap 19. p.451.

5. Sampaio S, Rivitti EA. Dermatologia. $3^{a}$ ed. São Paulo: Artes Médicas; 2007. Cap 76. Tumores epiteliais malignos. p.1163-69.

6. Wolff K, Goldsmith LA, Katz SI, Gilchrest BA, Paller AS, Leffell DJ. Fitzpatrick's. Dermatology in General Medicine. $7^{\text {th }}$ ed. New York: MacGraw-Hill; 2008. Chap 119. p.1083.

7. Sampaio S, Rivitti EA. Dermatologia. $3^{a}$ ed. São Paulo: Artes Médicas; 2007. Capítulo 74. Tumores epiteliais benignos. p.1137-55.

8. Alves VFA, Bacchi CE, Vassalo J. Manual de Imuno-Histoquímica. São Paulo: Sociedade Brasileira de Patologia; 1999. p.1-270.

9. Barra MB. O uso da imunohistoquímica no diagnóstico: indicações e limitações. Revista da AMRIGS. 2006; 50: 173-184. 
10. Taylor CR, Cote RJ. Immnunomicroscopy: A diagnostic tool for the Surgical Pathologist. (Major Problems in Pathology - v.19). $2^{\text {nd }}$. ed. Philadelphia: WB Saunders; 1994. Chap 14. p.368.

11. Dabbs DJ. Diagnostic immunohistochemistry. Philadelphia: Churchill Livingstone; 2002. Chap 7. p.163.

12. Kirchman TTT, Prieto VG, Smoller BR. CD34 staining pattern distinguishes basal cell carcinoma from trichoepitelioma. Arch Dermatol. 1994; 130:589-92.

13. Smoller BR, Van de Rijn M, Lebrun D, Warnke RA. BCL-2 expression reliably distinguishes trichepitheliomas from basal cell carcinomas. Br J Dermatol. 1994; 131:28-31.

14. Illueca C, Monteagudo C, Revert A, Llombart-Bosch A. Diagnostic value of CD34 immunostaining in desmoplastic trichilemmoma. $J$ Cutan Pathol. 1998; 25: 435-9.

15. Moll R, Osborn M, Hartschuh W. Variability of expression and arrangement of cytokeratin and neurofilaments in cutaneous neuroendocrine carcinomas (Merkel cell tumours): immunohistochemical and biochemical analysis of twelve cases. Ultrastruct Pathol. 1986; 10:473-95.

16. Schulz T, Hartschuh W. Merkel cells are absent in basal cell carcinomas but frequently found in trichoblastomas. An imunohistochemical study. J Cutan Pathol. 1997; 24:14-24. 
17. Verhaeg MEJM, Arends JW, Majoie IML, Hoeczema R, Neumann HAM. Transforming growth factor beta and BCL-2 distribution patterns distinguish trichoepithelioma from basal cell carcinoma. Dermatol Surg. 1997; 23:695-700.

18. Swanson PE, Fitzpatrick MM, Ritter JH, Glusac EJ, Wick MR. Imunohistologic differential diagnosis of basal cell carcinoma, and trichoepitelioma in small cutaneous biopsy specimens. J Cutan Pathol. 1998; 25:153-9.

19. Basarab T, Orchard G, Russel-Jones R. The use of immunostaining for bcl-2 and CD34 and the lectin peanut agglutinin in differentiating between basal cell carcinomas and trichoepitheliomas. $A m \mathrm{~J}$ Dermatopathol. 1998; 20:448-52.

20. Abdelsayed RA, Guijarro-Rojas M, Ibrahim NA, Sangueza OP. Immunohistochemical evaluation of basal cell carcinoma and trichepithelioma using, Ki67, PCNA and P53. J Cutan Pathol. 2000; 27: 169-75.

21. Ohnishi T, Watanabe S. Imunohistochemical analysis of cytokeratin expression in various trichogenic tumours. Am $\mathrm{J}$ Dermatopathol. 1999; 21:337-43.

22. Poniecka AW, Alexis JB. An immunohistochemical study of basal cell carcinoma and trichoepitelioma. Am J Dermatopathol.1999; 21:3326. 
23. Jih D, Lyle S, Elenitsas R, Elder DE, Cotsarelis G. Cytokeratin 15 expression in trichoepitheliomas and a subset of basal cell carcinomas suggests they originate from hair follicle stem cells. $J$ Cutan Pathol. 1999; 26:113-8.

24. Kanitakis J, Bourchany D, Faure M, Claudy A. Expression of the hair stem cell-specific keratin 15 in pilar tumours of the skin. Eur $J$ Dermatol. 1999; 9:363-5.

25. Yamamoto O, Asahi M. Cytokeratin expression in trichoblastic fibroma (small nodular type trichoblastoma), trichoepitelioma and basal cell carcinoma. Br J Dermatol. 1999;140:8-16.

26. Kurzen H, Esposito L, Langbein L, Hartschuh W. Cytokeratins as markers of follicular differentiation. An imunohistochemical study of trichoblastoma and basal cell carcinoma. Am J Dermatopathol. 2001; 23:501-9.

27. Sezaki N, Ishimaru F, Tabayashi T, et al. The type 1 CD10/neutral endopeptidase 24.11 promoter: functional characterization of the 50 untranslated region. Br J Haematol 2003; 123:177-83.

28. Kanitakis J, Bourchany D, Claudy A. Expression of the CD10 antigen (neutral endopeptidase) by mesenchymal tumors of the skin. Anticancer Res. 2000; 20:3539-44.

29. Pham TTN, Selim MA, Burchette Jr JL, Madden J, Turner J, Herman C. CD-10 expression in trichoepitelioma and basal cell carcinoma. J Cutan Pathol. 2006; 33:123-8. 
30. Misago N, Satoh T, Miura Y, Nagase K, Narisawa Y. Merkel cell-poor trichoblastoma with basal cell carcinoma-like foci. $A m \quad J$ Dermatopathol. 2007; 29:249-55.

31. Choi CW; Park HS; Kim YK; Lee SH; Cho KH. Elastic fiber staining and cytokeratin 15 expression pattern in trichoepithelioma and basal cell carcinoma. J Dermatol. 2008; 35:499-502.

32. Costache $M$, Bresch $M$, Böer A. Desmoplastic trichoepithelioma versus morphoeic basal cell carcinoma: a critical reappraisal of histomorphological and immunohistochemical criteria for differentiation. Histopathol. 2008; 52:865-76.

33. Córdoba A, Guerrero D, Larrinaga B, Iglesias ME, Arrechea MA, Yanguas $\mathrm{JI}$. Bcl-2 and CD10 expression in the differential diagnosis of trichoblastoma, basal cell carcinoma, and basal cell carcinoma with follicular differentiation. Int J Dermatol. 2009; 48:713-7.

34. Kahn HJ, Bailey D, Marks A. Monoclonal antibody D2-40, a new marker of lymphatic endothelium, reacts with Kaposi's sarcoma and a subset of angiossarcomas. Mod Pathol. 2002; 15:434-40.

35. Liang $H$, Wu H, Giorgadze TA, Sariya D, Bellucci KS, Veerappan R, Liegl B, Acs G, Elenitsas R, Shukla S, Youngberg GA, Coogan PS, Pasha T, Zhang PJ, Xu X. Podoplanin is a highly sensitive and specific marker to distinguish primary skin adnexal carcinomas from adenocarcinomas metastatic to skin. Am J Surg Pathol. 2007; 31:304-10. 
36. Plaza JA, Ortega PF, Bengana C, Stockman DL, Suster S. Immunolabeling pattern of podoplanin (D2-40) may distinguish basal cell carcinomas from trichoepitheliomas: a clinicopathologic and immunohistochemical study of 49 cases. Am J Dermatopathol. 2010; 32:683-7.

37. Kononen J, Bubendorf L, Kallioniemi A, et al. Tissue microarrays for high-throughput molecular profiling of hundreds of specimens. Nature Med. 1998; 4:844-7.

38. DiVito KA; Charette LA, Rimm DL, Camp RL. Long-term preservation of antigenicity on tissue microarrays. Lab Invest. 2004; 84:1071-8.

39. Shen SS, Zhang PS, Eton O, Prieto VG. Analysis of protein tyrosine kinase expression in melanocytic lesion by tissue array. J Cutan Pathol. 2003; 30:539-47.

40. Pacifico MD, Grover R, Richman P, Daley F, Wilson GD. Validation of tissue microarray for the immunohistochemical profiling of melanoma. Melanoma Res. 2004; 14:39-42.

41. Plaza JA, Suster D, Perez-Montiel D. Expression of immunohistochemical markers in primary and metastatic malignant melanoma: a comparative study in 70 patients using a tissue microarray technique. Apl Immunohistochem Mol Morphol. 2007; 15:421-5.

42. Rosalynn MN, Prieto VG, Elder DE, Duncan LM. Melanoma biomarker expression in melanocytic tumour progression: a tissue microarray study. J Cutan Pathol. 2010; 37:41-7. 
43. Zagrodnik B, Kempf W, Seifert B, Muller B, Burg G, Urosevic M, Dummer R. Superficial radiotherapy for patients with basal cell carcinoma. Recurrence rates, histological subtypes, and expression of p53 and Bcl-2. Cancer. 2003; 98:2708-14.

44. Urosevic M, Kempf W, Zagrodnik B, Panizzon R, Burg G, Dummer R. HLA-G expression in basal cell carcinomas of the skin recurring after radiotherapy. Clin Exp Dermatol. 2005; 30:422-5.

45. Freier K, Flechtenmacher C, Devens F, Harschuh W, Hofele C, Lichter $\mathrm{P}$, Joos $\mathrm{S}$. Recurrent NMYC copy number gain and high protein expression in basal cell carcinoma. Oncol Rep. 2006; $15: 1141-5$

46. Salto-Telez, Peh BK, Ito K, Tan SH, PY Chong, Han HC, Tada K, Ong WY, Soong R, Voon DC, Ito $Y$. RUNX3 protein is overexpressed in human basal cell carcinomas. Oncogene. 2006; 25:7646-49.

47. Oh ST, Kim HS, Yoo NJ, Lee WS, Cho BK, Reichrat J. Increased immunoreactivity of menbrane type-1 matrix metalloproteinase (MT1MMP) and beta-catenin in righ-risk basall cell carcinoma. $\mathrm{Br} \mathrm{J}$ Dermatol. 2011; 165:1197-1204.

48. Narvaes, D; Kanitakis, J; Faure, M; Claudy, C Immunohistochemical study of CD34 positive dendritic cells of human dermis. Am J Dermatopathol. 1996; 18:283-8.

49. Yada K, Kashima K, Daa T, Kitano S, Fujiwara S, Yokoyama S. Expression of CD10 in basal cell carcinoma. Am J Dermatopathol. 2004; 26:463-71. 
50. Carr RA, Sanders DSA. Basaloid skin tumours: Mimics of basal cell carcinoma. Curr Diagn Pathol. 2007; 13:273-300.

51. Abeasamis-Cubillan E, El-Shabrawi-Caelen L, LeBoit PE. Merkel cells and sclerosing epithelial neoplasms. Am J Dermatopathol. $2000 ; 22: 311-5$.

52. McNiff JM, Eisen RN, Glusac EJ. Immunohistochemical comparison of cutaneous lymphadenoma, trichoblastoma, and basal cell carcinoma: support for classification of lymphadenoma as a variant of trichoblastoma. J Cutan Pathol. 1999; 26:119-24.

53. Moll I, Kuhn C, Moll R. Cytokeratin 20 is a general marker of cutaneous Merkel cells while certain neuronal proteins are absent. $J$ Invest Dermatol. 1995; 104: 910-5.

54. Hartschuh W, Schulz T. Merkel cells are integral constituents of desmoplastic trichoepithelioma: An immunohistochemical and electron microscopic study. J Cutan Pathol.1995; 22:413-21.

55. Katona TM, Perkins SM, Billings SD. Does the panel of cytokeratin 20 and androgen receptor antibodies differentiate desmoplastic trichoepithelioma from morpheaform/infiltrative basal cell carcinoma? J Cutan Pathol. 2008; 35:174-9.

56. Troy TC, Arabzadeh A, Turksen K. Re-assessing k15 as an epidermal stem cell marker. Stem Cell Rev. 2011; 7:927-34.

57. Kalof NA, Cooper K. D2-40 immunohistochemistry-So far! Adv Anat Pathol. 2009; 16:62-4. 
58. Schirren CG, Rutten A, Kaudewitz P, Diaz C, McClain S, Burgdorf WHC. Trichoblastoma with follicular differentiation sharing the same profile of cytokeratin intermediate filaments. Am J Dermatopathol. 1997; 19:341-50. 